\title{
Bio-aviation Fuel: A Comprehensive Review and Analysis of the Supply Chain Components
}

\begin{abstract}
Stephen S. Doliente ${ }^{1,2}$, Aravind Narayan ${ }^{1}$, John Frederick D. Tapia ${ }^{1,3}$, Nouri J. Samsatli ${ }^{4,5}$, Yingru Zhao ${ }^{6}$ and Sheila Samsatli ${ }^{1 *}$

1 Department of Chemical Engineering, University of Bath, Bath, United Kingdom, ${ }^{2}$ Department of Chemical Engineering, College of Engineering and Agro-Industrial Technology, University of the Philippines Los Baños, Los Baños, Philippines, ${ }^{3}$ Chemical Engineering Department, De La Salle University-Manila, Manila, Philippines, ${ }^{4}$ Process Systems Enterprise Ltd., London, United Kingdom, ${ }^{5}$ Samsatli Solutions, Ventonlace, Flatwoods Crescent, Bath, United Kingdom, ${ }^{6}$ College of Energy, Xiamen University, Xiamen, China
\end{abstract}

The undeniable environmental ramifications of continued dependence on oil-derived jet fuel have spurred international efforts in the aviation sector toward alternative solutions. Due to the limited options for decarbonization, the successful implementation of bio-aviation fuel is crucial in contributing to the roster of greenhouse gas emissions

OPEN ACCESS

Edited by:

Gurkan Sin,

Technical University of

Denmark, Denmark

Reviewed by:

Emre Gencer,

Massachusetts Institute of Technology, United States Isuru Udugama,

Technical University of

Denmark, Denmark

${ }^{*}$ Correspondence:

Sheila Samsat/

S.M.C.Samsatli@bath.ac.uk

Specialty section:

This article was submitted to Process and Energy Systems

Engineering,

a section of the journal

Frontiers in Energy Research

Received: 18 September 2019

Accepted: 11 May 2020

Published: 10 July 2020

Citation:

Doliente SS, Narayan A, Tapia JFD,

Samsatli NJ, Zhao Y and Samsatli S

(2020) Bio-aviation Fuel: A

Comprehensive Review and Analysis

of the Supply Chain Components.

Front. Energy Res. 8:110

doi: 10.3389/fenrg.2020.00110 mitigation strategies for the aviation sector. Since fleet replacement with low-carbon technologies may not be a feasible option, due to the long lifetime and significant capital cost of aircraft, "drop-in" alternatives, which can be used in the engines of existing aircraft in a seamless transition, may be required. This paper presents a detailed analysis of the supply chain components of bio-aviation fuel provision: feedstocks, production pathways, storage, and transport. The economic and environmental performance of different potential bio-feedstocks and technologies are investigated and compared in order to make recommendations on short- and long-term strategies that could be employed internationally. Hydroprocessed esters and fatty acids production pathway, utilizing second-generation oil-seed crops and waste oils, could be an effective immediate solution with the potential for substantial greenhouse gas emissions savings. Microalgal oil could potentially offer far greater yields of bio-aviation fuel and reductions in greenhouse gas emissions, but the technology for large-scale algae cultivation is inadequately mature at present. Fischer-Tropsch production pathway using lignocellulosic biomass has the potential for the highest greenhouse gas emissions savings, which could potentially be the solution within the medium- to long-term plans of the aviation industry, but further research and optimization are required prior to its large-scale implementation due to its limited technological maturity and high capital costs. In practice, the "ideal" feedstocks and technologies of the supply chains are heavily dependent on spatial and temporal criteria. Moreover, many of the parameters investigated are interlinked to each other and the measures that are effective in greenhouse gases emissions reduction are largely associated with increased cost. Hence, policies must be streamlined across the supply chain components that could help in the cost-effective and sustainable deployment of bio-aviation fuel.

Keywords: bio-aviation fuel, sustainable feedstocks, energy crops, waste biomass, microalgae, production pathways, storage and transport, supply chains 


\section{INTRODUCTION}

The aviation industry plays a major role in the global economy, serving as a crucial backbone for nearly 57 million jobs and USD 2.2 trillion in global GDP. Businesses, especially those involving international transactions, rely on its speed and efficiency. By 2035, the Air Transport Action Group (ATAG) expects 7.2 billion passengers will be served by the airline industry through the world's major airports as shown in Figure 1A, which is twice the number of passengers in 2016 (ATAG, 2012). Consequently, this surge in aviation demand is projected to result in 3.1 billion tons of GHG emissions by 2050, which is 4 times greater than the 2015 baseline of 0.78 billion tons.

It is a significant challenge to find a sustainable solution for the aviation industry's GHG emissions reduction due to the ambitious target set at $50 \%$ less than the 2005 baseline (IATA, 2009). The International Air Transport Association (IATA) and the International Civil Aviation Organisation (ICAO) developed the four pillars to achieve this goal: (1) technological improvements, (2) operational improvements, (3) measures based on the market, and (4) alternative jet fuel (AJF) (GutiérrezAntonio et al., 2013). Figure 1B displays the timeline of the various trajectories based on the actions taken by the industry. Without actions taken, the emissions will be twice as much as the 2005 level.

To date, technological improvements have already begun contributing to the GHG emissions reduction target. Airframe and engine manufacturers have made significant technological leaps including lighter and stronger composite materials than ever before, new innovative aircraft designs with improved aerodynamics and incrementally more efficient engines (Rye et al., 2010). For example, 15 billion liters of fuel, and 80 million tons of $\mathrm{CO}_{2}$, were saved by retro-fitting wing tip devices to the wings of over 5,000 existing aircraft (ATAG, 2019). By also using weight reduction measures on cargo containers, GHG emissions decreased by 10,000 t/year (ATAG, 2014). These improvements allow greater efficiency in mileage and lower fuel consumption during travel. However, the slow incremental changes in alreadymature engine technology and the long lifetime ( $>25$ years) of existing fleets point toward AJF as a much faster and potentially more cost effective option to reduce emissions (Bauen et al., 2009). AJF can be easily utilized in existing fleets, hence avoiding large capital costs involved with buying newer models. Biofuel, as an AJF, promises a tremendous cut in GHG emissions and possible achievement of the ambitious target by 2040 as depicted in Figure 1B. Thus, the bulk of the reduction can be attained by replacing conventional jet fuel (CJF) with this alternative.

CJF produced from crude oil is a blend of various kerosene hydrocarbons. The hydrocarbon length of jet fuel is between that of gasoline and diesel. In a classical refinery, shown in Figure S1, jet fuel (or kerosene) is the middle distillate making up to $10 \%$ of the crude oil fraction while the majority are gasoline and diesel. Table S1 shows the comparison of the physicochemical properties of gasoline, jet fuel and diesel. As fuel for aviation, jet fuel is preferred over gasoline as it is less volatile and denser; while compared to diesel, jet fuel is lighter and less prone to wax at low temperatures (Yang et al., 2019). An AJF should have physical and chemical properties similar to CJF. A suitable aviation fuel must have high cold stability, for temperatures -47 to $40^{\circ} \mathrm{C}$ and elevations above 30,000 feet and have sufficient energy density to supply the high energy demand of long-haul flights (The Engineering ToolBox, 2003; Wilbrand, 2018). The industry uses two major kerosene-based CJF: Jet A and Jet A1. With a lower melting point of $-4^{\circ} \mathrm{C}$, Jet $\mathrm{A}-1$ is the better choice for international flights. The desirable composition of a jet fuel should be $75-85$ vol\% consisting of paraffins, iso-paraffins, and cycloparaffins and the remaining $15-25$ vol\% of olefins and aromatics. Other important characteristics include global availability, acceptable costs, good combustion characteristics, and good flow behavior. Hence, AJF being a "drop-in" fuel can be easily integrated into existing infrastructure allowing a seamless transition (Rye et al., 2010). An AJF must also have lower carbon footprints over their life cycle than CJF, which typically have a carbon footprint of roughly four tons per ton of fuel (de Jong et al., 2017a).

Bio-aviation fuel (also known as bio-jet fuel, renewable jet fuel or aviation biofuel in some literature) or BAF (for short in this paper), a type of biofuel for the air transport sector, is recognized as a short- to medium-term solution toward an overall reduction of the sector's GHG emissions. Table $\mathbf{S 2}$ shows the standard specifications for both CJF and BAF, with which manufacturers must strictly comply (Wilbrand, 2018; Yang et al., 2019). Clearly, the resulting emissions profiles of an aircraft running on BAF would be very similar to one on Jet A-1 (Rye et al., 2010). But the closed carbon cycle established by sequestering atmospheric $\mathrm{CO}_{2}$ during biomass growth and released at the end of its life cycle as BAF, results in its significantly lower overall carbon emissions compared to CJF (Bosch et al., 2017). While this makes BAF an attractive AJF option, several issues arose in its implementation. It has not been receiving sufficient investments due to inadequate government support and industry commitment, unreliable supply of feedstocks, uncertain commerciality of the production pathways, and lack of supply chain certification (Gegg et al., 2014).

Figure 1C presents recent bibliometric trends for bio-aviation fuel research. The data were obtained from Scopus using the keywords: bio-jet fuel, biojet fuel, bio-aviation fuel, aviation biofuel, or renewable jet fuel. In the last 10 years, there is generally an increasing trend in research on BAF, which reflects increasing recognition of the need to decarbonize the aviation sector through AJF options. Recent reviews of BAF considered the progress and issues in the production pathways (Gutiérrez-Antonio et al., 2017) and of fuel performance (Yang et al., 2019). Reimer and Zheng (2017) discussed possible strategies for enabling commercial BAF uptake, such as the simultaneous implementation of taxes on CJF and incentives for BAF utilization. The possibility of BAF production from different feedstocks, such as microalgae (Bwapwa et al., 2018), lignocellulosic biomass (Cheng and Brewer, 2017), urban and agricultural wastes (Jiménez-Díaz et al., 2017), and vegetable oils (Vásquez et al., 2017) have also been discussed in recent review papers. Kandaramath Hari et al. (2015) presented production pathways utilizing second- and third-generation feedstocks with qualitative discussion on the feedstock. These studies provided 


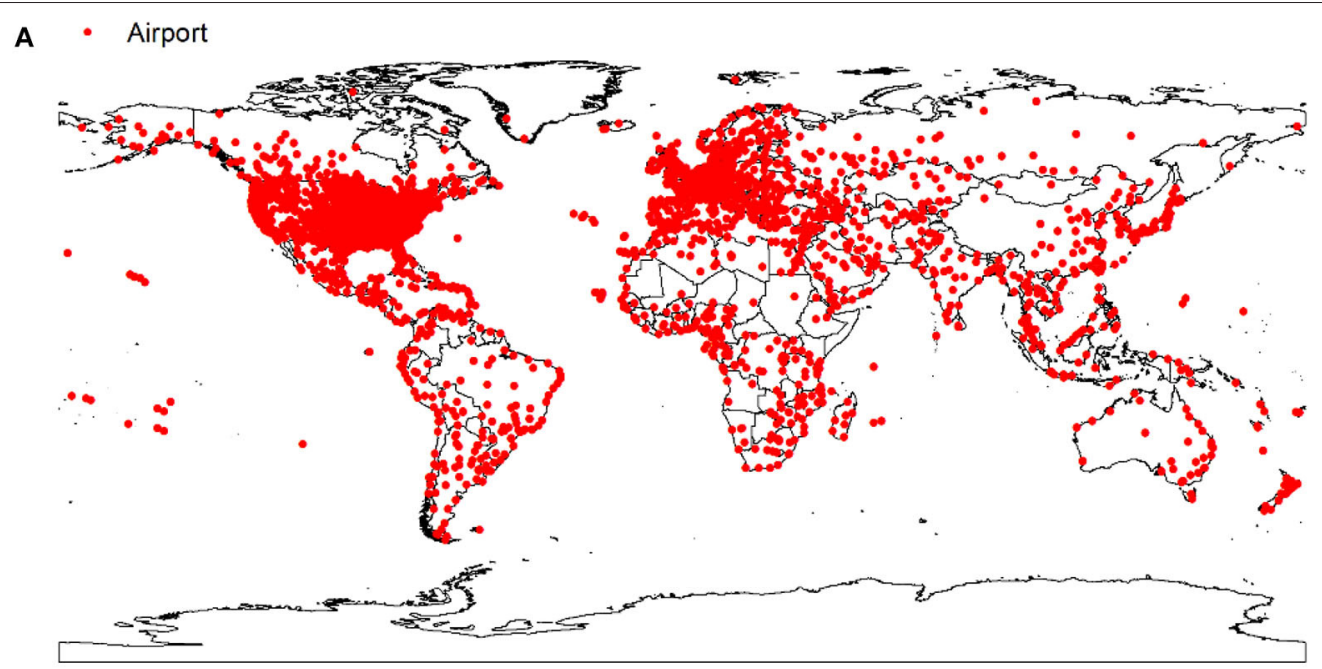

B

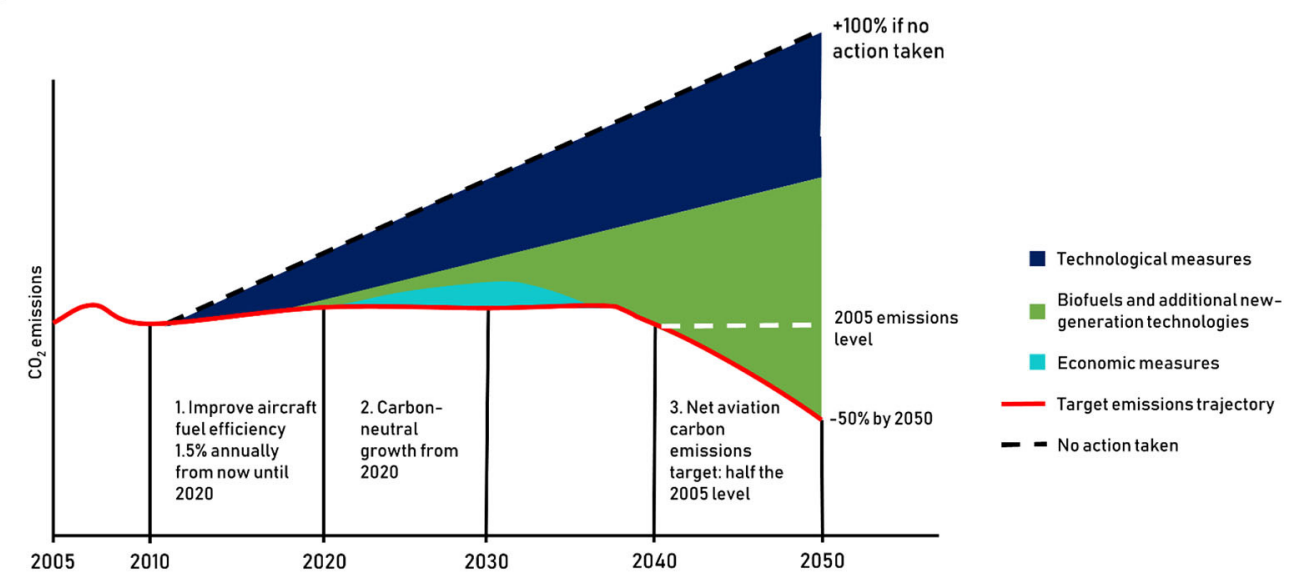

C

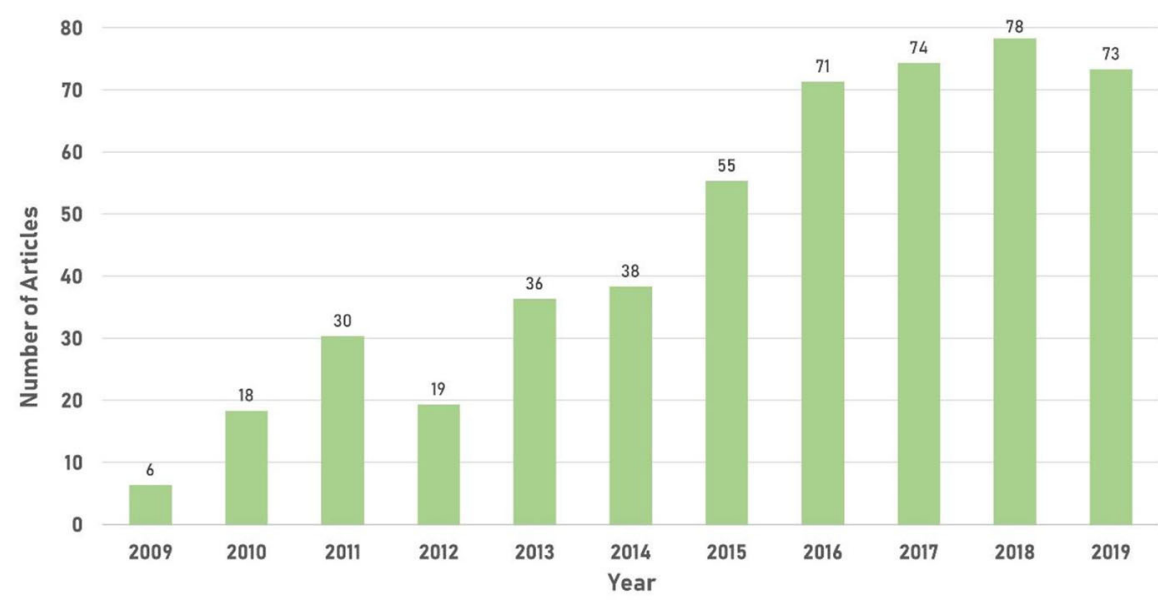

FIGURE 1 | Recent trends for the the aviation industry: (A) Global Airport Distribution (Plotted using data from www.arcgis.com, 2019); (B) Potential global atmospheric $\mathrm{CO}_{2}$ emissions released by the aviation sector under various development conditions (IATA, 2009); and (C) Publication history on bio-aviation fuel research (Plotted using data from Scopus accessed on January 17, 2020). 
insights on the status and future direction of the bio-aviation fuel industry. However, existing review papers are limited to individual components of the supply chain for BAF provision (e.g., raw materials, pretreatment, and conversion technologies) and there are currently no reviews discussing logistics strategies (e.g., storage and transportation of resources) or the economic and environmental analysis of the whole supply chain. Therefore, this review paper addresses this gap by being the first to provide a critical review of bio-aviation fuel from a whole-system supply chain perspective.

The focus of this review paper is on bio-aviation fuel examined holistically of its supply chain components: feedstock, production pathways, storage and transport. This review is organized into six sections. The next section gives an overview of bio-aviation fuel. The section on feedstocks for biomass-derived synthetic paraffinic kerosene is a comprehensive discussion of key feedstocks, which includes their cultivation requirements, supply chain models and economic and environmental impacts. The three most prominent production technologies are compared in the section of production pathways for synthetic paraffinic kerosene, in terms of their advantages and limitations, as well as their economic and environmental impacts. The storage and transport technologies for raw materials, intermediates, and final jet fuel product are discussed in the section on storage and transport of feedstocks and bio-aviation fuel. The penultimate section offers critical analyses, recommendations and future direction of each supply chain component. The key conclusions of this review paper are found in the final section.

\section{BIO-AVIATION FUEL}

Bio-aviation fuel is a biomass-derived synthesized paraffinic kerosene (SPK) that is blended into conventionally petroleumderived jet fuel (Yang et al., 2019). Table 1 presents the five types of SPK for blending (in specified volume fraction) with CJF as certified in ASTM D7566-19a (Table S2). The production platforms with their brief process description under which these SPK are classified are also presented in Table 1. The hydroprocessed esters and fatty acids production pathway (HEFA), an oil-to-jet production platform, produces HEFASPK via the deoxygenation of oils and fats followed by hydroprocessing (Yang et al., 2019). Hydrothermal liquefaction of plant or algal oil and fast pyrolysis of cellulose followed by jet fuel upgrading are also other oil-to-jet platforms (Wang and Tao, 2016). The gas-to-jet platform involves the gasification of biomass to produce syngas, which is converted to paraffinic and olefinic hydrocarbons by the Fischer-Tropsch production pathway (FT) and, subsequently, hydroprocessed to produce FTSPK. FT-SPK/A can also be produced by gas-to-jet platform but with the addition of alkylated and bio-based aromatics (Yang et al., 2019). In the alcohol-to-jet production platform or pathway (ATJ), biomass are hydrolyzed to produce fermentable sugars, the sugars are fermented to produce alcohols, and then they are dehydrated, oligomerized, hydrogenated and fractionated to produce ATJ-SPK (Yang et al., 2019). The sugar-to-jet production platform or direct sugar-to-hydrocarbon jet fuel synthesis (DSCH) involves the hydrolysis of fermentable sugars from biomass, the fermentation of these sugars to farnesene the
TABLE 1 | Five types of synthetic paraffinic kerosene based on the production platform (Wang and Tao, 2016; Yang et al., 2019).

\begin{tabular}{|c|c|c|}
\hline SPK & $\begin{array}{l}\text { Production } \\
\text { platform }\end{array}$ & Brief process description \\
\hline HEFA-SPK & Oil-to-jet & Deoxygenation of oils and fats $\rightarrow$ hydroprocessing \\
\hline FT-SPK & Gas-to-jet & $\begin{array}{l}\text { Gasification of biomass } \rightarrow \text { Fischer-Tropsch } \rightarrow \\
\text { hydroprocessing }\end{array}$ \\
\hline FT-SPK/A & Gas-to-jet & $\begin{array}{l}\text { Gasification of biomass } \rightarrow \text { Fischer-Tropsch } \rightarrow \\
\text { hydroprocessing } \rightarrow \text { increase aromatics content }\end{array}$ \\
\hline ATJ-SPK & Alcohol-to-jet & $\begin{array}{l}\text { Hydrolysis of biomass } \rightarrow \text { sugar fermentation to } \\
\text { alcohol } \rightarrow \text { dehydration } \rightarrow \text { oligomerization } \rightarrow \\
\text { hydrogenation } \rightarrow \text { fractionation }\end{array}$ \\
\hline SIP-SPK & Sugar-to-jet & $\begin{array}{l}\text { Hydrolysis of biomass } \rightarrow \text { sugar fermentation to } \\
\text { farnesene } \rightarrow \text { hydroprocessing } \rightarrow \text { fractionation }\end{array}$ \\
\hline
\end{tabular}

TABLE 2 | Advantages and disadvantages of bio-aviation fuel (Rye et al., 2010; Hendricks et al., 2011; Gegg et al., 2014; Bosch et al., 2017; de Jong et al., 2017a).

\begin{tabular}{ll}
\hline Advantages & Disadvantages \\
\hline $\begin{array}{l}\text { Theoretically unlimited feedstock } \\
\text { supply }\end{array}$ & $\begin{array}{l}\text { Problems associated with monocultures, } \\
\text { e.g., lack of biodiversity and susceptibility } \\
\text { to pests. }\end{array}$
\end{tabular}

Less risk in the long term in the case Competition with food supply if energy of fuel spillage crops become more profitable than food crops for farmers.

Capable of reduced net $\mathrm{CO}_{2}$ Detrimental land-use change, e.g., on production methods eutrophication from fertilizer use, and water/energy use during cultivation.

Use as "drop-in" alternative for existing engines

Spatial and temporal boundaries, e.g. feedstock may not be grown all year round or at all in some areas if specific conditions are required

Generally lower in contaminants, e.g., sulfur

hydroprocessing of farnesene and fractionation to produce SIPSPK (Yang et al., 2019). Catalytic reforming of sugar or sugar intermediates via chemical or biochemical process followed by upgrading to jet fuel via aqueous phase reforming and direct sugar to hydrocarbons are other sugar-to-jet platforms (Wang and Tao, 2016).

A summary of the advantages and disadvantages of BAF is presented in Table 2, but to ensure that it is truly an environmentally-friendly alternative, emissions savings are required over all phases of production: extraction, refining and transport. Energy security, price stability, and job creation are added potential gains that can be reaped. Rural development in terms of augmented employment in farming and production and increased productivity of non-arable marginal land can be expected with the deployment of bio-aviation fuel. Despite its economic benefits, deployment has not been receiving sufficient investment (Gegg et al., 2014). Hendricks et al. (2011) added that investments in the form of subsidies and legislative support are needed by the production pathways in order for them to become economically competitive against crude refinery production. 
The challenges faced by BAF are similar to those of biofuels, in general: the main one being how to ensure that the feedstocks, which come from biomass or other carbon-based sources, are secure, sustainable, economically viable, and sufficiently available within both time and location of demands (Hendricks et al., 2011; Su et al., 2015). With the aviation industry along with the sectors of heating, chemicals, road transport, and electricity, exerting efforts to decouple from fossil fuel dependence by shifting to biomass, their demands for the same feedstocks create a new supply competition (de Jong et al., 2017c). The following sections discuss the feedstocks and critically analyse their cultivation requirements, feasibility and sustainability of their supply chains, and their economic, and environmental performance. The discussions are focused specifically on feedstocks for bio-aviation fuel production but many of the issues also apply to production of biofuels in general since they share the same feedstocks.

\section{FEEDSTOCKS FOR BIOMASS-DERIVED SYNTHETIC PARAFFINIC KEROSENE}

Feedstocks can be categorized as follows: first-generation (1$G)$, second-generation (2-G), third-generation (3-G), and fourthgeneration (4-G). Table 3 presents some examples for BAF production in each category. An important factor in choosing a feedstock is its availability. For cultivated feedstocks, their availability, and potential yield are interrelated. Figure 2 shows the potential yields for a number of $1-G$ and $2-G$ feedstocks. Oil palm has the highest yield at $19.2 \mathrm{t} / \mathrm{ha}$ /year among these feedstocks. For 3-G feedstocks, the potential yield for microalgae has been reported to be much higher at $91 \mathrm{t} / \mathrm{ha} /$ year but there is uncertainty in this value due to algae cultivation being mostly from lab- to pilot-scale (Bwapwa et al., 2018).

\section{First-Generation Feedstocks}

Edible food crops, such as oil palm, corn, sugarcane, sugar beets, and wheat, belong to 1-G category (Lee and Lavoi, 2013). Sugar, starch, fat, and/or oil contents are extracted from these crops. Fats or oils can be easily converted to jet fuel through the well-established HEFA. Sugar or starch can be processed by the emerging DSCH technology. ATJ is another emerging technology, which is of high interest to the USA for their excess supply of 1-G ethanol from corn (Radich, 2015). While corn uses water efficiently, the sheer volume to be cultivated will result in high water demand and increased fertilizer use. Ramping up cultivation can strain a country's water resources and cause water-related issues like shortages and eutrophication. These are the main drawbacks in choosing 1-G feedstocks since most food crops typically have high water and nutrient demands (Table 4). Another main challenge of 1-G feedstock production is competition for land, water, and energy inputs with food production (Moioli et al., 2018). To circumvent scarcity of land resources, expansion to forestland has been the convenient option but at the expense of deforestation and biodiversity loss (Keles et al., 2018). Oil palm cultivation, a well-established food crop and promising BAF feedstock, has been linked to these adverse consequences (Vijay et al., 2016; Khatun et al., 2017).

\section{Oil Palm}

To date, HEFA is the only renewable jet fuel technology implemented industrially (Roth et al., 2018). Feedstock cost accounts for a significant fraction in the total production costs (Bosch et al., 2017). Palm oil can potentially offset the high cost of hydrogen in the HEFA being the least cost vegetable oil. Thus, there is a growing interest in oil palm as feedstock for bio-aviation fuel production (Schoneveld, 2010; Ernsting, 2017). Oil palm cultivation is an attractive business with relatively low nutrient demand, as shown in Table 4. Natural precipitation can also substantially satisfy the high-water requirements of plantations, which are mostly located in tropical and subtropical countries. Currently, Malaysia and Indonesia are at the forefront of palm oil production that supply more than $80 \%$ of the global demand driven mainly by food industries (Schoneveld, 2010). As the competing industry, biodiesel production is a recent growing demand for palm oil due to its higher energy output per unit energy input compared to other edible oils (Ail and Dasappa, 2016; Pirker et al., 2016).

Globally, oil palm plantations have already expanded by about 12 million hectares between 2000 and 2012 in large portions of tropical forests in Malaysia and Indonesia (Pirker et al., 2016). When either primary or secondary forests are converted to plantations, biodiversity loss has been well-associated with it (Koh and Wilcove, 2008). Rich concentrations of birds and mammals are highly at risk to extinction in the vulnerable forests of Southeast Asia, South America, Mesoamerica, and Africa (Vijay et al., 2016). Oil palm expansion is also well-associated with the degradation of peatlands. Instead of acting as carbon sinks, peatlands become net GHG emitters after their conversion to agricultural lands. Plantations in Southeast Asia, that were once peatlands, were estimated to have surface GHG emissions of 54 to $115 \mathrm{tCO}_{2}$ eq/ha/yr (Page et al., 2011). In palm oil mills, waste management of palm oil mill effluent (POME) is the main issue. Raw POME has a high biochemical oxygen demand ( $>25,000$ $\mathrm{mg} / \mathrm{L}$ ) and large volumes are generated yearly (Madaki and Seng, 2013). In 2015 alone, 60.88 and 94.76 million tons were generated in Malaysia and Indonesia, respectively (Choong et al., 2018). Due to high treatment costs, discharging of raw or partially treated POME to land or water bodies continues as an industry practice resulting in large-scale water pollution and ecosystem degradation (Madaki and Seng, 2013).

For oil palm to become a "good" feedstock option for bioaviation fuel production, sustainable practices in the cultivation and processing phases must be implemented. Selection of suitable available land through ecosystem service mapping can improve plantation sustainability as expansion to forestlands, land-use conversion of peatlands, and/or disruption to the environment can all be avoided. Optimal agronomic practices to maximize oil yield and minimize resource inputs can also reduce the negative impacts of plantations (Khatun et al., 2017). Improvements in sustainability of palm oil mills will need capital investments on biological treatment methods. These will not only eliminate POME but will also yield higher value products, which include fertilizers, livestock feeds, and biogas (Wu et al., 2009). To lower overall costs, the use of ultrasonic and membrane technology as an integrated system is a solution with good economic potential 
TABLE 3 | Feedstocks for bio-aviation fuel production (Rye et al., 2010; Warshay et al., 2011; Kandaramath Hari et al., 2015; ATAG, 2017; Chiaramonti Horta and Nogueira, 2017; Rödl, 2018; Roth et al., 2018; Staples et al., 2018; Alalwan et al., 2019).

\begin{tabular}{|c|c|c|c|}
\hline First-generation (1-G) & Second-generation (2-G) & Third-generation (3-G) & Fourth-generation (4-G) \\
\hline $\begin{array}{l}\text { Oil-seed crops: camelina, oil palm, } \\
\text { rapeseed, soybean, sunflower, } \\
\text { salicornia } \\
\text { - Sugar and starchy crops: corn, } \\
\text { wheat, sugarcane, sugar beets }\end{array}$ & $\begin{array}{l}\text { - Oil-seed energy crops: jatropha, castor bean } \\
\text { - Grass energy crops: switch grass, miscanthus, Napier } \\
\text { grass } \\
\text { - Wood energy crops: poplar, willow, eucalyptus } \\
\text { - Agricultural and forestry residues: corn stover, sugarcane } \\
\text { bagasse, wood harvesting/processing residues } \\
\text { - Food and municipal waste: used cooking oil, animal fats, } \\
\text { biogenic fraction of municipal solid waste }\end{array}$ & - Algae: microalgae & $\begin{array}{l}\text { - Genetically modified organisms } \\
\text { - Non-biological feedstocks: } \mathrm{CO}_{2} \text {, } \\
\text { renewable electricity, water }\end{array}$ \\
\hline
\end{tabular}

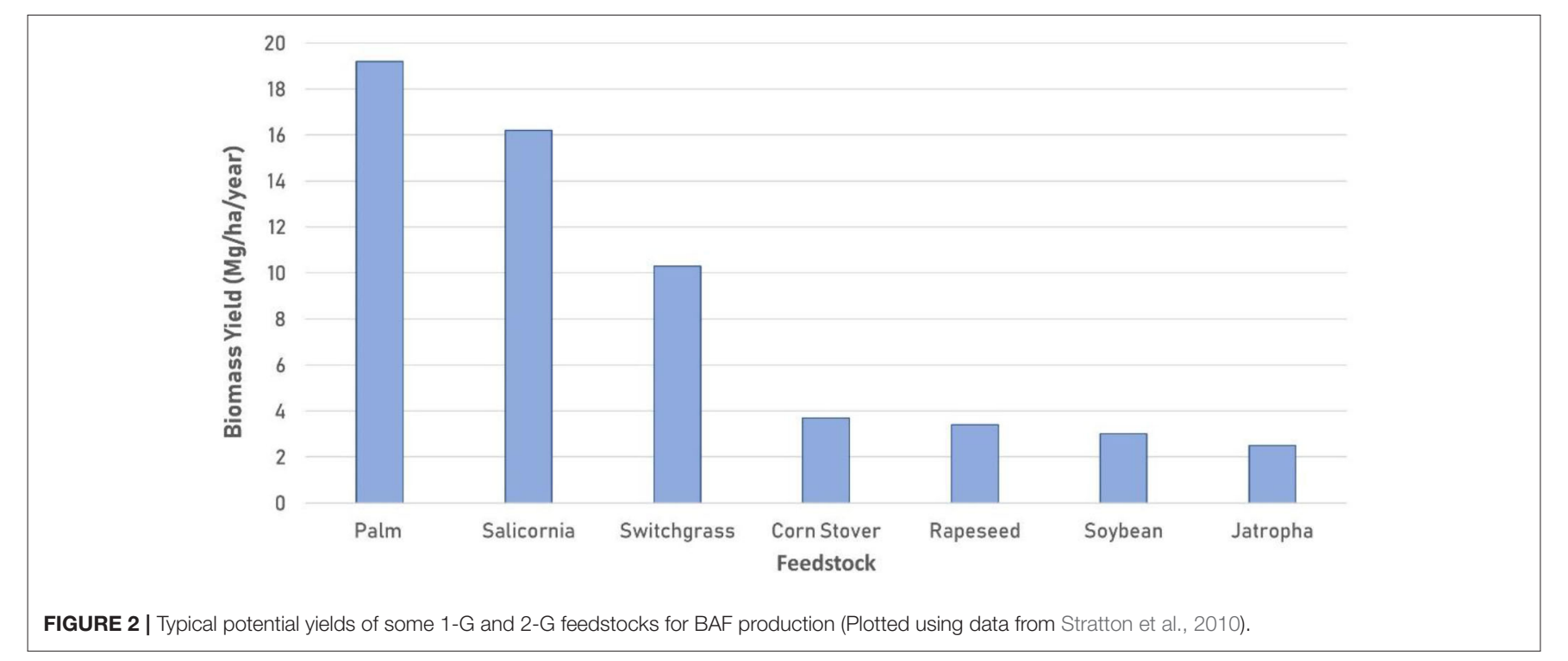

for biogas production (Abdurahman and Azhari, 2018). It has been recommended that mills are equipped with biogas capture to reduce overall GHG emissions by about $30 \%$ and improve biofuel net energy yield (Kaewmai et al., 2012; Harsono et al., 2014).

Current consumption of land transport biofuels and the resulting benefits of rural development and employment has already expanded the role of supply chains of 1-G crops, like oil palm, from food feed and fiber provision to fuel provision (KPMG International, 2013; Sims et al., 2015). However, the growing demand for food-based biofuels has been linked to rising global food prices and food supply imbalances (KPMG International, 2013; Oladosu and Msangi, 2013; Buchspies and Kaltschmitt, 2018). In the case of oil palm, the gap between supply and demand is expected to widen further in the future (Khatun et al., 2017). Hence, the inclusion of BAF production to the supply chain agenda of oil palm could further increase the complexity and challenges (KPMG International, 2013). In this arena, mathematical modeling and optimization techniques can aid in comprehending and formulating strategies for the needed transformation of future food supply chains that can sustainably provide food and non-food commodities simultaneously (FAO, 2014; Zhu et al., 2018). For example, Tapia and Samsatli (2020) developed an optimisation model for multi-product oil palm supply chains that ensures sustainable land and water use and biodiversity protection. It may be technically feasible to integrate BAF production with food production from 1-G feedstocks but the policies and management have to be systematically assessed and sustainably implemented (Sims et al., 2015).

\section{Second-Generation Feedstocks}

Non-edible 2-G biomass resources can circumvent the food vs. fuel dilemma of 1-G feedstocks (Alalwan et al., 2019). These are classified into two main groups: energy crops and waste biomass. Waste biomass is further categorized into agricultural and forestry residues and food and municipal wastes. Regardless of the classification, 2-G feedstocks are either oil- or sugar-rich materials. However, in contrast to $1-G$ crops, the sugars of $2-G$ feedstocks are trapped in the tough and recalcitrant lignocellulosic matrix of plant cell walls that need pretreatment with enzymes/microorganisms and/or thermochemical transformations for biofuel conversion (Boichenko et al., 2013; Lee and Lavoi, 2013). The technical barriers and high costs of these conversion technologies are the main issues of 2-G feedstocks utilization (Alalwan et al., 2019). However, the relatively high abundance and low use 
TABLE 4 | Comparison of the cultivation requirements of various 1-G and 2-G feedstocks (Escobar et al., 2009; Hickman et al., 2010; Fazio and Barbanti, 2014; Searle and Malins, 2014; Curneen and Gill, 2016; Surian Ganba et al., 2016; Liu W. et al., 2017; Campbell, 2018; Fabio and Smart, 2018; Fischer et al., 2018; Rödl, 2018).

\begin{tabular}{|c|c|c|c|c|}
\hline Category & Feedstock & Climate & Nutrients & Water \\
\hline \multirow[t]{8}{*}{$1-G$} & Camelina & $\begin{array}{l}\text { Temperate to tropical; also, in } \\
\text { semi-arid climate zones }\end{array}$ & Low demand & Low to moderate rainfall \\
\hline & Corn & Tropical & High-fertility soil required & Efficient water use \\
\hline & Oil Palm & Tropical and Subtropical $\left(25-32^{\circ} \mathrm{C}\right)$ & Low demand & $\begin{array}{l}\text { Higher (Uniform precipitation required all year round, } \\
1,800-5,000 \mathrm{~mm} / \text { year) }\end{array}$ \\
\hline & Rapeseed & $\begin{array}{l}\text { Most efficient growth at } 15-20^{\circ} \mathrm{C} \text {; } \\
\text { sensitive to high temperatures }\end{array}$ & High demand & Low to moderate demand (600 mm/year needed) \\
\hline & Sugar beet & Variety of moderate climates & High fertilizer demand & Moderate water use (550-750 mm rainfall during growth) \\
\hline & Sugarcane & Tropical and Subtropical & High demand & High precipitation required all year round \\
\hline & Soybeans & Subtropical to tropical & Moderate fertilizer demand & High water demand \\
\hline & Wheat & $\begin{array}{l}\text { Moderate climates (Subtropical with } \\
\text { rainy winters to mountainous } \\
\text { tropical regions) }\end{array}$ & High demand & High water demand \\
\hline \multirow[t]{8}{*}{$2-G$} & Jatropha & $\begin{array}{l}\text { Tropical: Annual average } \\
\text { temperature between } 20 \text { and } 28^{\circ} \mathrm{C}\end{array}$ & Low demand & $\begin{array}{l}\text { Low demand and drought resistant } \\
\text { (Minimum precipitation } 400 \text { mm/year needed) }\end{array}$ \\
\hline & Castor bean & Tropical: $20-30^{\circ} \mathrm{C}$ & Moderate demand & $\begin{array}{l}\text { Low demand } \\
\text { (At least } 400 \mathrm{~mm} \text { of precipitation during seedling and } \\
\text { blossoming) }\end{array}$ \\
\hline & Switch grass & Temperate & Low demand (0-50 kgN/ha) & $\begin{array}{l}\text { Moderate demand } \\
\text { (800 mm/year) }\end{array}$ \\
\hline & Miscanthus & Tropical to temperate; cold resistant & $\begin{array}{l}\text { Moderate demand }(50-75 \\
\left.\mathrm{kgN}_{\mathrm{N}} / \mathrm{ha}\right)\end{array}$ & Moderate to high demand (1,000 mm/year) \\
\hline & Napier grass & Tropical & $\begin{array}{l}\text { High demand (150-300 } \\
\mathrm{kgN} / \mathrm{ha})\end{array}$ & $\begin{array}{l}\text { High demand but drought resistant } \\
\text { (Precipitation of } 1,500 \mathrm{~mm} / \text { year) }\end{array}$ \\
\hline & Poplar & Temperate & Low demand & $\begin{array}{l}\text { Low to moderate demand } \\
\text { (Precipitation of } 400-800 \mathrm{~mm} / \text { year) }\end{array}$ \\
\hline & Willow & Temperate & $\begin{array}{l}\text { Low to moderate demand } \\
\left(0-150 \mathrm{~kg}_{\mathrm{N}} / \mathrm{ha}\right)\end{array}$ & $\begin{array}{l}\text { Moderate to high demand } \\
\text { (Precipitation of } 600-1,000 \mathrm{~mm} / \text { year) }\end{array}$ \\
\hline & Eucalyptus & Dry tropical to subtropical zones & Low demand & $\begin{array}{l}\text { Moderate to high demand } \\
\text { (Precipitation of } 600-1,000 \mathrm{~mm} / \text { year) }\end{array}$ \\
\hline
\end{tabular}

competition of lignocellulosic 2-G feedstocks make them a promising alternative to $1-\mathrm{G}$ crops (Rödl, 2018; Correa et al., 2019). Waste biomass utilization also offers far greater benefits, such as realization of circular economies, waste management, and environmental protection (Ahorsu et al., 2018; Richter et al., 2018). To date, production of biodiesel and bioethanol for land transport from 2-G feedstocks still lags behind 1-G feedstocks ( $\mathrm{Su}$ et al., 2015). For land transport, Millinger et al. (2017) predicted in the long-term that liquid biofuels from 1-G feedstocks will be more cost-competitive than those from 2-G feedstocks, while gaseous biofuels derived from 2-G feedstocks for gas-powered vehicles is seen to be the more cost- and resource-effective option in the medium-term. Nevertheless, liquid biofuels from $2-\mathrm{G}$ feedstocks may become more important for the aviation sector, where gaseous fuels are not feasible (Millinger et al., 2017). However, the supply of 2-G feedstocks must be proven adequate, stable, and affordable. In the following subsections, various 2-G feedstocks for BAF production are reviewed from this perspective.

\section{Energy Crops}

Oil-seed energy crops, like jatropha (Jatropha curcas) and castor bean (Ricinus communis), have no food value, as their oils are toxic for human consumption (Shahare et al., 2017; Molefe et al.,
2019). The oil content of jatropha and castor bean is typically $30-40$ and $50-60 \%$ of the seed weight, respectively (Tao et al., 2017; Heinrich, 2018). Transesterification, catalytic cracking (pyrolysis) or hydroprocessing can process castor bean oil to produce BAF (Molefe et al., 2019). The hydrocracking of oils from castor bean and jatropha for enhanced BAF production has been recommended by Molefe et al. (2019). Compared to castor bean, available literature shows jatropha as the more widely studied energy crop (Rye et al., 2010; Güell et al., 2012; Roda et al., 2015; Chiaramonti Horta and Nogueira, 2017; Heinrich, 2018; Neuling and Kaltschmitt, 2018; Yang et al., 2019). There have been both test and commercial flights using jatropha-blended jet fuel (Su et al., 2015; Chiaramonti Horta and Nogueira, 2017). Currently, markets of jatropha and castor bean as BAF feedstocks are not yet mature (Tao et al., 2017).

Several grass and wood energy crops have been proposed as 2-G feedstocks for BAF production via thermochemical and/or biochemical routes (Kandaramath Hari et al., 2015). The high lignocellulose content and readily available harvesting technologies make grass energy crops attractive for biofuel production (Herr et al., 2012). Rödl (2018) identified the following grasses:

- Switch grass is a perennial crop native to North America with an average annual yield of 12 t/ha/yr (Jacobson, 2013b; 
Rödl, 2018). It has a highly promising techno-economic and environmental performance as feedstock (Warshay et al., 2011). Experimental studies have been conducted for its conversion to BAF through fast pyrolysis-hydrotreating route (Howe et al., 2015), coal- and biomass-to-liquid hydrocarbon process (Folkedahl et al., 2011); and bio-based hydrocarbons production pathways (Sinha et al., 2015; Frederix et al., 2016). Techno-economic analysis reveals a break-even price of USD 1/L (or USD 5/gal) for ATJ fuel from switch grass (Yao et al., 2017); while life cycle assessment (LCA) shows that BAF from switch grass has lower emissions than from fossil sources (Agusdinata et al., 2011). No literature can be found reporting any large-scale production and/or test flights of switch grassderived BAF.

- Miscanthus is a family of perennial plants from its native origins in Asia and Africa brought to Europe as a garden plant (Rödl, 2018). The species, Miscanthus $x$ giganteus, is of great research interest due to its high productivity with an average annual yield of $25 \mathrm{t} / \mathrm{ha} / \mathrm{yr}$ (Jacobson, 2013a; McIsaac, 2014). Miscanthus has been shown to have greater bioenergy potential than switch grass, based on studies in USA and Europe (Scagline-Mellor et al., 2018). Despite several studies demonstrating viable production of jet fuel precursors like syngas (Jayaraman and Gökalp, 2015; Couto et al., 2017; Dupuis et al., 2019), pyrolysis oil (Conrad et al., 2019; Wang and Lee, 2019), and ethanol (Lee and Kuan, 2015; Boakye-Boaten et al., 2017; Lask et al., 2019), there is little to no systematic literature focusing on the conversion of miscanthus to BAF. Nevertheless, there have been proposed demonstration facilities for the production of miscanthus-derived jet fuel (Ondrey, 2012; BBI International, 2018).

- Napier grass or elephant grass (Pennisetum purpureum) is a perennial grass from the tropics with reported high yields of 20-140 t/ha/yr (Fontoura et al., 2015; Chang et al., 2017; Lamb et al., 2018; Rödl, 2018). It is a promising feedstock for the production of both solid and liquid biofuels (Fontoura et al., 2015; Lamb et al., 2018). However, little to no literature is available for systematic study of its conversion to BAF. Research to date has been on the production of jet fuel precursors, such as syngas (Khezri et al., 2019; Mohammed et al., 2019), pyrolysis oil (Suntivarakorn et al., 2018; Mohammed et al., 2019), and alcohols (Camesasca et al., 2015; He et al., 2017). Napier grass cultivation in Southeastern USA is highly considered as BAF feedstock via ATJ (United States Department of Agriculture - Research, 2012; Anderson, 2016).

Compared to grasses, woods have higher biomass availability per area and lower logistics costs that could make them a better feedstock option (Murphy et al., 2015). Woody energy crops for biofuel production are usually short rotation coppices. These are fast growing trees that within a cycle or rotation ( $<10$ years) are coppiced/planted and then harvested (Murphy et al., 2015; Rödl, 2018). Moreover, short rotation coppices can supplement low supply of grass energy crops during drought periods (Murphy et al., 2015). Rödl (2018) has also identified the following short rotation coppices as BAF feedstock produced at near intensive agro-industrial scale:

- Poplar (Populus spp.) is a family of temperate perennial trees that is also cultivable in warmer regions (Fazio and Barbanti, 2014; Searle and Malins, 2014; Rödl, 2018). Globally, 70 nations grow poplar, with $91 \%$ in natural forests and the remainder in plantations, with an average annual yield of $9 \mathrm{t}$ /ha (Ball et al., 2005; Rödl, 2018). Although it is mainly utilized for paper and timber production, poplar utilization for bioenergy is gaining traction among European countries (Ball et al., 2005). With the underlying reason for product diversification and expansion, poplar is a promising BAF feedstock (Crawford et al., 2016). Recent studies confirmed that poplar-derived hydrocarbons via pyrolysis and fermentation could be upgraded to jet fuel by hydrogenation (Crawford et al., 2016; Zhang et al., 2016). No literature can be found regarding test flights running on jet fuel derived from poplar.

- Willow (Salix spp.) is a genus of perennial flowering trees that grow from temperate to boreal regions with annual yields ranging in 4-10 t/ha (Searle and Malins, 2014; Rödl, 2018). About 94, 6, and 1\% of willows worldwide grow in natural forests, plantations, and agro-forestry systems, respectively. Wood production is the main application of willows (Ball et al., 2005). Its application for heat and electricity production is a growing trend among Northern hemisphere nations (Sassner et al., 2006; Woytiuk et al., 2017). Several experimental studies demonstrated willows as a viable source of jet fuel precursors, which include alcohols (Sassner et al., 2006; Han et al., 2013), syngas (Giudicianni et al., 2017; Woytiuk et al., 2017), and pyrolysis oil (Giudicianni et al., 2017; Miettinen et al., 2017). Despite these, no literature can be found on systematic studies of BAF production from willows.

- Eucalyptus (Eucalytpus spp.) is a group of fast-growing trees originating from Australia (Gonzalez et al., 2011b; Searle and Malins, 2014; Rödl, 2018). Plantations cover more than 20 million hectares worldwide with an average productivity of 10 t/ha annually (Ferreira et al., 2019). Intensive cultivation is driven primarily by paper and biomass demands (Gonzalez et al., 2011b; Surian Ganba et al., 2016). Bioenergy applications of eucalyptus is a growing sector in many parts of the world (Gonzalez et al., 2011c; De Jesus Eufrade Junior et al., 2016). In terms of BAF production, eucalyptus has been shown to be a promising feedstock in Brazil (Cantarella et al., 2015). Techno-economic assessments show that the ethanol-to-jet fuel production pathway is more favorable than the butanolto-jet fuel route but both are currently not cost competitive alternatives (Silva Braz and Pinto Mariano, 2018). Initial assessment of integrating BAF production from eucalyptus in Brazilian sugarcane biorefineries also show a favorable economic and environmental performance (Klein et al., 2018). No references can be found on test flights running on eucalyptus-derived jet fuel.

Table 4 presents resource demands for cultivating the energy crops that were discussed. In contrast to $1-G$ feedstocks, energy 
crops typically (except for Napier grass) have low to moderate demand for fertilizers. Thus, their cultivation in non-fertile and non-food productive marginal lands has been the main recommendation (Murphy et al., 2015; Callegari et al., 2019; Lask et al., 2019). Dependent on the type of land-use change (LUC), energy crops grown and farming practices, cultivation in degraded or abandoned land may improve biodiversity by providing opportunities for habitat (Pedroli et al., 2013). The cultivation in metal-contaminated marginal lands can also lead to phytoremediation (Ruttens et al., 2011; Pandey et al., 2016; Zalesny et al., 2019). The clean-up of highly saline and polluted agricultural soils with halophyte energy crops (e.g., Salicornia bigelovii) is another promising ecosystem service (Abideen et al., 2014). However, there are several drawbacks of cultivation in marginal lands. Marginal lands may have poor water access and supply that may be detrimental to water-intensive energy crops (Yan et al., 2018; Jiang et al., 2019). While some energy crops, like jatropha and Napier grass, could be argued as water-use efficient or even drought resistant, their yields are better with irrigation, which is highly recommended for farming in marginal lands (von Maltitz et al., 2014; Wani et al., 2016; Lamb et al., 2018). Hence, energy crops may indirectly compete with food production via water consumption. Marginal lands typically also have low agro-economic performance. Growing energy crops in these lands may be high in cost and result in lower yields (Searle and Malins, 2014; Jiang et al., 2019). Often, commercial biomass developers opt for highly productive lands that give better returns on investment. Therefore, energy crops have a high risk of competing with food production for suitable lands and of expanding into forestlands (Schoneveld, 2010; Keles et al., 2018). Clearly, inclusion of energy crops in the portfolio of BAF feedstock requires optimal land-use for truly genuinely available and suitable marginal land (Schoneveld, 2010; Popp et al., 2014).

The high economic costs associated hinder the commercialization of most lignocellulosic feedstocks (Correa et al., 2019). Hence, actual supply chains have yet to be fully realized. Notwithstanding, mathematical modeling and optimization techniques have been applied to model these supply chains. Potential minimization of costs within the agricultural, transport, and industrial activities of the supply chain has been shown (Atashbar et al., 2016, 2018). To date, a few modeling studies have been published on energy crop supply chains for BAF provision. Perkis and Tyner (2018) presented a sequential start-up model, based on mixed-integer non-linear programming, with the aim of minimizing the production and logistics costs of jet fuel from switch grass in Indiana, USA. Domínguez-García et al. (2017) developed a multi-objective mixed-integer linear programming (MILP) model to plan strategically a cellulosic aviation fuel industry in Mexico. The model considers bio- and fossil-resources, biomass farming sites, and processing technologies (including hydrogen production) in the minimization of cost and $\mathrm{CO}_{2}$ emissions of the supply chain. Samsatli et al. (2015) formulated a novel MILP for the Biomass Value Chain Model (BVCM) for the UK, which can comprehensively model a large variety of bioenergy system pathways including BAF production from energy crops. This model is also a flexible optimization toolkit that can account economic and environmental impacts. Samsatli and Samsatli (2018b) presented an optimisation model for the combined supply chains for biomass and wind energy to meet demands for services in the heat, power and mobility sectors. A general MILP model was also proposed by Samsatli and Samsatli (2018a) for designing energy supply networks of eco-towns using biomass. The cost optimization feature in these supply chain studies is important in demonstrating the cost-competitiveness and attractiveness to investors of an energy crops-based BAF business (Martinkus et al., 2018). However, a full-scale implementation of energy crops for jet fuel production would not only entail economic impacts. Both impacts on and synergies with food (land), water, energy, and environment sectors are expected that are not typically assessed and analyzed holistically in most biomass supply chain models (Tapia et al., 2019).

\section{Waste Biomass}

Waste biomass could be better feedstocks over energy crops as they have no land requirement (as they are co-produced from activities in agro-forestry, domestic, commercial, and industrial sectors), little to no economic value, and lower water footprints than cultivated crops (Caicedo et al., 2016; Chiaramonti Horta and Nogueira, 2017; Mathioudakis et al., 2017; Rödl, 2018). Given the low-cost of most waste biomass, BAF developers have been rapidly considering these as feedstock (Mawhood et al., 2016; Barbosa, 2017; Wenger and Stern, 2019). BAF production from waste streams could be a superior option given that the energy requirements and emissions associated with cultivation only need to be accounted for once. If the amount of resources used for purifying and upgrading wastes into jet fuel is less than that for cultivated feedstocks, wastes will prove to be a more cost-effective option for the aviation industry's emissions reduction.

The first group of waste biomass come in the form of many agricultural and forestry residues. These are typically lignocellulosic by-products resulting from cultivation, harvesting, logging, and post-harvest activities (e.g., milling, crushing, wood processing etc.) (Dornack et al., 2018; Staples et al., 2018). Primary and secondary agricultural or crop residues include corn stover, sugarcane bagasse, wheat straw, rice straw, rice hull, palm kernel, and empty fruit bunches. On the other hand, primary and secondary forestry residues include unprocessed portions of felled trees (e.g., leaves, stumps, branches, and treetops), wood pulp, wood chips, scrap wood, cutter shavings, and saw dust (de Corato et al., 2018; Dornack et al., 2018). Technologies to convert these lignocellulosic wastes into jet fuel precursors, such as syngas, pyrolysis oil, ethanol and butanol, are already available (de Corato et al., 2018; Huzir et al., 2018; Pandiyan et al., 2019; Schmitt et al., 2019). There have been initiatives reported of BAF derived from agro-forestry residues via isobutanol-to-jet and direct sugar-to-farsenene routes (AviationPros, 2015; Green Car Congress, 2016; Chiaramonti Horta and Nogueira, 2017).

Systematic studies focusing on the production of BAF from agricultural and forestry residues are still few. Xue et al. (2017) presented a rational process design of integrating acetone-butanol-ethanol production from corn stover and their successive catalytic conversion ( $76 \%$ efficiency) to long chain 
ketones as jet fuel precursors. The economic and environmental analysis of Agusdinata et al. (2011) showed corn stover as BAF feedstock with least total unit cost and GHG emissions in meeting the GHG emissions reduction of USA's aviation industry by 2050 but it can only compete in the short-term when CJF prices are high. LCA by Trivedi et al. (2015) confirmed that corn stover-based BAF via FT and advance fermentation have lower GHG emissions than CJF at 87 and 55\%, respectively. Sugarcane bagasse, produced at 200 million tons annually, can be a significant feedstock for the production of biofuels for both road and air transport via established thermochemical production pathways like gasification and pyrolysis (Nicodème et al., 2018). Michailos (2018) conducted a techno-economic and life cycle analysis of BAF (farnesane) production from sugarcane bagasse via direct sugar to hydrocarbon route. With a low yield of $12.1 \% \mathrm{w} / \mathrm{w}$ fuel per sugarcane bagasse, the minimum jet fuel selling price (MJSP) would be $\mathrm{USD}_{2018}$ 2.78/L (4 times greater than CJF) suggesting government subsidies will be needed; while 49\% reduction in GHG emissions against CJF would be expected indicating a favorable sustainability potential. Roda et al. (2015) assessed the available crop residues for BAF production in Malaysia, an agricultural and developing country, to a maximum of 3.8 million liters per year from the waste streams of oil palm, rubber, sugarcane, coconut, and rice industries. Although the quantity of oil palm residues is highest in Malaysia, the associated environmental concerns of its cultivation constraints its sustainable availability. There are also oil-rich agro-forestry residues that can be potential BAF feedstocks. Rice bran, a byproduct of rice milling and annually produced at 75 million t/year, contains 10-20\% w/w oil (Sharif et al., 2014; Nguyen et al., 2019). Nguyen et al. (2019) designed a transesterification process in the presence of $\mathrm{Ni}(\mathrm{II})$-Schiff base chelate promoter catalyst and $\mathrm{H}_{2}$ gas environment to convert rice bran oil to a biodiesel product with even better cetane index values and lower glycerol impurities than the conventional biodiesel. The hydrotreatment of rice bran oil in the presence of $\mathrm{NiMo} / \mathrm{Al}_{2} \mathrm{O}_{3}$ catalyst has also been performed yielding fuel products with similar to enhanced properties than petroleum ones (El Khatib et al., 2018). Alternatively, eucalyptus leaves can also be a source of highoctane oil, which has a potential biofuel application for road and aviation transport (Kainer and Kulheim, 2016; Masimalai and Subramaniyan, 2017). Due to yearlong production of forestry residues, they can be more preferable BAF feedstocks than crop residues (Richter et al., 2018). Shah et al. (2019) showed that upgraded pyrolysis oil from sawdust of eucalyptus blended with waste cooking oil has similar physico-chemical characteristics to aviation kerosene. Alves et al. (2017) also found that ethanol-tojet production pathway is a favorable techno-economic design for BAF production from eucalyptus residues in Brazil. Ganguly et al. (2018) also conducted a well-to-wake (WTW) LCA of BAF production from mild bisulfite pretreated forestry residues via butanol-to-jet production pathway that revealed a $78 \%$ reduction in global warming impact compared to CJF.

Food and municipal wastes are the second group of waste biomass that can be considered as feedstocks for BAF production. According to de Corato et al. (2018) and Dornack et al. (2018), this group consists of the following:
- Animal and fish farming wastes (e.g., manure, excreta, scales, scraps);

- Food processing wastes (e.g., de-oiled seed meals/cakes, exhausted pulps, slaughterhouse wastes, feathers, animal fats);

- Industry and commercial processing wastes from beer, wine, baking, dairy, and cheese industries;

- Household/urban wastes (used cooking oil or UCO, used engine oils, kitchen wastes, spent coffee grounds, and tea bags);

- Spoiled (unmarketable) vegetables, fruits, meat, bread, cheese, and other by-products;

- Landscape management wastes (e.g., pruning, branches, twigs, leaves, flowers);

- Biomass/organic portion of municipal solid waste (MSW); and

- Biomass/organic portion of sewage sludge.

In the aviation industry, low cost UCO (waste cooking oil in some literature) is currently the only waste stream of practical use due to HEFA (Roth et al., 2018). The hydrotreating process of $\mathrm{UCO}$ is also continually being improved, such as development of a one-pot reaction, contrary to the conventional two-step process (Zhang Z. et al., 2018), and screening of catalyst and process conditions for better quality jet biofuel (Chen and Wang, 2019). There have been many demonstration and commercial flights running on UCO-derived or UCO-blended jet fuel (Chiaramonti Horta and Nogueira, 2017; Yang et al., 2019). UCO from households and restaurants ending up in the gutter has been recently used as jet fuel blends in Boeing flights in China (Karmee, 2017). Animal fats (e.g., tallow, yellow grease), is another low cost food waste stream and a promising feedstock for BAF production (Chiaramonti Horta and Nogueira, 2017). Biofuels produced from animal fats potentially have better combustion quality over those produced from oil-seed crops (Popov and Kumar, 2013). Tallow was reported to be an environmentally favorable feedstock for biodiesel production due to its low life cycle GHG emissions (Kalnes et al., 2011). However, the demand by the transportation sector for tallow has to compete with increasing demands from the cosmetic and biochemical industries (Ernsting, 2017). World consumption of animal fat, together with vegetable fat, has also increased due to biodiesel consumption (Mielke, 2018). Though animal fats can be easily converted to jet fuel by hydroprocessing (Buchspies and Kaltschmitt, 2018; Zhang B. et al., 2018), no literature can be found on commercial or demonstration flights running on animal fat-derived jet fuel.

MSW has also been increasingly considered as BAF feedstock. Dabe et al. (2019) reviewed the various existing and advancing thermo- and bio-chemical production pathways of syngas and alcohols from MSW as precursors for BAF conversion. Dabe et al. (2019) added that the current technologies could already enable the utilization of the high-energy value of MSW and alleviate problems associated with landfills. In fact, Fulcrum Bioenergy is reported to produce jet fuel via FT commercially by processing 30,000 t/year of MSW by 2020 (Richter et al., 2018). On the one hand, Swedish Biofuels is expected to complete an ATJ demonstration facility this year (2019) that will process 5,000 t/year of MSW along with other waste streams (Mawhood et al., 2016). However, systematic studies focusing in the production 
of BAF from MSW seem limited. This lack of data on the performance and cost of MSW conversion technologies hinders strategic decision-making. Pham et al. (2010) performed a techno-economic assessment of a mixed fermentation process that uses MSW to produce jet fuel, gasoline and diesel in the USA. MSW comes with a tipping fee that is an average price of $\mathrm{USD}_{2010} 45 / \mathrm{dry}$ ton. For a $40 \mathrm{t} / \mathrm{h}$ plant with internal production of hydrogen, the MJSP is $\mathrm{USD}_{2010}$ 0.33/L. Suresh et al. (2018) conducted a techno-economic and environmental assessment with Monte Carlo uncertainty analysis of BAF from MSW via FT and ATJ in the USA. The results revealed that production costs of BAF from MSW are still more expensive than CJF production with a MJSP of $\mathrm{USD}_{2018} \quad 0.99 / \mathrm{L}$ and $\mathrm{USD}_{2018} \quad 1.20 / \mathrm{L}$ of $\mathrm{BAF}$ via FT and ATJ, respectively. However, both show about $93 \%$ increase in net present value due to the GHG emissions savings via implementation of carbon pricing. Compared to CJF, life cycle GHG emissions reduce by $63 \%$ and $41 \%$ with BAF from MSW via FT and ATJ, respectively. There have been no reported test flights yet with jet fuel derived from MSW.

Logistical complexity and variable availability of waste biomass are the primary challenges as BAF feedstock (Iakovou et al., 2010; Mawhood et al., 2016). The bulkiness of some can lead to high logistic operating costs and constrain the capacity of centralized processing plants (Mawhood et al., 2016). Collection, transportation and storage of large amounts of biomass wastes, like animal manure and MSW, are additional issues due to health and safety risks (Rentizelas et al., 2009; Downie and van Zwieten, 2013). Other waste management inadequate legislation, such as landfills, incineration and recycling, can potentially hinder their streamlined acquisition (Mawhood et al., 2016). The highly uncertain availability of waste biomass remains an issue for their sustainable utilization (Roth et al., 2018). Many of the candidates as feedstocks are not available all year round and at the same location where they are needed (Staples et al., 2018). Compared to energy crops, studies on the potential and actual availability of waste biomass are limited (Roth et al., 2018). Hence, conversion technologies need to be robust in order to adapt to their variability and still produce the desired BAF product (Mawhood et al., 2016; Conrad et al., 2019).

Table 5 summarizes all the supply chain models specifically for BAF provision reviewed in this paper. Studies on the supply chain of waste biomass for BAF production are still few. Most literature available are supply chain models for forest residues. Jacobson et al. (2016) developed a Forest Residue Economic Assessment Model (FREAM), a supply chain model integrated with GIS data and stakeholder engagement, for the simulation and cost estimation of harvest, transport, and conversion of forest residues. A regional-scale production of BAF via ethanolto-jet production pathway in Inland Northwest of USA was conducted revealing a total production cost of $\mathrm{USD}_{2016} 1.23 / \mathrm{L}$ with capital and transport accounting at 15 and $32 \%$, respectively, of the total cost per ton of forest residue processed. Martinkus et al. (2018) integrated multi-criteria decision analysis and a total transportation cost model for the assessment of existing industrial facilities within a forest residue-based depot-andbiorefinery supply chain. A least cost supply chain for woody biomass conversion into aviation fuel in Inland Northwest, USA was determined, which showed the capital and operational costs for disaggregated biomass pre-processing in depots are lower than an integrated biorefinery. Elia et al. (2013) developed a MILP model for the cost optimization of a biomass-to-liquid supply chain producing diesel, gasoline, and jet fuel using forest residues in the whole of USA. The BVCM by Samsatli et al. (2015) is also capable of optimizing the cost and GHG emissions for a forest residue- and/or other waste biomass-based supply chain for jet fuel provision. Alves et al. (2017) performed a techno-economic assessment of co-producing renewable jet fuel and high-value platform chemicals in Brazil through a supply chain comprising feedstock logistics, decentralized pretreatment facilities and a centralized biorefinery. Their results showed the ethanol-to-jet processing of eucalyptus residues or sugarcane residues as the most economically feasible. Contrary to studies focusing on economics, Ravi et al. (2018) studied the environmental impacts of a forest residue-based BAF supply chain in the Pacific Northwest of USA. Using a regional air quality model with high-resolution, their results showed that the biorefineries can be a substantial local source of $\mathrm{NO}_{\mathrm{x}}$ and $\mathrm{CO}$ but regionally the increase is insignificant. Moreover, the utilization of the residues in the supply chain results in air quality and health benefits outweighing the negative effects of pile burning. On the other hand, the sequential start-up model programme by Perkis and Tyner (2018) assessed the economic performance of a corn stover- and wheat straw-based BAF supply chain in Indiana, USA. The study found that the first batch of investors would opt for corn stover and situate conversion facilities near locations of high feedstock availability. Vast quantities of rice straw and rice husk in many rice producing counties can be a potential waste stream for BAF production (Roda et al., 2015). The MILP model for efficient and sustainable rice supply chains by Doliente and Samsatli (2019) is the first to consider biomass-based production pathways of jet fuel using rice crop residues as a feedstock. Lastly on waste biomass-based supply chains for jet fuel, Lewis et al. (2019) coupled the Biomass Scenario Model, a system dynamics model, to study the supply chain evolution in the USA, with the Freight and Fuel Transportation Optimization Tool, to determine optimal transport flows and routes. Their results show that BAF production from 75 million to 4 billion liters per year is achievable with a mix of waste biomass streams and conversion technologies (HEFA leading in the short term and followed by advanced technologies in the long term). By considering the geospatial availability and holistically viewing the supply chain, these studies demonstrate the promising benefits of waste biomass and the respective conversion technologies in the provision of BAF (Mawhood et al., 2016; Gutiérrez-Antonio et al., 2017). Despite these efforts, the supply and demand for waste biomass-derived BAF continue to be insignificant to CJF (Mawhood et al., 2016).

\section{Third-Generation Feedstocks}

Algae are of high interest due to having no food value, high yields with virtually no land requirement, and relatively low cost requirements (e.g., grown in suspensions requiring only sunlight, simple nutrients, and $\mathrm{CO}_{2}$ that can be from industrial flue gases) (Cheng and Timilsina, 2011; Lee and Lavoi, 2013; Atashbar et al., 2018; Richter et al., 2018). Algae are capable of 
TABLE 5 | Summary of supply chain model for bio-aviation fuel provision.

\begin{tabular}{|c|c|c|c|c|}
\hline Author (Year) & Feedstock & Model & Model capability & Location \\
\hline Elia et al. (2013) & Forest residues & $\begin{array}{l}\text { A nation-wide mixed-integer linear } \\
\text { programming model for biomass-to-liquid } \\
\text { supply chain }\end{array}$ & $\begin{array}{l}\text { A supply chain cost optimization framework that } \\
\text { determines the best operating network }\end{array}$ & USA \\
\hline $\begin{array}{l}\text { Agusdinata and } \\
\text { deLaurentis (2015) }\end{array}$ & Microalgae & $\begin{array}{l}\text { Multi-actor life cycle assessment integrated } \\
\text { to a system dynamics model }\end{array}$ & $\begin{array}{l}\text { Evaluation of the GHG emissions reduction } \\
\text { potential of algal-based jet fuels }\end{array}$ & USA \\
\hline Newes et al. (2015) & $\begin{array}{l}\text { Cellulosic feedstock (Not } \\
\text { specified) }\end{array}$ & Biomass Scenario Model & $\begin{array}{l}\text { A system dynamics model for the simulation of } \\
\text { the complex incentive-production interaction }\end{array}$ & USA \\
\hline Samsatli et al. (2015) & $\begin{array}{l}\text { Energy crops } \\
\text { (miscanthus, willow) and } \\
\text { waste biomass (waste } \\
\text { wood, food wastes) }\end{array}$ & Biomass Value Chain Model (BVCM) & $\begin{array}{l}\text { A comprehensive and flexible whole system } \\
\text { optimization model for biomass supply chain with } \\
\text { spatio-temporal capabilities }\end{array}$ & UK \\
\hline $\begin{array}{l}\text { Jacobson et al. } \\
(2016)\end{array}$ & Forest residues & $\begin{array}{l}\text { Forest Residue Economic Assessment Model } \\
\text { (FREAM) }\end{array}$ & $\begin{array}{l}\text { Modeling platform for the analysis of the logistics } \\
\text { of wood-based bioenergy }\end{array}$ & USA \\
\hline Alves et al. (2017) & $\begin{array}{l}\text { Sugar crops, oil crops, } \\
\text { and lignocellulosic } \\
\text { biomass }\end{array}$ & $\begin{array}{l}\text { Techno-economic assessment of biorefinery } \\
\text { technologies: feedstock logistics, } \\
\text { pre-processing, biorefinery }\end{array}$ & $\begin{array}{l}\text { Scenario development for the co-production of } \\
\text { bio-aviation fuels and biochemicals }\end{array}$ & Brazil \\
\hline $\begin{array}{l}\text { Domínguez-García } \\
\text { et al. (2017) }\end{array}$ & Jatropha, camelina & $\begin{array}{l}\text { Multi-objective mixed-integer linear } \\
\text { programming model to plan strategically an } \\
\text { aviation biofuel supply chain with hydrogen } \\
\text { production }\end{array}$ & Minimization of cost and GHG emissions & Mexico \\
\hline $\begin{array}{l}\text { Martinkus et al. } \\
\text { (2018) }\end{array}$ & Wood residues & $\begin{array}{l}\text { Integrated multi-criteria decision analysis and } \\
\text { Total Transportation Cost Model (TTCM) }\end{array}$ & $\begin{array}{l}\text { Selection of depot for biorefinery based on least } \\
\text { cost analysis }\end{array}$ & USA \\
\hline $\begin{array}{l}\text { Perkis and Tyner } \\
\text { (2018) }\end{array}$ & $\begin{array}{l}\text { Corn stover, wheat straw, } \\
\text { and switch grass }\end{array}$ & $\begin{array}{l}\text { A sequential start-up model written as a } \\
\text { mixed-integer non-linear (quadratic) program }\end{array}$ & $\begin{array}{l}\text { Sequential optimization of units cost based on } \\
\text { selected siting and capacity of conversion } \\
\text { facilities and feedstocks }\end{array}$ & USA \\
\hline Ravi et al. (2018) & Wood residues & Regional air quality model at high resolution & $\begin{array}{l}\text { Estimation of air quality impacts of forestry-based } \\
\text { bio-aviation fuel supply chain }\end{array}$ & USA \\
\hline $\begin{array}{l}\text { Doliente and } \\
\text { Samsatli (2019) }\end{array}$ & Rice straw, rice husk & $\begin{array}{l}\text { A multi-objective spatio-temporal } \\
\text { mixed-integer linear programming model for } \\
\text { rice value chains }\end{array}$ & $\begin{array}{l}\text { Simultaneously determine the planning, design } \\
\text { and operation of efficient and sustainable rice } \\
\text { value chains }\end{array}$ & Philippines \\
\hline Lewis et al. (2019) & $\begin{array}{l}\text { Waste biomass (MSW, } \\
\text { waste oils and fats, and } \\
\text { agro-forestry residues) }\end{array}$ & $\begin{array}{l}\text { Integrated Biomass Scenario Model (BSM) } \\
\text { and Freight and Fuel Transportation } \\
\text { Optimization Tool (FTOT) }\end{array}$ & $\begin{array}{l}\text { System dynamics model with geo-spatial } \\
\text { capability to develop scenarios for the } \\
\text { deployment of bio-aviation fuel based on optimal } \\
\text { feedstock and fuel flows }\end{array}$ & USA \\
\hline
\end{tabular}

growing in polluted water or water unsuitable for agriculture that can simultaneously lower operating costs and provide wastewater treatment benefit (Acheampong et al., 2017; Alalwan et al., 2019). The demand for water (regardless of quality) by algae to produce $1 \mathrm{~L}$ of biodiesel is about $300-1,000 \mathrm{~L}$, which is lower than most 1-G feedstocks (e.g., 5,500 and 15,000 L for canola and soybean, respectively).

Microalgae is a type of algae dedicated for BAF production (Warshay et al., 2011; Rocca et al., 2015; ATAG, 2017; Richter et al., 2018). They are unicellular organisms with excellent photosynthetic efficiency and carbon fixation capability (Rocca et al., 2015; Su et al., 2017). Popov and Kumar (2013) have summarized the many advantages of microalgae over land-based crops as follows:

- High annual growth rates, e.g., an annual potential of 91 t/ha/yr (Stratton et al., 2010);

- High lipid content, e.g., average of $2-19 \%$ w/w (dry) but with some species in excess of 50\% w/w (dry) (Rocca et al., 2015; Su et al., 2017);
- No competition with food crops; and

- Production of high value co-products.

Microalgae as a feedstock promises both high productivity and availability of fatty acids readily convertible to BAF via HEFA (Ames, 2014; Tao et al., 2017). Thermochemical routes via pyrolysis and hydrothermal liquefaction technologies are also increasingly being developed to simplify and diversify the production pathways (Chiaramonti et al., 2017). Hence, microalgae is widely regarded for large-scale biofuel production (Stratton et al., 2010). While there has been significant investment into algae biofuels, a number of logistical and technological issues persists (Warshay et al., 2011; Richter et al., 2018). Issues in cultivation, harvesting, and oil extraction technologies, which are still inefficient and/or capital- and resource-intensive, along with prohibitive environmental impacts block commercialization (Doshi et al., 2016; Su et al., 2017; Behrendt et al., 2018). There have been a number of trial and pilot microalgae production plants, and demonstration flights run on algal-derived jet fuel but to date there is still 
no economically feasible production (Mawhood et al., 2016; Chiaramonti Horta and Nogueira, 2017; Bwapwa et al., 2018; Richter et al., 2018).

Ames (2014) estimated the global potential of algal oil ranges from 350 billion liters per year (limited productivity scenario) to 2 trillion liters per year (high productivity scenario) with cultivation in Asia and North America to have the highest potential. However, locations having high availability of marginal lands, tropical to semi-arid climate, and close proximity to sustainable water and $\mathrm{CO}_{2}$ sources are also favorable cultivation sites. Roth et al. (2018) reviewed the important criteria in selecting suitable sites for cultivating microalgae for BAF production. These include climatic conditions (e.g., available solar radiation and ambient temperature); terrain (commonly limited to $<5 \%$ slope); sources of water (fresh or salt water); sources of carbon dioxide (e.g., power, biogas, or fermentation plants) and; sources of nutrients (e.g., synthetic fertilizer or dissolved nutrients in wastewater). Chiaramonti et al. (2017) added that, in contrast to land-based crops, it can be technically feasible to modify the suitability of a site for microalgae cultivation (e.g., temperature control, artificial lighting, and longdistance gas/liquid pipelines) but the economic and ecological costs associated with the alteration can become prohibitive. In the perspective of planning a microalgae supply chain for BAF provision, both the geo-spatial and temporal aspects of microalgae cultivation must be incorporated for optimal economic and environmental performance. With butanol as a pre-cursor to jet fuel, Arabi et al. (2019) presented a multi-period MILP model for the planning and design of a microalgae supply chain for biobutanol production in Iran. They integrated fuzzy programming and data envelopment analysis to deal with uncertainties and tractability of the model, respectively. Other microalgae supply chain modeling studies focus on biodiesel provision, such as the single-objective robust MILP model for national level supply (Mohseni and Pishvaee, 2016), multi-objective fuzzy linear programming model for a multi-product supply chain (Ubando et al., 2014), and a two-objective metaheuristic model for the stochastic locationinventory-routing in a nationwide supply chain (Asadi et al., 2018). To date, only the studies of Asadi et al. (2018) and Arabi et al. (2019) considered explicitly the site suitability of microalgae cultivation. All these studies dealt with minimization of cost, while only the studies of Asadi et al. (2018) and Ubando et al. (2014) considered minimization of environmental footprints. Agusdinata and deLaurentis (2015) integrated LCA and multiactors (stakeholder's decisions) to assess the environmental impact of an algal-based BAF supply chain in the USA. They confirmed the potential of algal biofuels, in reducing the life cycle $\mathrm{CO}_{2}$ emissions of the country's airline industry by as much $85 \%$ in 2050 . While present algal technologies are still economically non-viable in the next 10 years or so, research on supply chain studies and generation of robust data must continue for microalgae-based biofuels (Behrendt et al., 2018).

\section{Fourth-Generation Feedstocks}

In the portfolio of feedstocks for sustainable aviation fuels, ATAG (2017) recognized the potential of non-biological resources and genetically modified organisms that are grouped together in a separate class called fourth-generation (4-G) feedstocks (Alalwan et al., 2019). Genetically modified organisms (e.g., microalgae, cyanobacteria, fungi, and yeast) have artificially enhanced oil and/or sugar yields and negative carbon capabilities, which are mostly in the infancy stage of research (Alalwan et al., 2019). In spite of their promising biofuel potential, more studies are needed on the health and environmental risks that these organisms can pose, on their containment, and/or mitigating strategies when they are deployed into the world's supply chains (Abdullah et al., 2019). Non-biological feedstocks (e.g., $\mathrm{CO}_{2}$, water, renewable electricity, and sunlight) can potentially be the more environmentally benign option especially when flue gases from industrial plants are utilized (ATAG, 2017; Richter et al., 2018). One route is power-to-liquid (PtL) which involves the splitting of water into hydrogen and oxygen via a renewableelectricity-powered electrolyzer and then hydrogen is combined with $\mathrm{CO}_{2} / \mathrm{CO}$ to produce BAF (ATAG, 2017; Schmidt et al., 2018). A recent techno-economic and environmental analysis by Schmidt et al. (2018) showed that the short term costs of PtL fuels (driven mainly by the price of renewable power) are greater than CJF. However, the environmental benefits of PtL fuels (e.g., nearly carbon neutral and low requirements for water and land) along with improvements in economies of scale can potentially outweigh the economics and externalities of CJF in the longterm. Another route is the use of concentrated solar energy in splitting water and $\mathrm{CO}_{2}$ to produce syngas as precursor for BAF production (Richter et al., 2018). While both routes are still at early stages of research, Richter et al. (2018) has identified two European initiatives, Sunfire and SOLAR-JET, that demonstrated the production of jet fuel with $\mathrm{CO}_{2}$, water and solar energy. In terms of the studies on supply chains of $4-\mathrm{G}$ feedstocks, although limited to date, Mesfun et al. (2017) applied a spatiotemporal MILP model for the integration of power-to-gas (PtG) and power-to-liquid technologies in an Alpine energy supply. Depending on the pricing of fossil fuel and carbon, the study confirmed that renewable energy systems become more flexible when integrated with PtG and PtL technologies as these convert the excess intermittent renewable power to fuels and enable the utilization of large amounts of captured $\mathrm{CO}_{2}(0.20-15$ million tons per year) via fuel production. When these technologies become commercially mature, BAF from 4-G feedstocks promise to be the most sustainable with the potential for negative carbon emissions and interlinking power, heating and aviation sectors (Mesfun et al., 2017; Richter et al., 2018).

\section{Economic Analysis}

The delivered cost of a feedstock accounts for the total costs of cultivation/plantation, harvesting and other postharvest processing, storage, and transporting to the biorefinery (Gonzalez et al., 2011a; Daystar et al., 2014). Figure 3A shows a comparison and breakdown of the delivered costs of some 1-G and 2-G feedstocks. Budzianowski and Postawa (2016) stated that the delivered cost at the biorefinery gates directly affects the economic feasibility of BAF, which can significantly contribute to the total production cost at about $50 \%$ or more, especially for food crops. Studies on the supply chain for BAF provision by 
Newes et al. (2015) and Alves et al. (2017) show that profitability is sensitive to the feedstock price. The comprehensive technoeconomic assessment by Tao et al. (2017) on HEFA in the USA have also revealed the price of oil as one of the main cost drivers of production. Hence, its economic success as a short- to medium-term solution lies upon the choice of oil-rich feedstocks.

Low-cost and/or high yielding oil-seed crops, such as oil palm and jatropha, are going to be the feedstock choices for BAF production (Ernsting, 2017; Tao et al., 2017). With better productivity of these crops in tropical regions (Schoneveld, 2010), countries with high jet fuel demand and low-yielding and/or expensive domestically-grown oil-rich crops would resort to importing cheaper vegetable oil from the tropics. However, importing vast quantities of oil will be costly for the environment. As the purchasing country becomes more dependent on imports, potential embargos or sanctions can also occur in the long term. Given the national burden of importation, countries should diversify their feedstocks to improve self-sufficiency (Zaher et al., 2015). Conversely, exporting countries, with favorable climatic conditions and large cultivable lands, can obtain potentially huge economic gain. In the case of the Indonesian oil palm industry, Susila (2004) reported that jobs generated in the cultivation and milling sectors resulted in the country's national economic growth and regional decrease in poverty. However, exporting can also become a national burden as these countries become dependent upon the income from exports and vulnerable to market forces demanding shifts to a new feedstock. In either case, this diversification and/or shifting to other feedstocks entails land. Agusdinata et al. (2011) has highlighted that both oil price and land availability govern the viability of a feedstock. Despite of the potential economic benefits from cultivating productive feedstocks for low-income countries in the tropical region, it is vital to note that the majority of people at risk of foodinsecurity rely heavily on agricultural land for their livelihoods (Alexandratos, 1999). Thus, it is important to ensure that BAF feedstocks used do not place a greater strain upon the populations by either farming 1-G feedstocks on arable lands that would have been processed and eaten or encouraging farmers to switch to 2-G feedstock cultivation that would reduce available arable land for food production. Moreover, the rapid increase in oil palm plantations in the past three decades has been linked to deforestation, biodiversity loss and increased greenhouse gas emissions (Page et al., 2011; Pirker et al., 2016; Vijay et al., 2016). These environmental concerns result in friction toward the use of biofuels, which can negate the progress of current investments on BAF (Ernsting, 2017).

UCO and animal fats are going to be important in the choice of feedstocks for HEFA due to their lower costs (Mandolesi de Araújo et al., 2013; Tao et al., 2017). Figure 3B presents average market prices of fresh edible oils and waste oils. Although UCO has essentially negligible delivered cost, Mandolesi de Araújo et al. (2013) reported that UCO is usually priced about 2 and 3 times lower than fresh edible oil. Roth et al. (2018) added that there is a global potential of about 6 to 7 billion liters per year of bio-aviation fuel based on UCO. However, the persisting unaddressed uncertainty and variability of waste streams raises concerns about their significant contribution in the future jet fuel supply mix (Mawhood et al., 2016; Roth et al., 2018). Furthermore, the UCO demand in BAF production has to compete with established demands for biodiesel production (Roth et al., 2018). Lastly, in the view of economies of scale, Dodd et al. (2018) have recently found through a qualitative investigation of industry experts that the limited capacity of feedstocks is the major hindrance for the growth of the sustainable aviation fuels industry.

When proven commercially feasible, microalgae as a feedstock of HEFA is expected in the future. Its current high price bars its utilization as a biofuel feedstock (Tao et al., 2017). The pricing of algal oil is significant to the overall viability of a microalgaebased HEFA. They carried out a rigorous comparative cost analysis that revealed no strong correlation between production scale and the cost of producing algal oil because of increased capital costs associated with the infrastructure required for algal cultivation. Sun et al. (2011) recommended that the ideal method of improving the production costs was to identify a strain of algae capable of yielding a high lipid content while sustaining a strong growth rate. The sensitivity analysis in the same paper showed that a 2 -fold increase in both lipid yield and algal production could improve cost structure of the business by half.

Given the relatively low delivered costs of MSW, agro-forestry residues and lignocellulosic energy crops, they are economically promising feedstocks for the yet commercially feasible FT and ATJ (Dupuis et al., 2019). When the more advanced technologies become commercially viable, these feedstocks are key to the medium- and long-term decarbonization of the aviation industry (Lewis et al., 2019). A direct economic comparison of feedstocks, however, is generally difficult to carry out due to the many interdependent factors for consideration, which are for some both spatially and temporally dependent. The outlook and geographic location of aviation industries are also interdependent, which have potential implications on the policies and implementation for sustainable aviation fuels (Dodd et al., 2018). Furthermore, perspectives by the society, culture and market in a specific region results in large differences in its supply chain configuration for BAF from other parts of the world (Murphy et al., 2015).

\section{Environmental Analysis}

The environmental impacts of the feedstock accounts for the total emissions associated with cultivation/plantation, harvesting and/or post-harvest processing, storage, and transportation of the feedstock to the biorefinery gate (Gonzalez et al., 2011a; Daystar et al., 2014). Daystar et al. (2014) carried out this cradleto-gate analysis of the life cycle greenhouse gas emissions of cellulosic biomass supply chains for biofuel provision in the Southern USA. Recently, O'Connell et al. (2019) conducted a similar analysis on the feedstocks supply chains for BAF provision in the EU. Figure 4A presents a comparison of the cradle-to-gate GHG emissions of feedstocks for BAF production.

Cultivation and harvesting of $1-G$ and $2-G$ feedstocks represents significant contributions to their total GHG emissions due to the continued reliance on fossil fuels in both the direct and indirect inputs of many farming activities (Pimentel, 2009; Liu X. et al., 2017). Direct inputs include diesel and gasoline to 


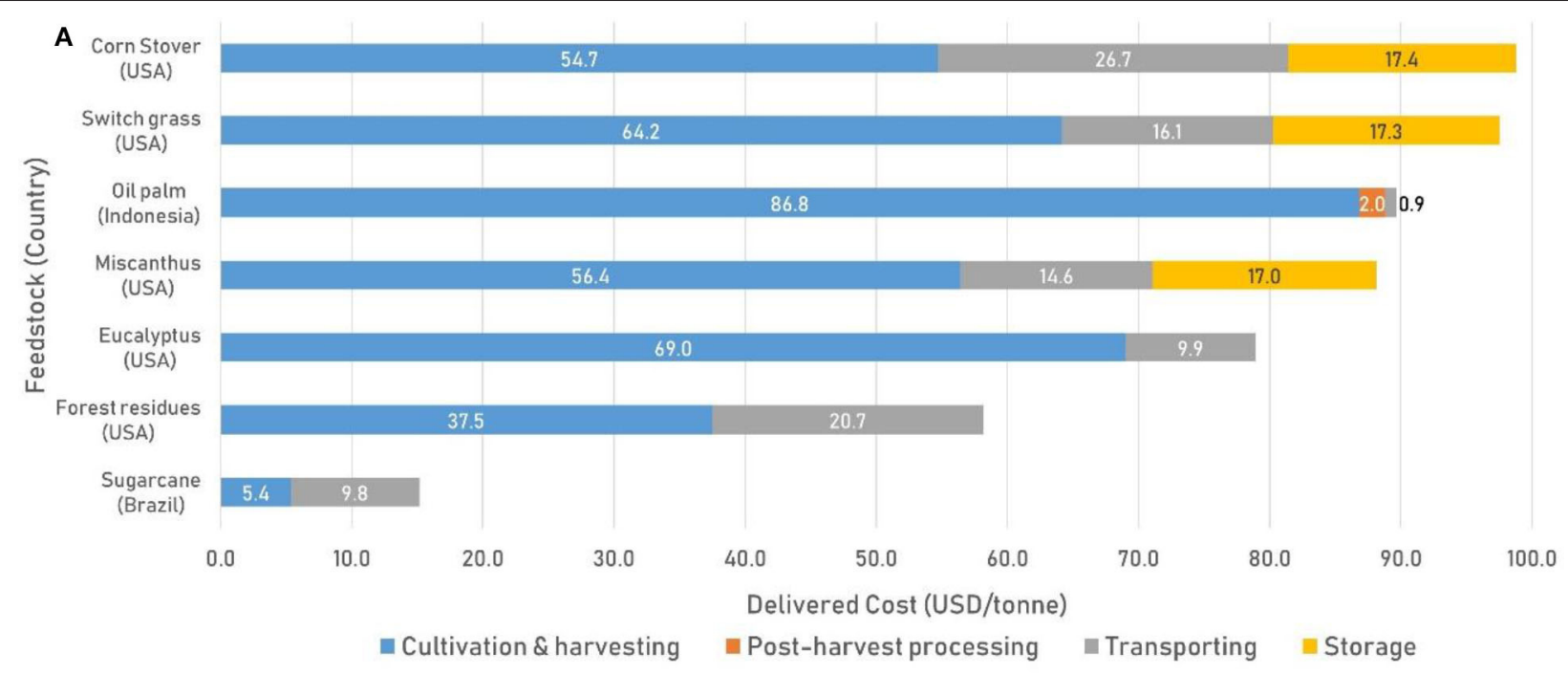

B

1200

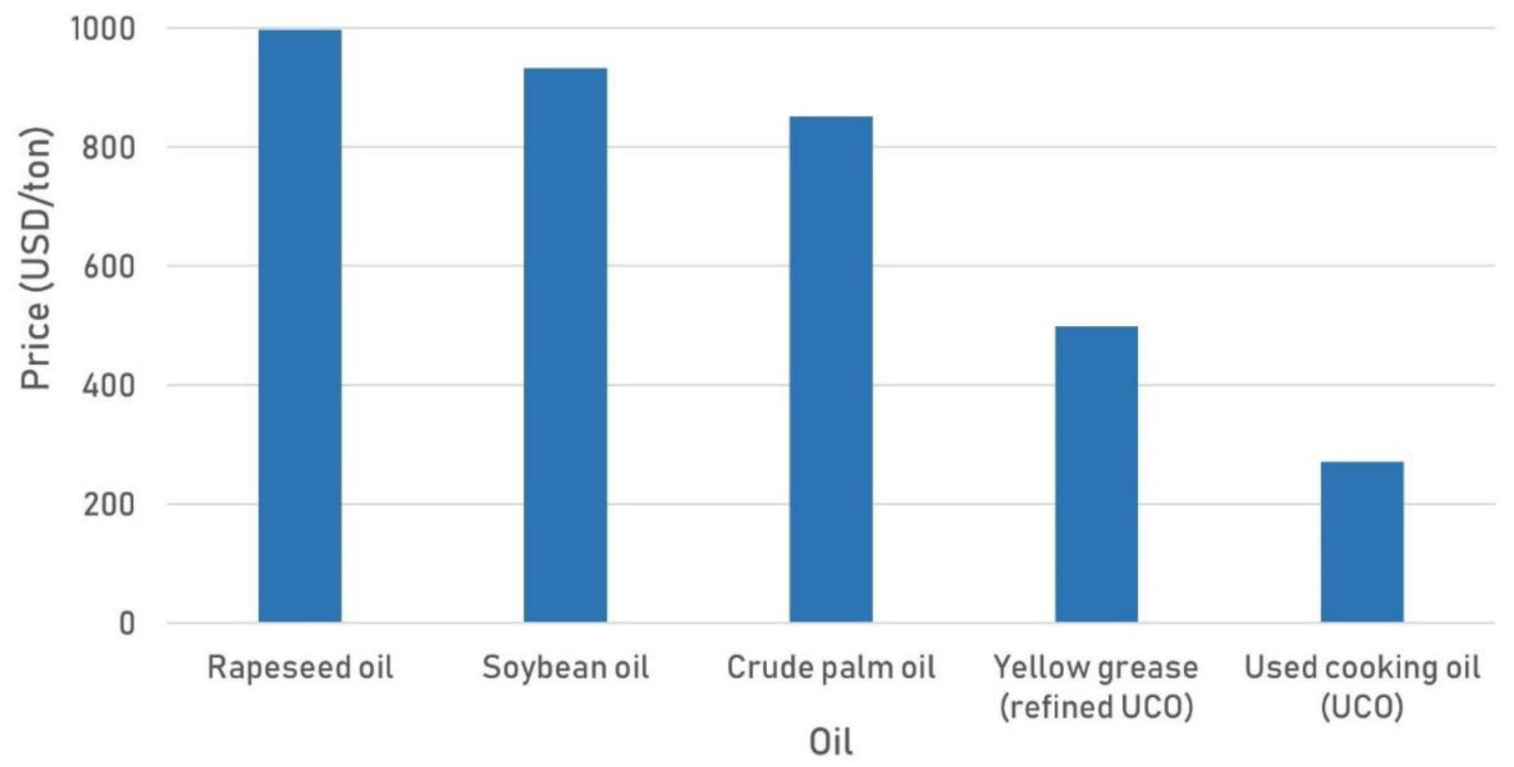

FIGURE 3 | Typical economic impacts (adjusted to 2019 levels) of some 1-G and 2-G feedstocks for BAF production: (A) Delivered (farm-to-gate) cost (Plotted using data from Gonzalez et al., 2011a; Gonzales et al., 2013; de Castro et al., 2018; Harahap et al., 2019); and (B) Average market price of fresh edible and waste oils (Plotted using data from Mandolesi de Araújo et al., 2013.

power machinery for land preparation and cultivation, pumps for irrigation, and vehicles for transportation. While indirect inputs consist of fertilizers, pesticides, water, and seeds whose embodied energy (from production to transportation in the farm) are also from fossil fuels (Azwan et al., 2016; Elsoragaby et al., 2019). Typically, GHG emissions from fertilizers account for most of the indirect inputs since their chemical production requires large amounts of natural gas (Pimentel, 2009; Liu X. et al., 2017). Post-harvest processing can also be a significant source of GHG emissions. For oil-bearing crops, oil mills require electricity and heat that are mostly fossil-based. Figure $4 \mathrm{~B}$ depicts a comparison of the energy requirements for farming and oil 


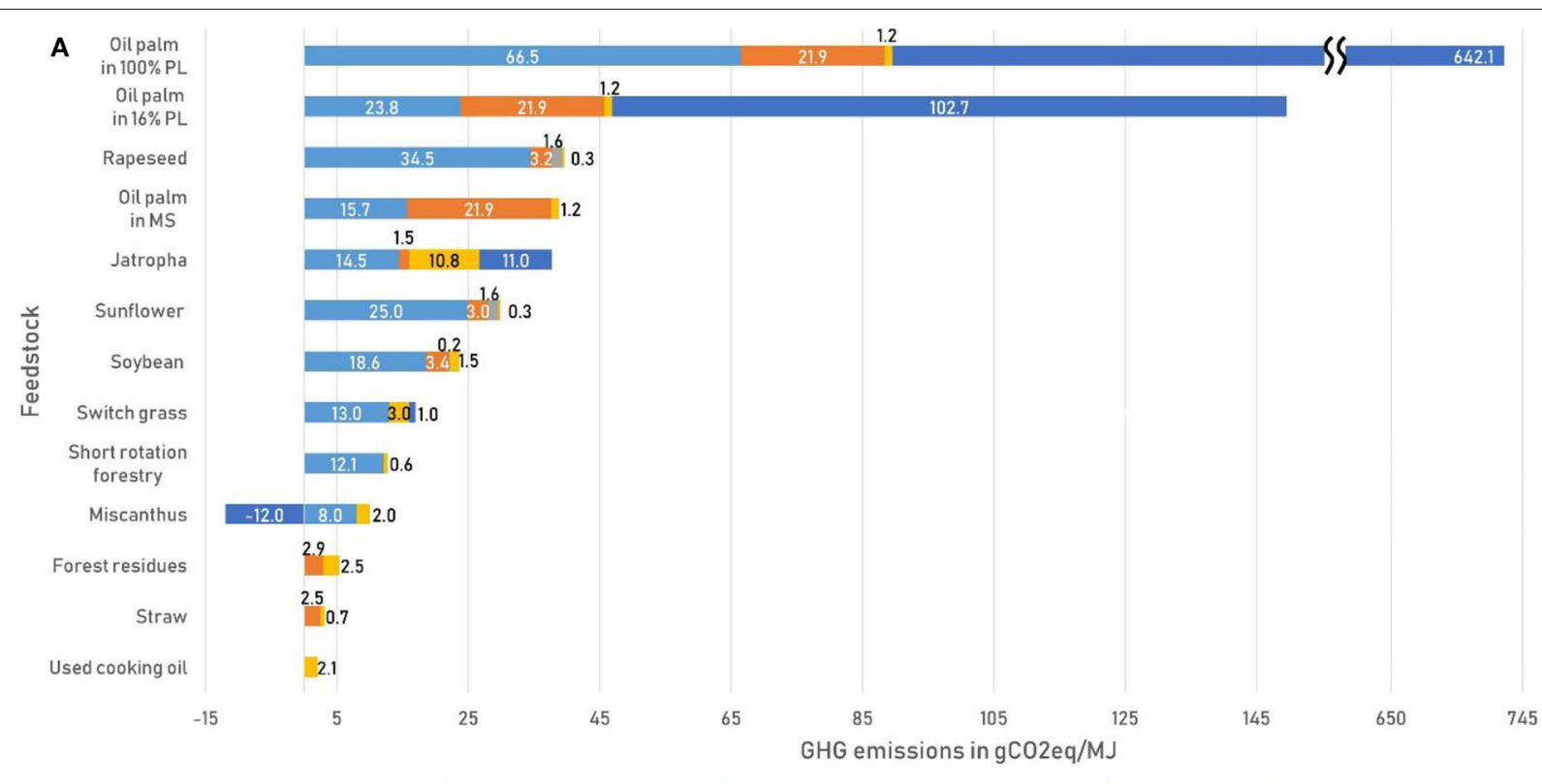

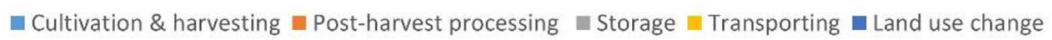

B 4000

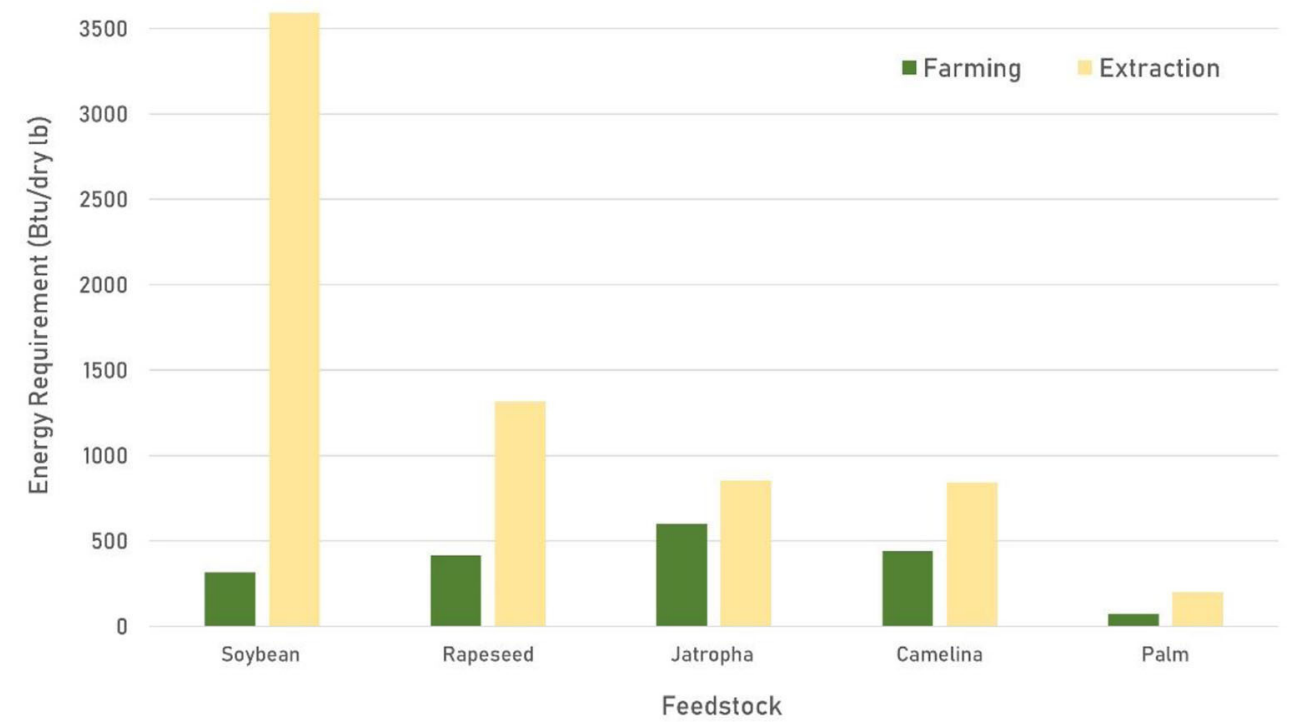

FIGURE 4 | Typical environmental impacts of some 1-G and 2-G feedstocks for BAF production: (A) Farm-to-gate GHG emissions (Plotted using data from Bailis and Baka, 2010; Wang et al., 2012; Velazquez Abad et al., 2015; O'Connell et al., 2019); and (B) Energy requirements for farming and extraction of some oil-seed crops (Plotted using data from Elgowainy et al., 2012).

milling of oil-seed crops for BAF production. To improve the environmental sustainability of a BAF feedstock, the use of biofuels in the machinery and bio-electricity/heat (from agroforestry residues) in milling operations should be practiced (Sims et al., 2015). Storage and transport (to the mill and/or bio-refinery gates) of the harvested and/or pre-processed feedstocks usually account for a minor portion of the total GHG emissions. A transport process is a function of load and distance (Cefic ECTA, 2011). Greater GHG emissions result from transporting large amounts of feedstocks over large distances. Importing 


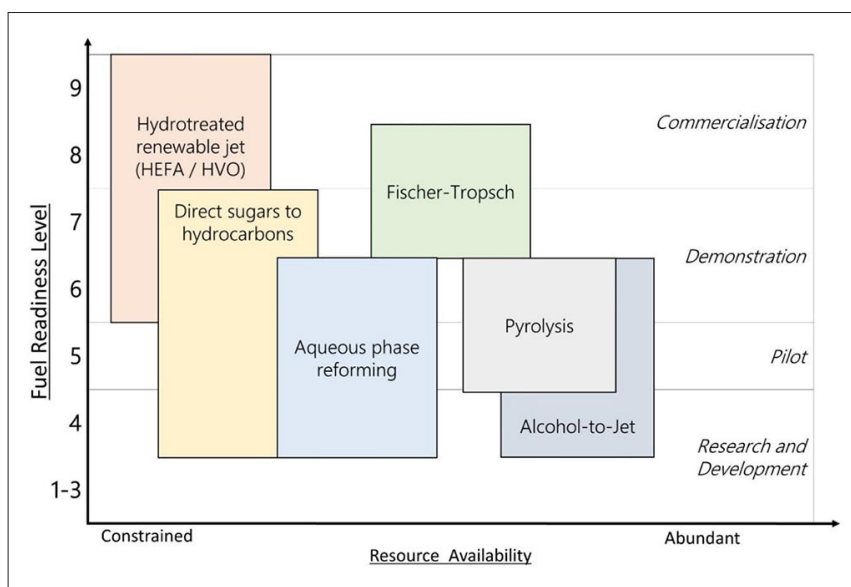

FIGURE 5 | Future scope for adapting processes to a commercial level based on resource availability and technology maturity (Drawn using data from Mawhood et al., 2016; Bosch et al., 2017).

processed oil from the tropics to the EU have been reported to result in additional GHG emissions (O'Connell et al., 2019). While some storage facilities may use minimal energy, feedstock requirements may use considerable energy and lead to GHG emissions, especially when fossil-based (Egg et al., 1993; Emery et al., 2015).

Among oil-seed food crops, O'Connell et al. (2019) demonstrated that oil palm cultivation grown in mineral soil has the least GHG emissions (Figure 4A). Elgowainy et al. (2012) showed that palm oil extraction energy requirement is also the least (Figure 4B). Hence, oil palm as a BAF feedstock may be the best food crop-based option, even when considering an average of $6.0 \mathrm{gCO}_{2}$ eq emissions associated with transporting it to the EU. However, when LUC associated with cultivation happens, land-based crops like oil palm become environmentally unsustainable feedstocks. LUC can result in both direct and indirect emissions (Bauen et al., 2009). Direct LUC emissions represent activities associated with changing the land from its past condition to feedstock cultivation. While indirect LUC emissions, due to low availability of arable lands, result from land expansion at the cost of deforestation. Even without considering the indirect LUC emissions of recent land expansion of oil palm plantations, O'Connell et al. (2019) confirmed a staggering 100 to 600 times increase in GHG emissions from direct LUC of 16 and $100 \%$ peatland, respectively. The resulting life cycle GHG emissions of oil palm grown in peat land are even higher than the production of CJF at $20 \mathrm{gCO}_{2} \mathrm{eq} / \mathrm{MJ}$. In the investigation of ICAO (2009), peatland forests being repurposed into plantations have increased GHG emissions by a factor of 7.5. Large amounts of carbon stored in peatlands have not only been removed from biomass clearing, but new plants grown typically have much lower carbon-storing capacities. Murdiyarso et al. (2010) quantified a 254.5 te $\mathrm{C} /$ ha storing capacity for natural peatland reduces to 24.2 te $_{\mathrm{C}} / \mathrm{ha}$ for oil palm cultivation. Hence, large-scale clearing of peatland forests would potentially result in large increases in atmospheric carbon. Although the work of O'Connell et al. (2019) focused on oil palm, other land-based crops can display the same trend of increased emissions when cultivated in peatland forests. Research conducted by Wong (2008) and ICAO (2009) showed that LUCs for biomass cultivation have the potential for high GHG emissions. Page et al. (2011) recommended that the reuse of peatland for energy crop cultivation should be avoided due to its environmental consequences.

Considering that the type of land-use conversion is a vital consideration for feedstock cultivation, the use of marginal land for energy crops can ensure avoidance of LUC emissions and preservation of agricultural land (Rathmann et al., 2010; Lask et al., 2019). In the case of jatropha cultivation, direct LUC emissions of converting degraded pastureland is 42 times lower than that of converting a tropical rainforest, as shown in Figure 4A. However, energy crops like jatropha have low productivity in marginal lands, which significantly improves in suitable lands (von Maltitz et al., 2014; Wani et al., 2016; Lamb et al., 2018). Hence, their possible encroachment on both agricultural land and forestland can potentially result in significant LUC emissions and their poor environmental sustainability as BAF feedstocks (Schoneveld, 2010; Keles et al., 2018). If LUC emissions are to be significantly abated, waste streams and algae represent the best alternatives. Considering that algal cultivation continues be a long-term tech-economic endeavor, the utilization of waste streams, such as UCO, agroforestry residues, and MSW, has to be prioritized within the short- to medium-term, as attested by several initiatives and projects of BAF developers (Mawhood et al., 2016). In Figure 7, GHG emissions of waste biomass are significantly lower than all land-crop based feedstocks. Moreover, LCA of feedstocks for high-octane gasoline production by Dupuis et al. (2019) showed waste biomass to have the lowest cradle-to-gate GHG emissions with forest residues as most environmentally benign in both feedstock and fuel production phases. Although the utilization of agro-forestry residues are going to be essential in meeting sustainable energy goals, they also play a significant role in maintaining soil carbon for productivity function and ecosystem services (Karlen et al., 2019). Hence, only a certain portion of these resources is truly retrievable from the plantations, which could be a limiting factor of their actual contribution in BAF production. At the current state of technology and GHG emissions, a similar conclusion by Roth et al. (2018) shows UCO as the most environmentally sustainable feedstock for BAF production.

A BAF cannot be preferable over the existing solution unless the net carbon emissions of its life cycle, from feedstock production, fuel conversion and combustion, are lower than CJF. Bauen et al. (2009) found that GHG emissions savings over the life cycle of biofuel production depend heavily on the feedstock used. Table S3 summarizes WTW life cycle emissions for both 2-G and 3-G feedstocks. WTW life cycle comprises both the well-to-tank (WTT) and tankto-wake (TTW) stages. Elgowainy et al. (2012) defined the WTT stage as all GHG emissions resulting from feedstock production, fuel production, emissions associated with the creation of co-products and all transport processes within these 


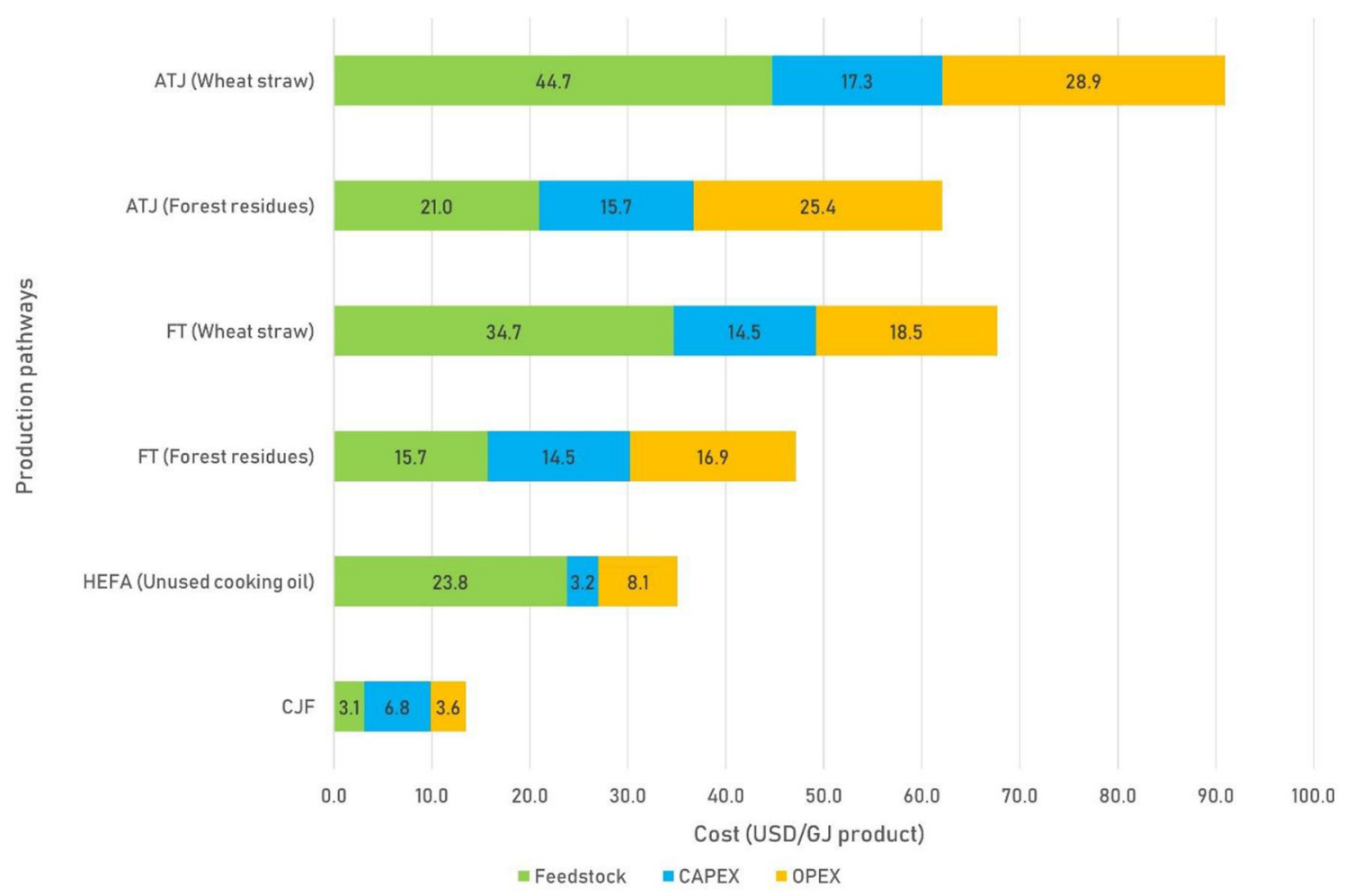

FIGURE 6 | Breakdown of cost (adjusted to 2019 levels) of producing bio-aviation fuel by HEFA, FT and ATJ (Plotted using production cost of the production pathways from de Jong et al., 2015). Production cost of CJF by crude oil refinery, which was calculated and adjusted to 2019 levels from data of Sannan et al. (2017) and US EIA (2020), is also plotted for comparison.

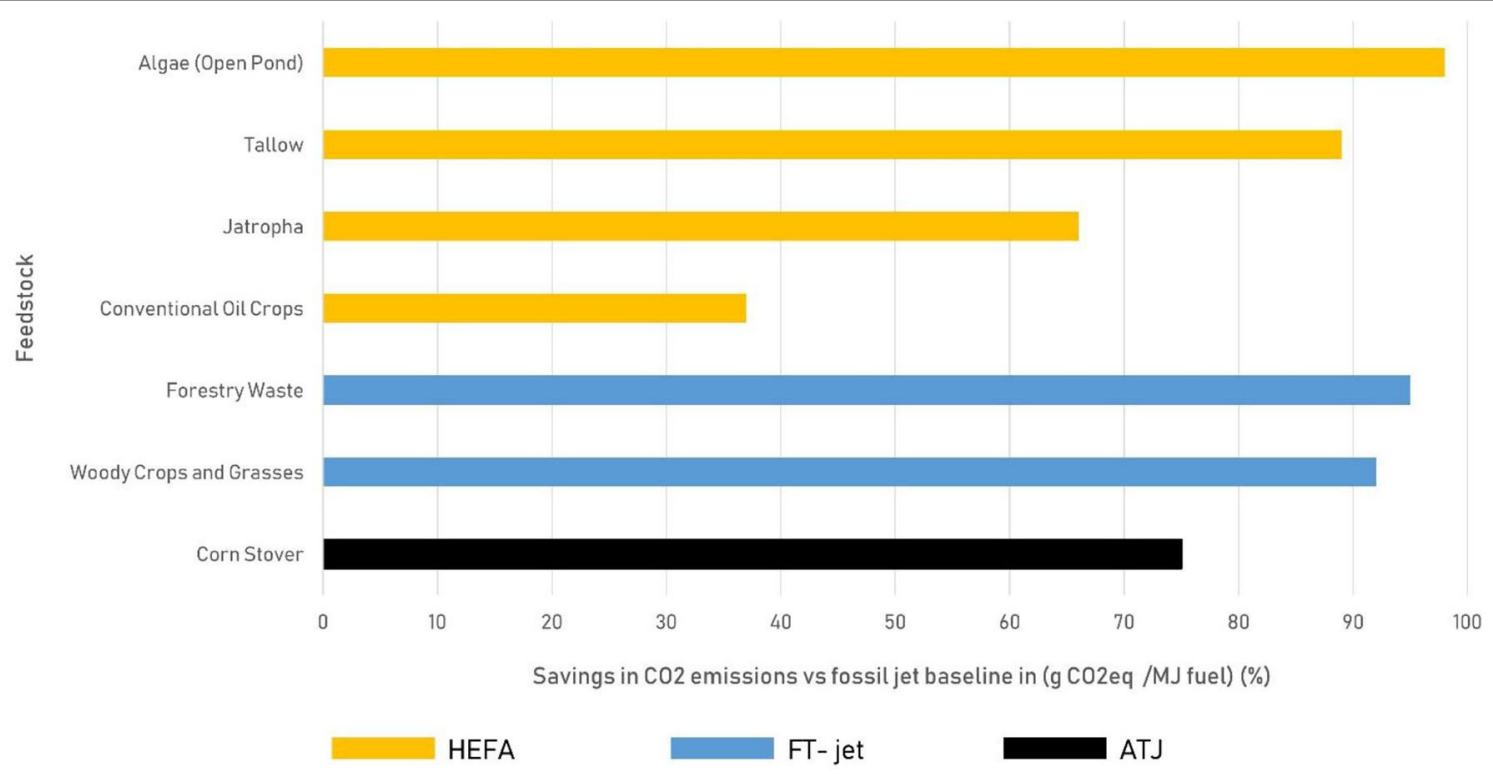

FIGURE 7 | Potential well-to-wake GHG emissions savings from using different BAF feedstocks and production pathways (Plotted using data from Bauen et al., 2009; de Jong et al., 2017a).

elements. Whereas, TTW stage incorporates the combustion and use of the fuel in the engine. However, Table S3 do not consider emissions due to direct or indirect LUC.
Nevertheless, WTW results show promising environmental sustainability of energy crops, waste biomass and algae as feedstocks. 


\section{PRODUCTION PATHWAYS FOR SYNTHETIC PARAFFINIC KEROSENE}

There have been great strides made in the research on BAF production platforms, and some have been approved for industry use. Figure 5 shows the relative maturity of these technologies in terms of fuel readiness level (FRL) against the resource availability of feedstocks. Having commercial readiness at FRL $>7$, bio-aviation fuel from FT and HEFA have been approved in up to 50\% blends with CJF (ASTM, 2019). Fuel approval in the form of certification from a recognized authority has been achieved after laboratory tests, technical evaluations, and successful pilot-scale plants. Microbial sugar-to-jet and ATJ technologies have been also approved but at lower blends. Following further research and flight tests, their efficacy with the existing engines determines the approval of higher blends in the future. Increasing the FRL would entail additional investments, studies and demonstrations but as long as a technology receives continued interest, its commercialization could happen in the coming years. The aviation industry could potentially choose from a variety of production pathways based on available feedstock and existing infrastructure. Consequently, these can help reduce geographical dependency on feedstock and ultimately make global implementation of BAF possible. Although many emerging technologies will be important soon, this paper focuses on three prominent production methods with higher FRL and potential for implementation. The following subsections discuss and compare HEFA, FT, and ATJ.

\section{HEFA}

\section{Process Description}

Feedstocks for HEFA include animal fats, vegetable oils, and algal oils (Seber et al., 2014). HEFA often use waste oils and fats that are more sustainable sources. Suitable and sustainable feedstocks can also be determined for individual countries based on geographical and industrial characteristics. Nevertheless, the applicability of HEFA to a wide variety of oil-rich $1-G$ and $2-G$ feedstocks allows global viability of the technology. On the other hand, bio-aviation fuel from HEFA is a specific type of HVO fuel used in aviation. Hydrotreated vegetable oil (HVO) production is a mature and established technology in the automotive industry. There are several existing companies already producing bioaviation fuel via HEFA but at lower outputs compared to crude oil refinery production (Table S4). Most of these companies focus on producing biodiesel and/or bio-aviation fuel. These have capacities ranging from 0.1 million tons to about 100 million tons annually (Vásquez et al., 2017). A particular HVO pathway, the UOP Honeywell process or "Ecofining," is certified to produce aviation fuel from renewable sources (Bwapwa et al., 2018). This technology primarily produced green diesel but it has been the most established technology for bio-aviation fuel production for over 10 years (Stratton et al., 2010).

A simplified process flow diagram of HEFA by UOP is shown in Figure S2A. It involves four main steps, namely: extraction and refinement, deoxygenation and hydrogenation, cracking and isomerization, and distillation (Richter et al., 2018). The extraction and refinement stages of the process can be made more or less expensive depending on the quality and type of feedstock used. The oil can be extracted using methods that include centrifugation, filtration, and traditional pressing mechanisms. Depending on the oil purity required, a variety of purification and treatment processes are available such as steam injection, neutralization, vacuum evaporation, and filtration (Mandolesi de Araújo et al., 2013).

Figure S2B summarizes the reaction pathways for HEFA. The building blocks that constitute vegetable oils are fatty acid carbon chains found within triglyceride molecules. Initially, the double bonds in the fatty acid carbon chains are converted to single bonds by the addition of $\mathrm{H}_{2}$ (Vásquez et al., 2017). Then, the triglycerides are broken down into three fatty acid chains and propane by further cracking with $\mathrm{H}_{2}$. Through cracking, long hydrocarbon chains are reduced to lengths within the jet fuel range. The subsequent processing involves the removal of oxygen from the fatty acid chain (Choudhary and Phillips, 2011). These processes differ in side products and $\mathrm{H}_{2}$ requirement: (a) hydrodeoxygenation produces $\mathrm{H}_{2} \mathrm{O}$ molecules; (b) decarboxylation produces $\mathrm{CO}_{2}$; and (c) decarbonylation produces $\mathrm{CO}$ and $\mathrm{H}_{2} \mathrm{O}$ in addition to the fatty acids (Boichenko et al., 2013). Deoxygenation reactions produce linear hydrocarbons chains by removing oxygen atoms from the molecules. Important factors in these reactions include $\mathrm{H}_{2}$ input that is used to saturate the fatty acid chains and cleave the glycerol backbone, as well as catalyst selection to improve the yield. The reactions occur between 250 and $400{ }^{\circ} \mathrm{C}$ and between 10 and 18 bar with a variety of possible catalysts, such as $\mathrm{NiMo} / \gamma-\mathrm{Al}_{2} \mathrm{O}_{3}$ and $\mathrm{CoMo} / \gamma-\mathrm{Al}_{2} \mathrm{O}_{3}$ (Popov and Kumar, 2013). Sulfidation agents can be added to improve yields in order to maintain catalyst activity (Eller et al., 2016). Thereafter, the combustion properties of the products are improved by further processing through either isomerization, cracking or cyclization to obtain iso-alkanes, lighter hydrocarbons, and aromatics, respectively. In isomerization, linear hydrocarbon chains are converted into branched hydrocarbons with the same carbon number, which can improve the freezing point of the bio-aviation fuel (GutiérrezAntonio et al., 2013). Finally, distillation separates the bioaviation fuel from the other product.

\section{Advantages}

Gutiérrez-Antonio et al. (2013) outline the advantages of HEFA. The reaction is exothermic and therefore the energy generated in the first reaction can be used to decrease the energy costs for the overall process, which has positive economic and environmental implications. Notably, the quality of fuel is independent of the feedstock used, whereas the quality of fatty acid methyl ester (FAME) is known to depend heavily on the choice of feedstock. BAF from HEFA has characteristics that outperform CJF. The BAF produced has a higher heating value $(44 \mathrm{MJ} / \mathrm{kg})$ and faster ignition than Jet $\mathrm{A}$. It is also less susceptible to oxidation than FAME, which makes it a suitable aviation fuel (Crown Oil UK, 2019). Note that the limited oxygen proportion in jet fuel needs to be considered, especially to prevent contamination of the fuel supply due to oxidation. Liati et al. (2019) reported that blending Jet A-1 with 35\% BAF via HEFA generates less reactive soot when 
aircraft are idling (on the ground) or climbing out (during takeoff). This is an important factor for jet fuels as this affects air quality in regions close to the airport. Given the commercial maturity of HEFA, there have been several pilot-scale plants and demonstration (and some commercial) flights using BAF via HEFA (Mawhood et al., 2016; Chiaramonti Horta and Nogueira, 2017).

\section{Limitations}

Despite being technically feasible for commercial deployment, HEFA is largely constrained by resource availability. The supply of oil required for these processes, provided by oil-rich crops and waste oils, is currently insufficient to meet projected industrial demands (Bosch et al., 2017). Rye et al. (2010) argue that HVO production is more suitable for diesel production than jet fuel. They state that the chain length of most triglycerides from plants is closer to the length of diesel oil in their unrefined state $\left(\mathrm{C}_{14}\right.$ to $\left.\mathrm{C}_{20}\right)$. Hence, the production of alkanes by cracking these triglycerides uses large amounts of hydrogen: about 10-15 moles per mole of triglycerides (Huber et al., 2007). The most commonly used method for hydrogen production is natural gas steam reforming, making up 50\% of global hydrogen demand; whereas, steam reforming of other fossil fuels including oil and coal make up a further $48 \%$ of the world hydrogen demand (Dincer and Acar, 2014). With hydrogen used extensively across the whole spectrum of $\mathrm{HVO}$ jet fuel production, there is a need for alternative and sustainable sources of hydrogen. Recently, there has been increased interest regarding the use of hydrogen as a fuel in fuel cells (Samsatli et al., 2016) and as a medium for energy storage (Quarton and Samsatli, 2018; Samsatli and Samsatli, 2019). As a result, alternative production methods to reduce emissions and reduce cost have been gaining momentum through investment and research (Dincer and Acar, 2014). Process optimization may be able to reduce the hydrogen consumption but, of course, not to below the stoichiometric requirements and existing processes already recycle most of the unused hydrogen (Popov and Kumar, 2013). Stratton et al. (2010) suggested retrofitting of existing petroleum refineries to accommodate a HVO facility, which permits access to on-site hydrogen production facilities. Moreover, the naphtha fractions after distillation can be easily reincorporated into the petroleum pipelines for further processing into valuable products.

\section{FT}

\section{Process Description}

In comparison with HEFA, FT is more attractive due to a greater variety of options for feedstocks that do not compete with the food supply. Many commercially established plants use FT with fossil fuel feedstock, such as coal and natural gas, and the technology of producing a liquid transportation fuels is wellestablished (Ail and Dasappa, 2016). In South Africa, Sasol, an energy and chemicals company, operate multiple synthesis plants using "coal-to-liquid" process (CTL) (Ail and Dasappa, 2016). A 50\% blend of BAF via FT and CJF known as Sasol's "Semi Synthetic Jet Fuel" has been supplied to Johannesberg since 1999 (Lobo et al., 2011). The fuel produced using biomass is identical to CTL and very similar in composition to jet fuel but with lower net GHG emissions (Bauen et al., 2009). It is also reported that the energy efficiency of BAF via FT $(77 \%)$ is higher than that of coal-based $(64 \%)$ or natural gas-based $(68 \%)$.

Figure S3A presents the major steps involved in FT. During gasification, biomass is reacted with oxidants (most commonly $\mathrm{CO}_{2}$, steam or air) in a ratio such that partial oxidation occurs, producing $\mathrm{CO}$ and $\mathrm{H}_{2}$ rich gas, also known as syngas. The ratio of $\mathrm{H}_{2}$ to $\mathrm{CO}$ is determined partially by the oxidant used (Klinghoffer, 2013). To produce high yields of heavier hydrocarbons, which is necessary for BAF, a lower $\mathrm{H}_{2}$ to $\mathrm{CO}$ ratio is ideal, making $\mathrm{CO}_{2}$ a better choice than steam (Raje and Davis, 1997). Following gasification, the syngas stream is purged of impurities and unwanted compounds including $\mathrm{CO}_{2}$ and other gaseous impurities before the synthesis. The removal of $\mathrm{CO}_{2}$ from syngas improves the selectivity of the downstream process. On the other hand, the removal of $\mathrm{H}_{2} \mathrm{~S}$ avoids the deactivation of the catalyst (Wei et al., 2019). Iron and cobalt are the main catalysts used. The $\mathrm{CO}$ to $\mathrm{H}_{2}$ ratio is managed by water-gas-shift reaction, and subsequent $\mathrm{CO}_{2}$ removal is made. Then the Fischer-Tropsch synthesis takes place. The basic reactions underpinning this produce alkanes or alkenes with water as a by-product as displayed in Figure S3B (Radich, 2015). Fischer-Tropsch reactions can occur as either a high-temperature process $\left(300-350^{\circ} \mathrm{C}\right)$ or a low-temperature process $\left(200-240^{\circ} \mathrm{C}\right)$ (Dry, 2002). These reactions are extremely exothermic and, as a result, it is important that this heat is removed quickly and efficiently to prevent the catalyst deactivation due to sintering and to minimize unwanted methane production (Dry, 2002). Ail and Dasappa (2016) stated that modern plants use low temperature processes for producing liquid fuels. These plants commonly use a multi-tubular reactor wherein the catalyst is placed within the tubes and the cooling medium on the shell side. Other conditions can also be altered during the reactions, such as pressure, type of catalyst and residence time, in order to specify the hydrocarbon ranges in the product (Dry, 2002). Following Fischer-Tropsch synthesis, lighter hydrocarbons can be oligomerized or heavier hydrocarbons can be cracked to increase or decrease, respectively, in order to obtain bio-aviation fuel having hydrocarbon lengths within the specified range (Richter et al., 2018). The crude products are then isomerized to generate branched iso-alkanes from n-alkanes in order to produce a jet fuel product within the specified freezing point. Lastly, the bio-aviation fuel is separated from the isomerized products using distillation.

\section{Advantages}

One advantage of BAF via FT is that the aromatics content is within the permitted range and the product is generally sulfur-free, which results to reduced emissions when burned in jet engines (Wang and Tao, 2016). Fuel production methods that contain no aromatics are unsuitable for use in an aircraft engine without blending with Jet $\mathrm{A}-1$, as the aromatics content of the fuel is essential for the engine fuel seals to function properly (Corporan et al., 2011; Liu et al., 2013). However, fuels with a high aromatics content form a larger amount of carbonaceous particles which can have detrimental effects including engine failure and erosion on turbine blades after 
combustion (Hemighaus et al., 2006). Having aromatics within the allowable range increases the viability to gain accreditation for use as a stand-alone fuel without blending. Gray et al. (2007) found that these additional requirements in producing BAF via FT, compared to other products (e.g., biodiesel), do not add significant costs to the process. From an economic perspective, this increases the feasibility of constructing an FT facility as ratios of products can be altered easily to maximize profits.

\section{Limitations}

While FT is a very promising avenue due to nearing commercial maturity of the technology and wide variety of applicable biomass feedstocks, de Jong et al. (2017b) commented that much of the current progress of FT is still based on coal and natural gas as the feedstock. Ernsting (2017) stated that even the successful coal-based Sasol FT plant would be unable to compete with CJF without heavy subsidy from the South African government as CTL is still a relatively expensive technology. Ernsting (2017) also argued that the implementation of high-volume production via FT is unlikely in the near term based on the failed efforts of companies like Choren Tech GmBH and Solena.

British Airways partnered with Solena in 2012 with plans to produce BAF via FT from MSW by retrofitting an unused petroleum refinery near London (Radich, 2015). However, Solena filed for bankruptcy and British Airways scrapped the project in 2016. A spokesperson from British Airways attributed this to the lack of government support and record-low oil prices at the time (Neslen, 2016). This validates the comments by Hendricks et al. (2011) that the large-scale development of BAF may prove difficult without the strong collaboration between the government and the aviation industry.

\section{ATJ}

\section{Process Description}

ATJ can be used for sugar-rich or lignocellulosic biomass feedstocks (Wei et al., 2019). These biomass raw materials can be converted to ethanol first by hydrolysis to release the sugar and then fermentation takes place to convert it to ethanol. When ethanol is used as a feedstock, the choice of intermediate defines the reaction pathway taken; examples of the intermediates include ethylene, propylene, higher alcohols, and carbonyl (Brooks et al., 2016). The intermediate chosen dictates the method of production and reaction conditions but with each method having a number of benefits and drawbacks. Brooks et al. (2016) compared these technologies with a variety of parameters including catalyst cost, process efficiency, level of maturity, and process complexity. Ethylene, propylene, and butene were found to perform better than the other intermediates explored with regards to these parameters.

The process diagram for ATJ depicted in Figure S4A are similar for all alcohol feedstocks and intermediates. Due to the maturity of the technology associated with alcohols, each stage has been researched extensively. The alcohols are firstly dehydrated. The removal of water yields alkene molecules, while simultaneously removing impurities. Dehydration of ethanol for ethylene production has been in use since the 1960s, so routes with higher selectivity using heterogeneous catalysts have been developed, such as "Syndol," a specialized catalyst for this process (Geleynse et al., 2018). For isobutanol, the use of strong acidic catalysts can have a 2 -fold effect of dehydration and commencing the oligomerization reaction but the fuel produced has been found to be inferior in quality to that produced if the reactions were to occur separately (Taylor et al., 2010). In the oligomerization step, the alkene monomer molecules are reacted to synthesize longer chain molecules. As presented in Figure S4B, the larger oligomers (olefins) remain unsaturated, containing double bonds. As with the other steps, specific oligomerization processes have been developed by a variety of companies, depending on the feedstock used, such as the Chevron Phillips "Ziegler" process for ethanol. For the Ziegler "one-step" process, the catalyst cannot be recycled, but must be collected and disposed of, whereas the catalyst in the "two-step" reaction can be reused (Weissermel and Arpe, 2008). The reaction conditions for these processes vary and must be balanced with their cost and the overall process cost. The oligomerized product consists of a wide range of carbon chain lengths. Wright et al. (2008) reported a $96 \%$ conversion of but-1-ene into $\mathrm{C}_{8}, \mathrm{C}_{12}, \mathrm{C}_{16}, \mathrm{C}_{20}$ oligomers. The required carbon lengths are between $\mathrm{C}_{14}$ and $\mathrm{C}_{20}$ for jet fuel and, to maximize the yield in this desired range. The $\mathrm{C}_{8}$ olefins can be separated then recycled or sent to a secondary dimerization facility. This would increase the carbon chain length and produce a greater yield of jet fuel per unit of feedstock. Subsequently, the oligomers are then hydrogenated to yield a product stream containing the synthetic paraffinic kerosene. Finally, distillation separates the bio-aviation fuel product stream from the bionaphtha and biodiesel product streams.

\section{Advantages}

A major benefit of ATJ compared to the other processes discussed can be attributed to the BAF produced. Similar to FT, the ATJ primarily produces synthetic jet fuel with permissible aromatics content to be used in existing engines without fuel seal concerns. As the aromatics content is a major requirement in the current necessity to blending synthetic fuels with Jet A-1, it could be foreseen that BAF via ATJ without blending could achieve approval for use.

A demonstration for BAF via ATJ has been proposed at a medium-scale. The process by LanzaTech utilizes industrial waste gases (e.g., flue gas) from steel production containing $\mathrm{CO}$, $\mathrm{CO}_{2}$, and $\mathrm{H}_{2}$. The process permits the recycling of carbon in the waste gas that would have been emitted to the atmosphere and takes advantage of the little to no cost of the waste gas that is likely to be cheaper than producing biogas or syngas from other feedstocks. These gases are supplemented by gasified biomass as discussed in section Advantages and fermented using microbiological species to produce alcohols (Brooks et al., 2016). In addition, this process can also use municipal waste to augment the feedstock requirement. LanzaTech, supported by Virgin Altantic Airways, are planning to develop a facility capable of producing over 13.5 million L of BAF via ATJ blended with CJF and diesel. The intention is predominantly to use waste streams from industrial and municipal sources as feedstock (Surgenor, 2018). The facility is likely to proceed as it has received a $\mathrm{USD}_{2018}$ 
520,700 grant following an application to the UK Department for Transport (LanzaTech, 2018).

Ethanol production is a long-established process that is already globally at commercial production levels (Escobar et al., 2009). Using ATJ to upgrade the alcohols into jet fuel would allow the aviation industry to take advantage of the established infrastructure and construct "upgrading" facilities close to the ethanol factories in order to decrease transportation costs. On the other hand, higher alcohols in general have a higher energy content and lower water solubility than ethanol but are not as widely used in fuel production (Brooks et al., 2016). In terms of GHG emissions, comparing between nbutanol, iso-butanol and ethanol, n-butanol has the highest and ethanol has the lowest (Tao et al., 2014). Butanol has a higher calorific value of 29.2 MJ/L compared to $19.6 \mathrm{MJ} / \mathrm{L}$ for ethanol but has lower heat of vaporization and less corrosivity, which make it a more attractive feedstock (Dziegielewski et al., 2014). Furthermore, butanol as feedstock could decrease production costs further due to lower temperature and pressure requirements during alcohol dehydration and higher jet fuel yields during oligomerization (Brooks et al., 2016). Moreover, the wide range of alcohol-intermediates (i.e., ethanol, n-butanol, iso-butanol) for the ATJ allows more opportunity to retrofit existing infrastructure and facilities. For example. the capital required for infrastructure costs could be further decreased significantly for butanol production as existing ethanol plant could be reconfigured to produce butanol with minor changes (Kolodziej and Scheib, 2012). Finally, Geleynse et al. (2018) reported that newly developed fermentation technologies could make the production of higher alcohols than ethanol more cost competitive in the future.

\section{Limitations}

Bioethanol produced through lignocellulosic biomass is currently widely used by the petrochemical industry as a component of automobile fuel. Almost all of the gasoline sold in the USA is around $10 \mathrm{vol} \%$ ethanol (U.S. Energy Information Administration, 2018). In effect, commercialization of BAF via ATJ may create competition between the air and land transport sectors in terms of feedstock availability. In addition, the main issue with ATJ is the low yield associated with bioalcohol production (Gutiérrez-Antonio et al., 2017). This is an important step in profitability of bio-aviation fuel. Some technical disadvantages for ATJ include a long process route involving sugarcane and a long production cycle involving starch crops (Wei et al., 2019). There is a need for more research and development of the ATJ in order to reduce its high production costs and maximize its future benefits.

\section{Economic Analysis}

Figure 6 displays the cost breakdown of producing BAF, in terms of the feedstock, capital expenditures (CAPEX) and operating \& maintenance expenditures (OPEX), for HEFA, FT, and ATJ. This was plotted from values (adjusted to 2019 levels) of de Jong et al. (2015) for a stand-alone plant on a new industrial site, which the authors calculated by a harmonized techno-economic framework using existing process modeling data. Feedstock considered for this comparison are used cooking oil, forest residues and wheat straw (de Jong et al., 2015). The cost breakdown of producing CJF via crude oil refining is also included for comparison. This was calculated and adjusted to 2019 levels from data of Sannan et al. (2017) and US EIA (2020).

Among the three production pathways, financial data exist for HEFA being on commercial scale (Table S4). For a HEFA plant, both its CAPEX and OPEX are also cheapest among the three pathways, which reflects the maturity of the technology. The CAPEX of a HEFA plant is even cheaper by about half of a crude oil refinery. However, the feedstock cost of HEFA is about 8 times greater than a crude oil refinery. Thus, the cost of sustainable feedstocks could determine the economic performance of the HEFA (de Jong et al., 2015).

ATJ and FT are yet to be on commercial scale (Figure 5). Between the two, FT is nearing commercial maturity but its deployment could be limited due to construction challenges of operational plants (Mawhood et al., 2016). Nevertheless, FT and ATJ require higher capital with their CAPEX about 3 and 5 times greater than the CAPEX for crude oil refinery and HEFA, respectively. The gasification facilities for the FT and facilities for pretreatment, hydrolysis, and fermentation for ATJ are the major costs in the CAPEX of these production pathways. The biochemical route of ATJ results to the highest OPEX among the three production pathways as these would involve several unit operations from alcohol synthesis to alcohol conversion to BAF (Mawhood et al., 2016). In terms of feedstock, forest residues is more preferable over wheat straw for both FT and ATJ given its lower delivered costs (de Jong et al., 2015).

The production cost of the three production pathways discussed range from 3 to 7 times greater the refinery production of CJF as depicted in Figure 6. Hence, it is important to improve these processes for them to become cost-efficient and be able to compete with CJF. The price of BAF could also be lowered by subsidies and taxes though policy development. Yang et al. (2019) suggested that if BAF production via HEFA meets policy targets, it could become economically attractive by imposing a $17 \%$ subsidy on BAF and $20 \%$ tax on CJF. Anderson et al. (2012) estimated that the carbon cost for BAF that gives a $50 \%$ carbon savings should be about $\mathrm{USD}_{2012} 380 / \mathrm{tCO}_{2}$ eq, although this value is optimistic as the price of BAF might increase in the future.

\section{Environmental Analysis}

Figure 7 presents the GHG emissions savings based on WTW analysis of HEFA, FT and ATJ at different feedstocks. The use of algal oil via HEFA was found to have the highest potential GHG emissions savings at an average of 98\% relative to fossil sources (Bauen et al., 2009). Since algae production is mostly from lab- to pilot-scale, so there is uncertainty of its actual GHG emissions savings when the technology matures (Bwapwa et al., 2018). Of the production pathways that are at and/or near commercial maturity, FT using 2-G feedstocks, such as woody crops, grasses, and forestry residues, have the highest potential for GHG emissions savings from 92 to $95 \%$. Fleming et al. (2006) corroborate this, compared to a gasoline standard, a 91\% reduction in WTW GHG emissions could be obtained from FT 
using 2-G feedstocks. The potential GHG emissions savings from HEFA are generally lower than using the FT independent of the feedstock used. However, Figure 7 clearly shows that non-food based feedstocks, such as waste tallow and jatropha, would be more suitable than conventional oil-seed crops, such as palm oil and rapeseed.

Aside from GHG emissions, particulate matter (PM) generated from these production pathways also needs to be considered. The incomplete combustion of fuel produces PM, which is mainly composed of soot and ash (Liati et al., 2019). These particulates can have an adverse effect on air quality and cause a wide range of health, safety and environment problems, which include exacerbating respiratory diseases, causing heart ailments, and formation of acid rain (Keefe, 2013). Lobo et al. (2011) found that PM emissions from a commercial jet engine could be decreased when CJF is mixed with either FAME or BAF via FT. The operating points specified by the ICAO's Landing Take-off Cycle were used to simulate the use of an engine under $30,000 \mathrm{ft}$, wherein the quality of local air would be affected. The use of a $50 \%$ blend of BAF via FT with CJF reduced PM in terms of number and mass-based emissions by $34 \pm 7 \%$ and $39 \pm 7 \%$, respectively. When this was increased to $100 \%$ BAF via $\mathrm{FT}$, the reduction in PM emissions was more pronounced at $52 \pm 4 \%$ and $62 \pm 4 \%$ for number and mass-based emissions, respectively. These results could be a further incentive for stakeholders to dedicate funds in the development of BAF via FT as an independent fuel without blending. Liati et al. (2019) also discovered that a $25 \%$ blend of BAF via HEFA and Jet A-1 produced less soot overall than pure Jet A-1. Hence, both BAF via HEFA and FT have a potential for soot reduction in the aviation industry. The use of $100 \%$ BAF in engines could potentially permit the aviation sector to completely detach from Jet A-1 dependency and to reduce its overall GHG and PM emissions.

\section{STORAGE AND TRANSPORT OF FEEDSTOCKS AND BIO-AVIATION FUEL}

The storage and transport of raw materials, intermediates, and/or finals products within the supply chain for BAF provision presents additional hurdles to their planning and implementation by the aviation industry. Transporting feedstocks and fuels over long distances significantly increases both costs and GHG emissions of the supply chain. Hence, the impacts associated are to be minimized in order to make BAF more cost-effective and environmental-friendly alternative to CJF. Generally, storage of feedstock has minimal impact on the supply chain. However, energy consuming facilities that provide medium-to long-term drying and preservation of the feedstocks can pose additional costs and emissions to the whole supply chain. Opportunely, storage of final BAF products becomes less of a concern after leaving the biorefinery as sophisticated systems already exist to support these during transport, e.g., carrier tanks equipped with particulate settlement and removal to preserve fuel (Hemighaus et al., 2006). Nevertheless, the associated impacts of storage, if considered within a supply chain for BAF provision, have to be included for its comprehensive planning, design, and operation.

\section{Raw Materials and Intermediates}

Storage and transport within the supply chain mainly facilitate the matching of supply and demand for raw materials, intermediates and products along the sequence of activities (Gold and Seuring, 2011; Ko et al., 2018). Mass and/or volume are commonly shared parameters in the choice of transport and storage technologies (Gold and Seuring, 2011). In the case of for oil-seed crops, the amount of dry biomass can be up to 4.7 times as much as the oil produced as shown in Table S5. While the storage of oil palm fresh fruit bunches is unnecessary, their immediate transport to oils mills is crucial in maintaining high quality oil with minimal impurities and in facilitating high oil extraction rates (Harahap et al., 2019). Storage becomes significant for feedstocks with short harvesting periods and widely scattered geographical distribution (Gold and Seuring, 2011). For lignocellulosic feedstocks, such as energy crops and agro-forestry residues, the prevention of microbial activity and spontaneous combustion are additional considerations of having a storage with drying facilities in a supply chain (Emery et al., 2015). On the other hand, distance and speed affect transport operations (Gold and Seuring, 2011). The available infrastructures also influence the transport operations (Gold and Seuring, 2011; Ko et al., 2018). Overall, the storage and/or transport of feedstock and its corresponding intermediaries up to the production stage span from the upstream to the midstream portion of the supply chain.

The transport and storage of waste biomass is generally a difficult issue. Large quantities of agricultural wastes are being concentrated into smaller and dispersed areas due to both improvements in technology and intensification of the industry (Sims and Maguire, 2005; Roth et al., 2018). While BAF production facilities can be located near regions with large quantities of waste biomass to relatively shorten the transport distance, Downie and van Zwieten (2013) argued that the bulky and wet nature of these feedstocks could still lead to high transport operation costs. The low-energy density and heterogeneous composition of most waste biomass upon collection offer additional challenges to their economic feasibility (Roth et al., 2018). Some waste biomass also have inherent health and safety risks (Rentizelas et al., 2009). For example, Europe generally incinerates animal waste at routine intervals. With animal wastes being wet and generated in large volumes, farms may find difficulty in their storage and transport. Moreover, storing large quantities of this matter may breach biosecurity legislation when regular collection cannot be achieved (Downie and van Zwieten, 2013).

Bearing in mind the various consideration of storage and transport, sophisticated mathematical models can be used to optimize supply chains, which consider the geographical distribution of feedstock, type and siting of production facilities, applicable storage facilities, available transport modes and routes (Gold and Seuring, 2011; de Jong et al., 2017b). The structure of the supply chain is more pertinent on the transport operations from farm to refinery gate as various models can be applied. de Jong et al. (2017c) outlined three models, the centralized supply chain, and two variations of distributed supply chains: the linear and hub and spoke 
models. The centralized supply chain model is characterized by a central location in which all processing occurs including pretreatment and upgrading. Whereas, in distributed models, the feedstocks can undergo pre-processing where they are extracted/harvested at separate facilities then transported further to an upgrading facility. This is an important consideration as the distributed models typically have a higher CAPEX and OPEX, but lower transportation costs overall (de Jong et al., 2017c).

\section{Final Jet Fuel Product}

The final transportation of processed jet fuel contributes to the final cost of the product and increases overall GHG emissions. The current distribution of jet fuel from the refinery as shown in Figure 8A comprises a variety of modes of transport including pipelines, barges, rail and trucks. Using a variety of modes of transport was found to decrease the cost of transporting fuel over longer distances, thereby allowing facilities to take advantage of cheaper feedstock sources from further away (de Jong et al., 2017b). Figure 8B also depicts pipeline transport of BAF, which makes up $60 \%$ of all refined petroleum products in the USA. The product that leaves the refining facilities can be in excess of 1.5 million liters per batch and the best form of transport suited to transporting such large volumes of fuels is pipeline systems (Hemighaus et al., 2006).

Fuels, including BAF, traveling through pipelines inevitably become contaminated with particulate matter and water. These contaminants must be removed at their destination (Hemighaus et al., 2006). As a result, the distance that fuels are transported should also be minimized in order to decrease the cleaning costs required at the end of the line. Research conducted in the bioethanol supply chain also found that the cultivation, harvesting, and transportation costs of the fee made up 35 to $50 \%$ of the final bioethanol product cost (Shastri and Ting, 2014). Similarly, decreasing the feedstock transportation costs could help make BAF become more cost competitive with CJF. Taking this in consideration, recent specifications for bioaviation fuel has permitted higher tolerable levels of FAME, such that biodiesel and BAF can use the same existing transportation chains (ASTM, 2015).

For smaller airports or airports relying on one mode of transport, it is important to have contingency measures to ensure fuel availability in the case of a supply disturbance, such as the fuel shortage in Manchester Airport in June 2012 (BBC, 2012). However, this could involve the airport incurring additional costs for measures like intermediate storage facilities in the distribution chain as presented in Figure 8A, or large holding tanks, which are not efficient and expensive to construct. Although airports are widely distributed around the world, due to increased population density and demand, the concentration of airports is greater around major city hubs in the vast majority of countries. As illustrated in Figure 9, Great Britain's jet fuel demands are in the regions of high demands for aviation transport close to major cities that include London, Manchester, Birmingham, and Newcastle. The 30 mile pipeline in place from the Essar refinery near Ellesmere Port to Manchester Airport transports the amount of fuel that would correspond to 79 road tankers on a daily basis
(BBC, 2012). Many existing fuel-refining facilities are already in advantageous locations for fuel distribution, thus established pathways and capital costs could be minimized by converting these to $\mathrm{BAF}$ refineries or producing $\mathrm{BAF}$ as a secondary product.

\section{Economic and Environmental Analyses}

The transport of feedstocks by truck, rail and ship are the most common, while the use of pipelines is currently the least established but may become significant in the future (Ko et al., 2018; Zafar, 2018). A recent review on feedstock logistics by Ko et al. (2018) stated that interests on multimodal movement (combination of modes) will increase due to the influence of transportation costs and distances on feedstock utilization. Figure 10A depicts a comparison of the cost and GHG emissions of transport by truck, rail and ship at $100-\mathrm{km}$ radius of transport distance for logging residues and straw. Transportation cost consists of a fixed cost and a variable cost (dependent on distance), which is typically less for both ship and rail than for truck. Ko et al. (2018), however, added that transportation costs vary among countries due to feedstock type and composition, transport capacities and geographical differences. Shastri and Ting (2014) estimated that generally beyond the range of 150 to $200 \mathrm{~km}$, transport of biomass is no longer feasible due to high transportation costs. Moreover, Zafar (2018) reported that for crop residues with low-density and high moisture content, even distances larger than a 25 to $50 \mathrm{~km}$ radius could be uneconomical. Similarly, transporting large quantities of feedstocks over long distances can contribute increased emissions from a life cycle standpoint (Gold and Seuring, 2011). Supply chains with heavy reliance on transport by truck of feedstocks are expected to emit more GHGs than transport by ship or rail as shown in Figure 10A. Furthermore, Figure 10B displays the breakdown of GHG emissions for hydro-processing, FT and sugar-to-jet production pathways for a variety of feedstocks showing the portion attributed to transportation. Although BAF produced from forest residues via FT have the lowest potential for overall WTW GHG emissions (Figure 7), over 20\% of this value is due to transportation (Figure 10B).

On feedstock storage, its primary function in a BAF supply chain is to address temporal variability of the demand, especially during seasons of low productivity. In the case of lignocellulosic feedstocks, the challenge of storing without significant dry matter losses (DML) must be overcome (Lemus, 2009; Emery et al., 2015). Storage depends on the location and climatic conditions that influence the quality of lignocellulosic feedstocks being stored. Different ways to store lignocellulosic feedstock are presented by Darr and Shah (2012) in which the majority are stored in rectangular bales. Costs for each storage infrastructure are also reported. Open storage costs around $\mathrm{USD}_{2014} 4.13 / \mathrm{t}$ while covered biomass storage costs $\mathrm{USD}_{2014}$ 5.44/t. Permanent storage infrastructures, involving enclosed structures, cost around $\mathrm{USD}_{2014} 14-28 / \mathrm{t}$. The cost for permanent storage structures is significantly higher than the first two options but the advantage is that $2 \%$ DML can be achieved compared to typical 6\% DML in covered storage and up to $20 \%$ DML in open storage. In the case of storing vegetable oil (e.g., palm oil) tankers (ships) are used as storage infrastructures with energy 

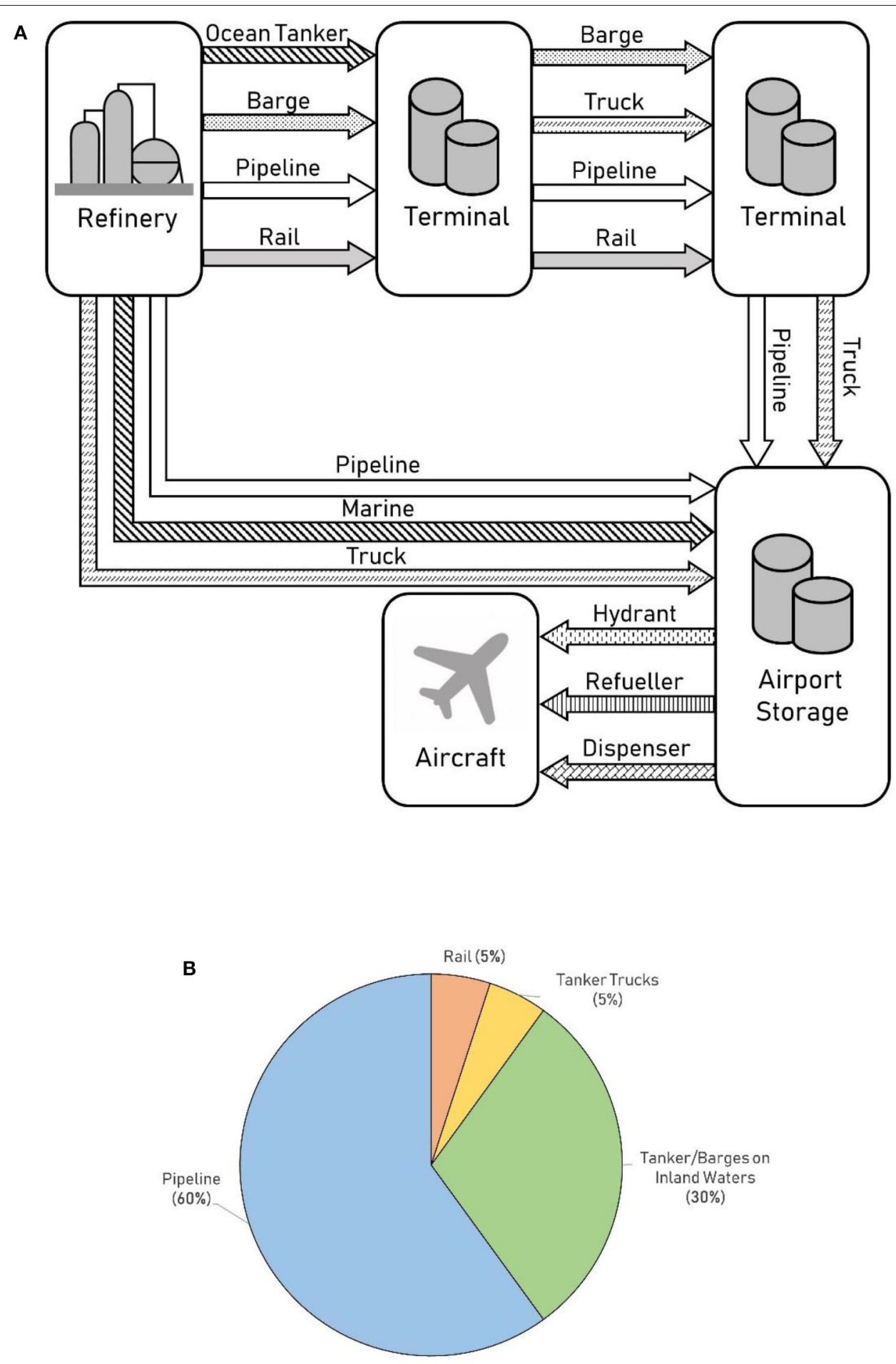

FIGURE 8 | Storage and transport of jet fuel: (A) Typical jet fuel distribution chains (Drawn using data from Hemighaus et al., 2006); and (B) Breakdown of major transport mechanisms for all refined fuel products in the U.S. (Plotted using data from Davidson et al., 2014).

requirements to maintain the vessel temperature (MPOB, 2010). Given the different options for feedstock storage, the studies on their GHG emissions are limited. Nevertheless, the addition of storage facilities to a supply chain can be expected to increase both the net energy consumption and GHG emissions (Emery et al., 2015). 


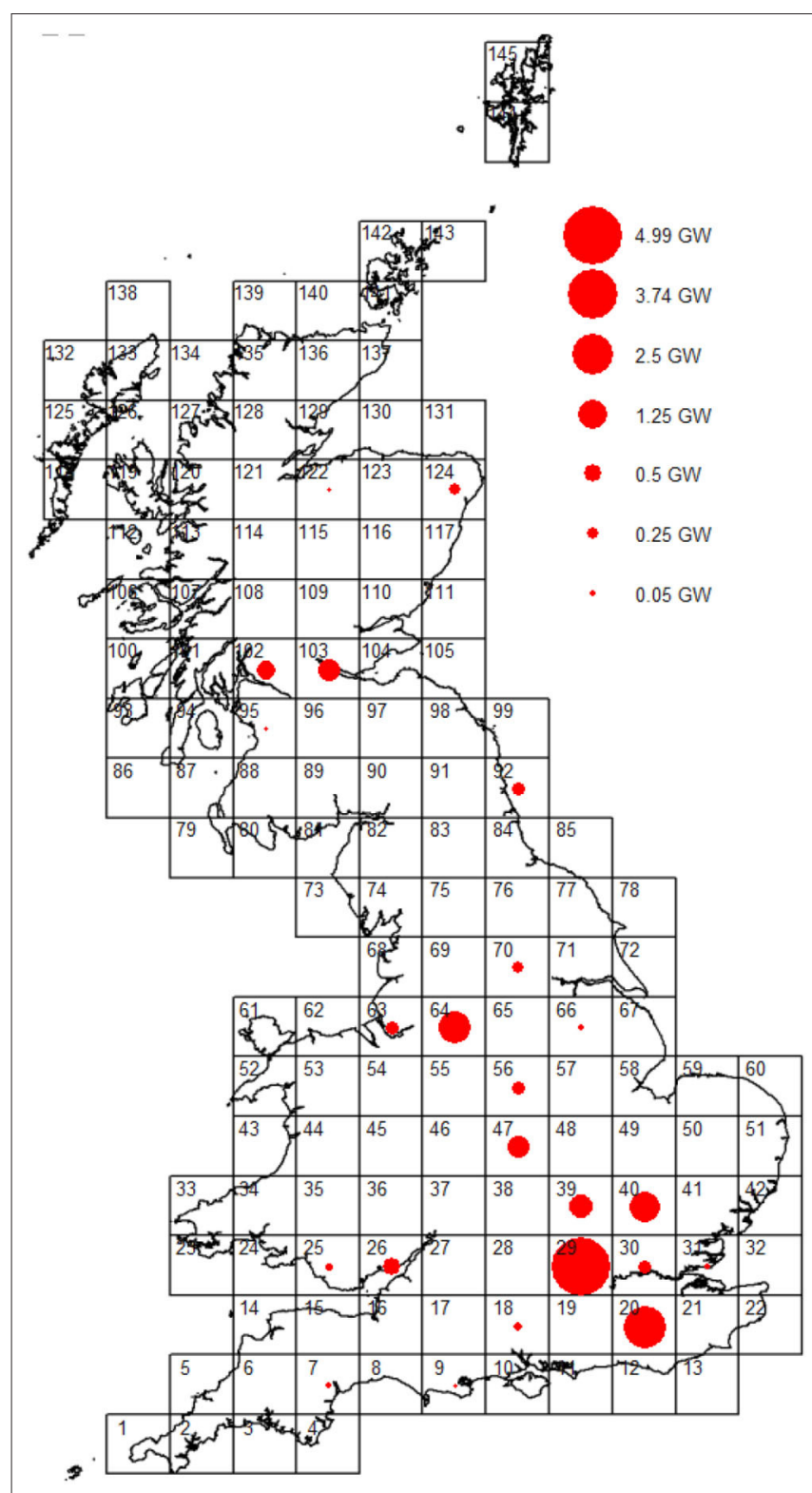

FIGURE 9 | Jet fuel demands for Great Britain at $50 \mathrm{~km}$ resolution.

\section{CRITICAL ANALYSIS, RECOMMENDATIONS, AND FUTURE DIRECTIONS}

For the successful and sustainable planning and implementation of BAF supply chains, it is vital that international aviation bodies, such as the ICAO and IATA, continue to develop linkages across country borders and to create agreements between the various stakeholders in the agriculture, production, and logistics sectors. This coordination will allow technology that has a high FRL (Figure 5) to be implemented on a commercial scale in the near future. Moreover, government-driven incentives for the use of
BAF and taxes on CJF will contribute significantly to its largescale development. Finally, the development of an integrated and uniform conceptual framework for the BAF industry will ensure that international stakeholders are able to share ideas with one another and develop effectively.

Developing new technologies, or scaling up existing technologies to commercial levels, will inevitably incur higher costs than continuing to use established conventional methods and infrastructures. This is reflected in consistently higher prices of BAF than Jet A-1. Tackling this barrier requires funding for both research into cost optimization of processes. Aviation companies also need subsidies in order to encourage fuel switching from Jet A-1 to BAF. These subsidies would offset the purchase cost of BAF over time. The financial incentives and aid that contributed to the success of biofuel implementation in the automobile industry are not as widely distributed to the aviation industry (Radich, 2015). This would require continued dialogue between international bodies and governments to raise the profile and accelerate the paradigm shift that the aviation industry is undergoing.

More LCA data are required on each component of the supply chain for BAF in different countries to support its planning, design, and operation. However, in order for these data to be robust and reliable for critical assessment, the methodologies used for the LCA should also be standardized and made open access for easier comparison. This could follow ISO 14040:2006-the LCA principles and framework from the International Organisation for Standardisation. It is also important for adequate peer reviewing to take place to ensure the validity of the results provided. Overall, within each component of the supply chain, the research conducted had a number of advantages and limitations associated with every alternative. Due to the complex nature of this topic, the options fare differently for each of the parameters chosen, and are often intertwined.

\section{Feedstocks}

From the review, the type of feedstocks utilized and production pathways selected are highly interrelated. Sustainable oil-rich feedstocks are required for HEFA. Currently, the security and availability of these feedstocks are its major limitations. Thus, a portfolio of feedstocks should be researched and developed that can satisfy several social, economic, environmental, and sustainability dimensions. High yielding, cost-effective, and low resource-intensive oil-seed crops can potentially serve as feedstocks for HEFA in the short term. In the case of oil palm, however, several negative environmental consequences have to be avoided or at least minimized. Reforestation with intensive biodiversity protection, avoidance of peatland LUC, and valorization of POME can improve the environmental performance of oil palm as feedstock. Competition of 1-G feedstocks, like oil palm, for the same resources with food production is going to limit their applicability as BAF feedstocks. Non-food oil-seed crops, like jatropha, can potentially fill some gaps in the feedstock supply and simultaneously provide some ecosystem services. While $2-\mathrm{G}$ energy crops can be grown in marginal lands in order to avoid food competition, responsible cultivation is of paramount importance to ensure that no 


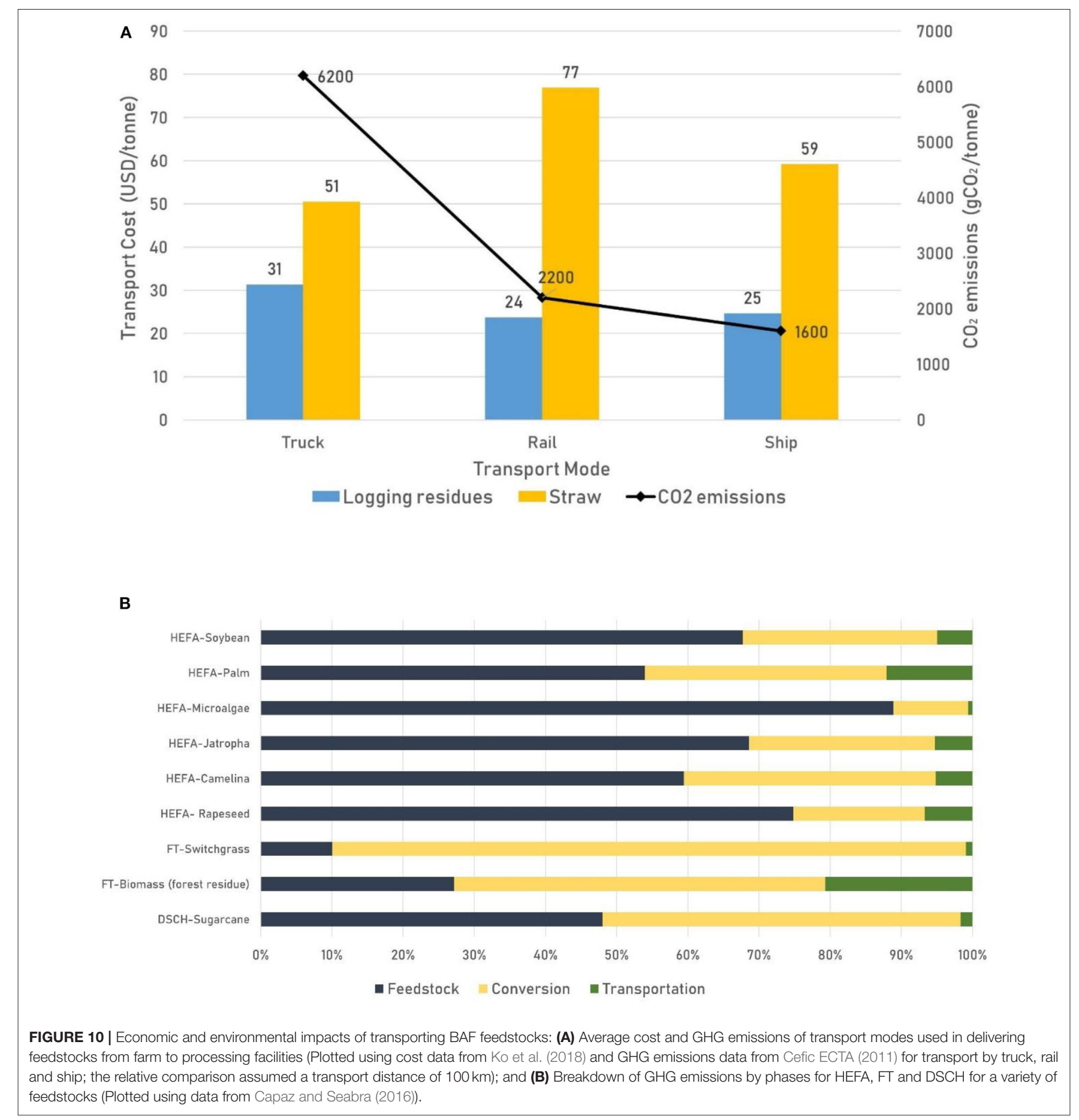

encroachment on forestland and arable land occurs and no LUC of peatland happens. Alternatively, low cost waste streams and residues are increasingly being developed as feedstocks. To date, $\mathrm{UCO}$ is considered as the most economical and environmentally friendly feedstock for BAF production. However, the variability of its supply and uncertainty of its actual contribution in meeting GHG emissions reduction targets can limit its applicability.
Other waste biomass such as MSW and agro-forestry residues also share this limitation as feedstocks to on-going commercial and technological developments of FT and ATJ. In the long-term, further research and development would enable commercial microalgae cultivation, which could provide a sustainable high oil-yielding feedstock for BAF production, superior to any 1$G$ and 2-G feedstocks given the low photosynthetic efficiency of land-based crops. Moreover, along with ecosystem services 
(wastewater treatment and $\mathrm{CO}_{2}$ fixation), microalgae-derived BAF can provide the highest potential WTW $\mathrm{CO}_{2}$ emissions savings. On the other hand, BAF derived from 4-G feedstocks can result in even greater negative net GHG emissions. However, these are at a very early stage of research but could be alternative solutions in the future, when they become commercially feasible.

The review on the supply chain models for BAF provision reveal that more research has to be done in this field. A supply chain analysis framework is highly needed in developing a portfolio of feedstocks for BAF provision. Particularly for land-based feedstocks, only genuinely available suitable lands should be considered in the assessment in order to minimize and/or avoid negative consequences of intensive cultivation, e.g., soil degradation, expansion to forestlands and peatlands, and depletion of water resources. GIS-based tools should be increasingly integrated in BAF supply chain models, especially for waste biomass, the spatio-temporal variability and uncertainty of which have to be resolved and captured in the planning, design and operation of their supply chains. More scenario development on various tax incentives and other legislations should be explored that could reveal strategies for economical feedstock production or extraction while avoiding food competition and additional GHG emissions. Waste valorization and negative emissions technologies could also be integrated into the BAF feedstock supply chain development in order to potentially enhance their environmental performance.

\section{Production Pathways}

Considering 2020 deployment, HEFA presents the most immediate solution. It has the lowest CAPEX and OPEX among the three reviewed production pathways due to its commercial maturity. Utilizing 2-G feedstocks, potential GHG emissions savings of $70-90 \%$ could be realized by this production pathway. However, the major challenges for HEFA are to obtain low cost sustainable feedstocks and to further develop the process in order to reduce the costs of the final product. Focusing future investments in securing a reliable and efficient supply chain could augment BAF production via HEFA.

Within the medium- to long-term goals of the aviation sector, FT presents the next best solution. It is a technology approaching commercial maturity. Utilizing agricultural and forestry residues as feedstock, FT has the highest potential GHG emissions savings among the production pathways near or at commercial maturity, which is at well over $90 \%$. MSW is increasingly being considered as feedstock, which could lessen the environmental concerns associated with landfills. However, the high capital costs of FT make it an unattractive option at present. The limited biomass-based application of FT could also be a major hindrance of its successful deployment. Hence, there is a need to focus investments on more demonstration to commercial scale projects for FT utilizing biomass feedstocks along with a strong commitment from and collaboration with the aviation industry.

At present, ATJ using lignocellulosic biomass as a feedstock has the highest CAPEX and OPEX among the three production pathways reviewed. The relatively high abundance of lignocellulosic feedstocks and the benefit of potential GHG emissions savings (75\% using corn stover as feedstock) strongly support its potential commercial deployment in the long-term. Given the FRL of this technology, more efforts in research and development to demonstration scale project could pave the way of its commercial maturity. Available infrastructure and facilities of well-established alcohol supply chains could also support the aviation industry in adopting the ATJ. However, the aviation industry must consider that alcohol is also a fuel additive for land transport, which could give rise to competing interests in the supply.

Overall, HEFA, ATJ, and FT demonstrate the capability to produce BAF for the needed decarbonization of the aviation industry. With the goal of bringing their costs to a comparable level with conventional jet fuel, the implementation of all three fuels at a commercial scale could enable increased availability of BAF and in turn, decrease the selling price to the consumers. Given the availability of feedstock in a particular region for BAF production, it is paramount to develop decision-making frameworks to determine what capacities of these technologies should be installed, where the processing facilities should be deployed and when and how they should be operated.

The development of other novel processes such as DSCH and hydrothermal liquefaction should be a priority for future work. There is currently limited quantitative data available on these new technologies, due to the lack of large-scale production facilities at present.

\section{Storage and Transport}

The total distance that feedstock, all intermediates and refined fuel are transported, and all associated emissions and costs can be minimized by using mathematical modeling and optimization strategies to tactically design supply chains. Some models have been proposed for optimizing production facilities location in BAF supply chains. However, the proposed models only considered the transportation aspect of the supply chains. Supply chain models for BAF need to be improved more in terms of detail, accounting for the storage that would enable to satisfy short-term future demands and accounting for impacts to biodiversity and to food-energy-water-energy-environment nexus. These should be carried out using recent data as possible to ensure that the results are reliable and relevant.

\section{CONCLUSIONS}

With the demand on the aviation sector projected to increase in the near future, the dilemma is how to satisfy this demand while complying with international efforts for emissions reductions. The implementation of alternative jet fuel is a pivotal step that will help the sector decarbonize and simultaneously become independent from limited fossil fuel supply. In this paper, the opportunities in the future bio-aviation fuel industry have been explored through a comprehensive analysis of the feedstocks, production processes, storage, and transport mode options. The key conclusions are as follows:

1. A range of feedstocks for bio-aviation fuel production is available with different economic potential and environmental 
benefits. In the short- to medium-term, low-cost and highyielding oil-rich feedstocks could be an effective transitionary solution. The negative environmental consequences of landbased crops, such as oil palm and jatropha, can limit their applicability, while the uncertainty and variability of waste streams such as used cooking oil and municipal solid waste can limit their contribution. The great potential of microalgae as a feedstock, due to its higher yield than oil-bearing crops, must still be proven economical in the long-term. A wide range of feedstocks are going to be needed to ensure security, availability, and sustainability of bio-aviation fuel.

2. Production pathways are available but at different readiness levels. HEFA, being a mature technology, could be a solution for the immediate, cost-effective implementation of bioaviation fuel. It is necessary to explore these production pathways further, especially FT, which has near commercial maturity and higher GHG savings than other pathways but also higher capital costs.

3. The structure of biomass feedstock and refined fuel products transportation, whether distributed or centralized, should be optimally designed to developed streamlined supply chains. Utilizing multiple transport modes in the chain was found to lower transportation costs and GHG emissions over long distances.

4. Optimization models are valuable as decision-making tools for planning and designing supply chains for bio-aviation fuel provision. Supply chain decisions are dependent on spatial and temporal factors. Spatial factors include the yield and location of feedstocks, capacity and location of processing and storage facilities-these determine the most appropriate modes of transport. Temporal factors include the seasonality and availability of feedstocks and variability of fuel demands-these affect the production and inventory levels.

5. Evidence-based policies are essential for the successful and sustainable implementation of the bio-aviation fuel supply chains. These policies must be streamlined across each component of the supply chain such that their growth and expansion are coordinated while simultaneously meeting socio-economic and environmental sustainability criteria. Given the trans-boundary nature of the aviation industry, specific policies must be standardized internationally but with

\section{REFERENCES}

Abdullah, B., Syed Muhammad, S. A. F., Shokravi, Z., Ismail, S., Kassim, K., Mahmood, A. N., et al. (2019). Fourth generation biofuel: a review on risks and mitigation strategies. Renew. Sustain. Energy Rev. 107, 37-50. doi: 10.1016/j.rser.2019.02.018

Abdurahman, N. H., and Azhari, N. H. (2018). An integrated UMAS for POME treatment. J. Water Reuse Desalin. 8, 68-75. doi: 10.2166/wrd.2016.124

Abideen, Z., Hameed, A., Koyro, H. W., Gul, B., Ansari, R., Khan, M. A., et al. (2014). Sustainable biofuel production from non-food sources - an overview. Emirates J. Food Agric. 26, 1057-1066. doi: 10.9755/ejfa.v26i12.19107

Acheampong, M., Ertem, F. C., Kappler, B., and Neubauer, P. (2017). In pursuit of sustainable development goal (SDG) number 7: will biofuels be reliable? Renew. Sustain. Energy Rev. 75, 927-937. doi: 10.1016/j.rser.2016.11.074 enough room for flexibility for the varying national goals of different countries.

\section{AUTHOR CONTRIBUTIONS}

SS conceptualized the topic and scope of the paper. AN gathered the data and completed an early draft of this work under SS's supervision. SD and JT expanded the initial draft by adding more data and discussion, with SD significantly expanding the discussion and presentation of the feedstock classification, supply chain models for bio-aviation fuel provision, transport and storage, and their economic and environmental analyses. SS and NS provided data, ideas and feedback, and wrote some parts of the manuscript. YZ reviewed the paper and provided feedback.

\section{FUNDING}

The Newton Fund and Engineering and Physical Sciences Research Council through the Biomass and the EnvironmentFood-Energy-Water Nexus Project (Grant No. EP/P018165/1). The CHED-Newton Agham PhD Scholarship grant under the Newton Fund Project and CHED K-12 Transition Programme by the British Council Philippines (Application ID: 333426643) and the Commission of Higher Education under the Office of the President, Republic of the Philippines (Scholar No.: BC-17-009).

\section{ACKNOWLEDGMENTS}

The authors would like to thank the main funding sponsors of this project: the Newton Fund, the Engineering and Physical Sciences Research Council and the Science and Technology Facilities Council ODA Institutional Award. The financial support from the British Council Philippines and Commission of Higher Education under the Office of the President, Republic of the Philippines through SD's $\mathrm{PhD}$ scholarship is also gratefully acknowledged.

\section{SUPPLEMENTARY MATERIAL}

The Supplementary Material for this article can be found online at: https://www.frontiersin.org/articles/10.3389/fenrg. 2020.00110/full\#supplementary-material 
Alalwan, H. A., Alminshid, A. H., and Aljaafari, H. A. S. (2019). Promising evolution of biofuel generations. Subject review. Renew. Energy Focus 28, 127-139. doi: 10.1016/j.ref.2018.12.006

Alexandratos, N. (1999). World food and agriculture: outlook for the medium and longer term. Proc. Natl. Acad. Sci. U.S.A. 96, 5908-5914. doi: $10.1073 /$ pnas.96.11.5908

Alves, C. M., Valk, M., de Jong, S., Bonomi, A., van der Wielen, L. A. M., and Mussatto, S. I. (2017). Techno-economic assessment of biorefinery technologies for aviation biofuels supply chains in Brazil. Biofuels Bioprod. Biorefining 11, 67-91. doi: 10.1002/bbb.1711

Ames, J. L. (2014). Microalgae-derived HEFA jet fuel : environmental and economic impacts of scaled/integrated growth facilities and global production potential (Masters thesis). Massachusetts Institute of Technology, Cambridge, MA, 74. Available online at https://dspace.mit.edu/handle/1721.1/97363 (accessed August 02, 2019).

Anderson, S., Cooper, J., Gudde, N., and Howes, J. (2012). Aviation renewable fuels: technical status and challenges for commercialisation. Aeronaut. J. 116, 1103-1122. doi: 10.1017/S0001924000007521

Anderson, W. F. (2016). Feedstock Readiness Level (FSRL) evaluation: Pennisetum purpureum (napier grass). Alcohol-to-Jet; A. D. Commons.

Arabi, M., Yaghoubi, S., and Tajik, J. (2019). A mathematical model for microalgae-based biobutanol supply chain network design under harvesting and drying uncertainties. Energy 179, 1004-1016. doi: 10.1016/j.energy.2019. 04.219

Asadi, E., Habibi, F., Nickel, S., and Sahebi, H. (2018). A bi-objective stochastic location-inventory-routing model for microalgae-based biofuel supply chain. Appl. Energy 228, 2235-2261. doi: 10.1016/j.apenergy.2018.07.067

ASTM (2015). Revised ASTM Standard Expands Limit on Biofuel Contamination in Jet Fuels. Available online at https:/www.astm.org/cms/drupal-7.51/ newsroom/revised-astm-standard-expands-limit-biofuel-contamination- jetfuels (accessed April 11, 2019).

ASTM (2019). ASTM D7566-19b, Standard Specification for Aviation Turbine Fuel Containing Synthesized Hydrocarbons. American Society for Testing and Materials (ASTM), 1-33.

ATAG (2012). A Sustainable Flightpath Towards Reducing Emissions. Geneva: Air Transport Action Group (ATAG), 1-6. Available online at http://www. flygreenfund.se/wp-content/uploads/2015/05/A-Sustainable-FlightpathTowards-Reducing-Emissions-ATAG-2012.pdf (accessed July 24, 2019).

ATAG (2014). Aviation Benefits Beyond Borders: Powering Global Economic Growth, Employment, Trade Links, Tourism and Support for Sustainable Development Through Air Transport. Geneva: Air Transport Action Group (ATAG), 1-68. Available online at https://aviationbenefits.org/media/26786/ ATAG_AviationBenefits2014_FULL_LowRes.pdf (accessed March 27, 2019).

ATAG (2017). Beginner's Guide to Sustainable Aviation Fuel. Geneva: Air Transport Action Group (ATAG), 1-24. Available online at https://aviationbenefits.org/ media/166152/beginners-guide-to-saf_web.pdf (accessed July 23, 2019).

ATAG (2019). Facts and Figures. Available online at: https://www.atag.org/factsfigures.html (accessed March 25, 2019).

Atashbar, N. Z., Labadie, N., and Prins, C. (2016). Modeling and optimization of biomass supply chains: a review and a critical look. IFAC Pap. OnLine 49, 604-615. doi: 10.1016/j.ifacol.2016.07.742

Atashbar, N. Z., Labadie, N., and Prins, C. (2018). Modelling and optimisation of biomass supply chains: a review. Int. J. Prod. Res. 56, 3482-3506. doi: 10.1080/00207543.2017.1343506

AviationPros (2015). Gevo's Jet Fuel to Be Used in First Ever Test Flight Flown on Fuel Derived From Wood Waste. Available online at: https://www.aviationpros. com/contact-us (accessed July 29, 2019).

Azwan, M. B., Norasikin, A. L., Rahim, A. S., Norman, K., and Salmah, J. (2016). Analysis of energy utilisation in Malaysian oil palm mechanisation operation. J. Oil Palm Res. 28, 485-495. doi: 10.21894/jopr.2016.2804.10

Bailis, R. E., and Baka, J. E. (2010). Greenhouse gas emissions and land use change from jatropha curcas-based jet fuel in Brazil. Environ. Sci. Technol. 44, 8684-8691. doi: 10.1021/es1019178

Ball, J., Carle, J., and Del Lungo, A. (2005). Contribution of poplars and willows to sustainable forestry and rural development. Unasylva 56, 3-9.

Barbosa, F. C. (2017). "Biojet fuel - a tool for a sustainable aviation industry - a technical assessment," in 26th SAE BRASIL Inernational Congress and Display (São Paulo: SAE International), 1-16. doi: 10.4271/2017-36-0 142

Bauen, A., Howes, J., Bertuccioli, L., and Chudzia, C. (2009). Review of the Potential for Biofuels in Aviation. London: E4Tech, 1-117. Available online at http://citeseerx.ist.psu.edu/viewdoc/download?doi=10.1.1.170.8750\& rep $=$ rep $1 \&$ type $=$ pdf

BBC (2012). Who, What, Why: How Can an Airport Run Out of Fuel? Available online at https://www.bbc.co.uk/news/magazine-18355592 (accessed March 29, 2019).

BBI International (2018). US DOE Grants $\$ 10.6 \mathrm{M}$ to Produce More Biodiesel, Biojet Fuel. Available online at http://www.biodieselmagazine.com/articles/2516287/ us-doe-grants-10-6m-to-produce-more-biodiesel-biojet-fuel (accessed July 22, 2019).

Behrendt, D., Schreiber, C., Pfaff, C., Müller, A., Grobbelaar, J., and Nedbal, L. (2018). "Algae as a potential source of biokerosene and diesel opportunities and challenges," in Biokerosene: Status and Prospects, eds M. Kaltschmitt and U. Neuling (Berlin; Heidelberg: Springer), 303-324. doi: 10.1007/978-3-662-53065-8_14

Boakye-Boaten, N. A., Kurkalova, L., Xiu, S., and Shahbazi, A. (2017). Techno-economic analysis for the biochemical conversion of Miscanthus x giganteus into bioethanol. Biomass Bioenergy 98, 85-94. doi: 10.1016/j.biombioe.2017.01.017

Boichenko, S., Oksana, V., and Anna, I. (2013). Overview of innovative technologies for aviation fuels production. Chem. Chem. Technol. 7:305. doi: $10.23939 /$ chcht07.03.305

Bosch, J., de Jong, S., Hoefnagels, R., and Slade, R. (2017). Aviation biofuels: strategically important, technically achievable, tough to deliver," in Grantham Briefing Papers (London: Imperial College London), 1-15. Available online at https://www.imperial.ac.uk/media/imperial-college/grantham-institute/ public/publications/briefing-papers/BP-23-Aviation-Biofuels.pdf (accessed March 15, 2019).

Brooks, K. P., Snowden-Swan, L., J., Jones, S., B., Butcher, M., et al. (2016). "Low-carbon aviation fuel through the alcohol to jet pathway," in Biofuels for Aviation, ed C. K. Chuck (London: Academic Press), 109-150. doi: 10.1016/B978-0-12-804568-8.00006-8

Buchspies, B., and Kaltschmitt, M. (2018). "Sustainability aspects of biokerosene," in Biokerosene: Status and Prospects, eds M. Kaltschmitt and U. Neuling (Berlin; Heidelberg: Springer), 325-373. doi: 10.1007/978-3-662-53065-8_15

Budzianowski, W. M., and Postawa, K. (2016). Total chain integration of sustainable biorefinery systems. Appl. Energy 184, 1432-1446. doi: 10.1016/j.apenergy.2016.06.050

Bwapwa, J. K., Anandraj, A., and Trois, C. (2018). Conceptual process design and -simulation of microalgae oil -conversion to aviation fuel. Biofuels Bioprod. Bioref. 12, 935-948. doi: 10.1002/bbb.1890

Caicedo, M., Barros, J., and Ordás, B. (2016). Redefining agricultural residues as bioenergy feedstocks. Materials 9:635. doi: 10.3390/ma9080635

Callegari, A., Bolognesi, S., Cecconet, D., and Capodaglio, A. G. (2019). Production technologies, current role, and future prospects of biofuels feedstocks: a state-of-the-art review. Crit. Rev. Environ. Sci. Technol. 50, 384-436. doi: 10.1080/10643389.2019.1629801

Camesasca, L., Ramírez, M. B., Guigou, M., Ferrari, M. D., and Lareo, C. (2015). Evaluation of dilute acid and alkaline pretreatments, enzymatic hydrolysis and fermentation of napiergrass for fuel ethanol production. Biomass Bioenergy 74, 193-201. doi: 10.1016/j.biombioe.2015.01.017

Campbell, M. (2018). "Camelina - an alternative oil crop," in Biokerosene: Status and Prospects, eds M. Kaltschmitt and U. Neuling (Berlin; Heidelberg: Springer), 259-275. doi: 10.1007/978-3-662-53065-8_12

Cantarella, H., Nassar, A. M., Cortez, L. A. B., and Junior, R. B. (2015). Potential feedstock for renewable aviation fuel in Brazil. Environ. Dev. 15, 52-63. doi: 10.1016/j.envdev.2015.05.004

Capaz, R. S., and Seabra, J. E. A. (2016). "Life cycle assessment of biojet fuels," in Biofuels for Aviation, ed C. J. Chuck (London: Academic Press), 279-294. doi: 10.1016/B978-0-12-804568-8.00012-3

Cefic and ECTA (2011). Guidelines for Measuring and Managing $\mathrm{CO}_{2}$ Emission From Freight Transport Operations. Brussels: The European Chemical Industry Council (Cefic) and European Communities Trade Mark Association (ECTA), 1-18. Available online at https://www.ecta.com/resources/Documents/Best 
\%20Practices\%20Guidelines/guideline_for_measuring_and_managing_co2. pdf (accessed September 17, 2018)

Chang, F.-C. L., Lin, D. C., Ko, H. H., Hsieh, C. B., Yang, Y. W., Chen, H., et al. (2017). Life cycle assessment of bioethanol production from three feedstocks and two fermentation waste reutilization schemes. J. Clean. Prod. 143, 973-979. doi: 10.1016/j.jclepro.2016.12.024

Chen, R. X., and Wang, W. C. (2019). The production of renewable aviation fuel from waste cooking oil. Part I: bio-alkane conversion through hydro-processing of oil. Renew. Energy 135, 819-835. doi: 10.1016/j.renene.2018.12.048

Cheng, F., and Brewer, C. E. (2017). Producing jet fuel from biomass lignin: potential pathways to alkyl-benzenes and cycloalkanes. Renew. Sustain. Energy Rev. 72, 673-722. doi: 10.1016/j.rser.2017.01.030

Cheng, J. J., and Timilsina, G. R. (2011). Status and barriers of advanced biofuel technologies: a review. Renew. Energy 36, 3541-3549. doi: 10.1016/j.renene.2011.04.031

Chiaramonti, D., and Horta Nogueira, L., A. (2017). “Aviation biofuels: processes, opportunities, constraints, and perspectives," in Biofuels Production and Processing Technology, eds R. Singh and S. Kumar (CRC Press), 295-318. doi: 10.1201/9781315155067-11

Chiaramonti, D., Prussi, M., Buffi, M., Rizzo, A. M., and Pari, L. (2017). Review and experimental study on pyrolysis and hydrothermal liquefaction of microalgae for biofuel production. Appl. Energy 185, 963-972. doi: 10.1016/j.apenergy.2015.12.001

Choong, Y. Y., Chou, K. W., and Norli, I. (2018). Strategies for improving biogas production of palm oil mill effluent (POME) anaerobic digestion: a critical review. Renew. Sustain. Energy Rev. 82, 2993-3006. doi: 10.1016/j.rser.2017.10.036

Choudhary, T. V., and Phillips, C. B. (2011). Renewable fuels via catalytic hydrodeoxygenation. Appl. Catal. A Gen. 397, 1-12. doi: 10.1016/j.apcata.2011.02.025

Conrad, S., Blajin, C., Schulzke, T., and Deerberg, G. (2019). Comparison of fast pyrolysis bio-oils from straw and miscanthus. Environ. Prog. Sustain. Energy 38:e13287. doi: 10.1002/ep.13287

Corporan, E., Edwards, T., Shafer, L., Dewitt, M. J., Klingshirn, C., West, Z., et al. (2011). Chemical, thermal stability, seal swell, and emissions studies of alternative jet fuels. Energy Fuels 25, 955-966. doi: 10.1021/ef101520v

Correa, D. F., Beyer, H. L., Fargione, J. E., Hill, J. D., Posingham, H. P., Thomas-Hall, S. R., et al. (2019). Towards the implementation of sustainable biofuel production systems. Renew. Sustain. Energy Rev. 107, 250-263. doi: 10.1016/j.rser.2019.03.005

Couto, N. D., Silva, V. B., Monteiro, E., Rouboa, A., and Brito, P. (2017). An experimental and numerical study on the Miscanthus gasification by using a pilot scale gasifier. Renew. Energy 109, 248-261. doi: 10.1016/j.renene.2017.03.028

Crawford, J. T., Shan, C. W., Budsberg, E., Morgan, H., Bura, R., and Gustafson, R. (2016). Hydrocarbon bio-jet fuel from bioconversion of poplar biomass: techno-economic assessment. Biotechnol. Biofuels 9:141. doi: 10.1186/s13068-016-0545-7

Crown Oil UK (2019). HVO Biodiesel (Hydrotreated Vegetable Oil). Available online at: https://www.crownoiluk.com/products/hvo-biodiesel/ (accessed April 8, 2019).

Curneen, S., and Gill, L. W. (2016). Willow-based evapotranspiration systems for on-site wastewater effluent in areas of low permeability subsoils. Ecol. Eng. 92, 199-209. doi: 10.1016/j.ecoleng.2016.03.032

Dabe, S. J., Prasad, P. J., Vaidya, A. N., and Purohit, H. (2019). Technological pathways for bioenergy generation from municipal solid waste: renewable energy option. Environ. Progress Sustain. Energy 38, 654-671. doi: 10.1002/ep.12981

Darr, M. J., and Shah, A. (2012). Biomass storage: an update on industrial solutions for baled biomass feedstocks. Biofuels 3, 321-332. doi: 10.4155/bfs. 12.23

Davidson, C., Newes, E., Schwab, A., and Vimmerstedt, L. (2014). An Overview of Aviation Fuel Markets for Biofuels Stakeholders. National Renewable Energy Laboratory (NREL); Department of Energy, 1-44. Available online at https:// www.nrel.gov/docs/fy14osti/60254.pdf (accessed July 31, 2019).

Daystar, J., Gonzalez, R., Reeb, C., Venditti, R., Treasure, T., Abt, R., and Kelley, S. (2014). Economics, environmental impacts, and supply chain analysis of cellulosic biomass for biofuels in the southern us: pine, eucalyptus, unmanaged hardwoods, forest residues, switchgrass, and sweet sorghum. Bioresources 9, 393-444. doi: 10.15376/biores.9.1.393-444

de Castro, R. E. N., de Brito Alves, R. M., do Nascimento, C. A. O., and Giudici, R. (2018). "Assessment of sugarcane-based ethanol production," in Fuel Ethanol Production From Sugarcane, eds T. P. Basso and L. C. Basso (IntechOpen), 1-21.

de Corato, U., de Bari, I., Viola, E., and Pugliese, M. (2018). Assessing the main opportunities of integrated biorefining from agro-bioenergy co/by-products and agroindustrial residues into high-value added products associated to some emerging markets: a review. Renew. Sustain. Energy Rev. 88, 326-346. doi: 10.1016/j.rser.2018.02.041

De Jesus Eufrade Junior, H., de Melo, R. X., Sartori, M. M. P., Guerra, P. S. S., et al. (2016). Sustainable use of eucalypt biomass grown on short rotation coppice for bioenergy. Biomass Bioenergy 90, 15-21. doi: 10.1016/j.biombioe.2016.03.037

de Jong, S., Antonissen, K., Hoefnagels, R., Lonza, L., Wang, M., Faaij, A., et al. (2017a). Life-cycle analysis of greenhouse gas emissions from renewable jet fuel production. Biotechnol. Biofuels 10:64. doi: 10.1186/s13068-017-0739-7

de Jong, S., Hoefnagels, R., Faaij, A., Slade, R., Mawhood, R., and Junginger, M. (2015). The feasibility of short-term production strategies for renewable jet fuels - a comprehensive techno-economic comparison. Biofuels Bioprod. Bioref. 9, 778-800. doi: 10.1002/bbb.1613

de Jong, S., Hoefnagels, R., van Stralen, J., Londo, M., Slade, R., Faaij, A., et al. (2017b). Renewable Jet Fuel in the European Union - Scenarios and Preconditions for Renewable Jet Fuel Deployment Towards 2030. Utrecht: Utrecht University, 1-26. Available online at https://www.uu.nl/ sites/default/files/renewable_jet_fuel_in_the_european_union_-_scenarios_ and_preconditions_for_renewable_jet_fuel_deployment_towards_2030.pdf (accessed July 12, 2019).

de Jong, S., Hoefnagels, R., Wetterlund, E., Pettersson, K., Faaij, A., and Junginger, M. (2017c). Cost optimization of biofuel production - The impact of scale, integration, transport and supply chain configurations. Appl. Energy 195, 1055-1070. doi: 10.1016/j.apenergy.2017.03.109

Dincer, I., and Acar, C. (2014). Review and evaluation of hydrogen production methods for better sustainability. Int. J. Hydrogen Energy 40, 11094-11111. doi: 10.1016/j.ijhydene.2014.12.035

Dodd, T., Orlitzky, M., and Nelson, T. (2018). What stalls a renewable energy industry? Industry outlook of the aviation biofuels industry in Australia, Germany, and the USA. Energy Policy 123, 92-103. doi: 10.1016/j.enpol.2018.08.048

Doliente, S. S., and Samsatli, S. (2019). "Multi-objective spatio-temporal optimisation for simultaneous planning, design and operation of sustainable and efficient value chains for rice crop," in Computer Aided Chemical Engineering, eds A. A. Kiss, E. Zondervan, R. Lakerveld, and L. Özkan (Amsterdam: Elsevier) 46, 1453-1458. doi: 10.1016/B978-0-12-818634-3.50243-5

Domínguez-García, S., Gutiérrez-Antonio, C., de Lira-Flores J. A., Ponce-Ortega, J. M., and El-Halwagi, M. M. (2017). Strategic planning for the supply chain of aviation biofuel with consideration of hydrogen production. Ind. Eng. Chem. Res. 56, 13812-13830. doi: 10.1021/acs.iecr.7b02632

Dornack, C., Zentner, A., and Zehm, A. (2018). "Waste as Resource," in Biokerosene: Status and Prospects, eds M. Kaltschmitt, and U. Neuling (Berlin; Heidelberg: Springer), 221-236. doi: 10.1007/978-3-662-53065-8_10

Doshi, A., Pascoe, S., Coglan, L., and Rainey, T., J. (2016). Economic and policy issues in the production of algae-based biofuels: a review. Renew. Sustain. Energy Rev. 64, 329-337. doi: 10.1016/j.rser.2016.06.027

Downie, A., and van Zwieten, L. (2013). "Biochar: a coproduct to bioenergy from slow-pyrolysis technology," in Advanced Biofuels and Bioproducts, ed J. W. Lee (New York, NY: Springer), 97-117. doi: 10.1007/978-1-4614-3348-4_8

Dry, M. E. (2002). The Fischer-Tropsch process: 1950-2000. Catal. Today 71, 227-241. doi: 10.1016/S0920-5861(01)00453-9

Dupuis, D. P., Grim, R. G., Nelson, E., Tan, E. C. D., Ruddy, D. A., Hermandez, S., et al. (2019). High-octane gasoline from biomass: experimental, economic, and environmental assessment. Appl. Energy 241, 25-33. doi: 10.1016/j.apenergy.2019.02.064

Dziegielewski, W., Gawron, B., Kazmierczak, U., and Kulczycki, A. (2014). Butanol/Biobutanol as a component of an aviation and diesel fuel. J. KONES Powertrain Transp. 21, 69-75. doi: 10.5604/12314005.113 3869 
Egg, R. P., Coble, C. G., Engler, C. R., and Lewis, D. (1993). Feedstock storage, handling and processing. Biomass Bioenergy 5, 71-94. doi: 10.1016/0961-9534(93)90009-S

El Khatib, S. A., Hanafi, S. A., Barakat, Y., and Al-Amrousi, E. F. (2018). Hydrotreating rice bran oil for biofuel production. Egypt. J. Petrol. 27, 1325-1331. doi: 10.1016/j.ejpe.2018.08.003

Elgowainy, A., Han, M., Wang, J., Carter, N., Stratton, R., Hileman, J., et al. (2012). Life Cycle Analysis of Alternative Aviation Fuels in GREET. Report, Energy Systems Division Argonne National Laboratory; US Department of Energy, Chicago, IL. 1-62. Available online at: https://greet.es.anl.gov/files/aviation-lca (accessed July 29, 2019).

Elia, J. A., Baliban, R. C., Floudas, C. A., Gurau, B., Weingarten, M. B., Klotz, S. D., et al. (2013). Hardwood biomass to gasoline, diesel, and jet fuel: 2. supply chain optimization framework for a network of thermochemical refineries. Energy Fuels 27, 4325-4352. doi: 10.1021/ef400430x

Eller, Z., Varga, Z., and Hancsók, J. (2016). Advanced production process of jet fuel components from technical grade coconut oil with special hydrocracking. Fuel 182, 713-720. doi: 10.1016/j.fuel.2016.06.055

Elsoragaby, S., Yahya, A., Mahadi, M. R., and Nawi, N. M. (2019). Energy utilization in major crop cultivation. Energy 173, 1285-1303. doi: 10.1016/j.energy.2019.01.142

Emery, I., Dunn, J., B., Han, J., and Wang, M. (2015). Biomass storage options influence net energy and emissions of cellulosic ethanol. Bioenergy Res. 8, 590-604. doi: 10.1007/s12155-014-9539-0

Ernsting, A. (2017). HVO Aviation biofuels: How ICAO and industry plans for 'sustainable alternative aviation fuels' could lead to planes flying on palm oil. Biofuelwatch, 1-25. Available online at https://www.biofuelwatch.org.uk/wpcontent/uploads/Aviation-biofuels-report.pdf (accessed July 7, 2019)

Escobar, J. C., Lora, E. S., Venturini, O. J., Yáñez, E., Catillo, E. F., and Almazan, O. (2009). Biofuels: environment, technology and food security. Renew. Sustain. Energy Rev. 13, 1275-1287. doi: 10.1016/j.rser.2008.08.014

Fabio, E. S., and Smart, L. B. (2018). Effects of nitrogen fertilization in shrub willow short rotation coppice production - a quantitative review. GCB Bioenergy 10, 548-564. doi: $10.1111 /$ gcbb. 12507

FAO (2014). Developing Sustainable Food Value Chains - Guiding Principles. Rome: Food and Agriculture Organization of the United Nations (FAO), 1-75. Available online at http://www.fao.org/3/a-i3953e.pdf (accessed June 22, 2019).

Fazio, S., and Barbanti, L. (2014). Energy and economic assessments of bio-energy systems based on annual and perennial crops for temperate and tropical areas. Renew. Energy 69, 233-241. doi: 10.1016/j.renene.2014.03.045

Ferreira, V., Boyero, L., Calvo, C., Correa, F., Figueroa, R., Gonçalves, J. F. Jr., et al. (2019). A global assessment of the effects of eucalyptus plantations on stream ecosystem functioning. Ecosystems 22, 629-642. doi: 10.1007/s10021-018-0292-7

Fischer, M., Zenone, T., Trnka, M., Orság, M., Montagnani, L., Ward, E., et al. (2018). Water requirements of short rotation poplar coppice: experimental and modelling analyses across Europe. Agric. For. Meteorol. 251, 343-360. doi: 10.1016/j.agrformet.2017.12.079

Fleming, J. S., Habibi, S., and MacLean, H. L. (2006). Investigating the sustainability of lignocellulose-derived fuels for light-duty vehicles. Transport. Res. Part D Transp. Environ. 11, 146-159. doi: 10.1016/j.trd.2006.01.001

Folkedahl, B. C., Snyder, A. C., Strege, J. R., Bjorgaard, S. (2011). Process development and demonstration of coal and biomass indirect liquefaction to synthetic iso-paraffinic kerosene. Fuel Process. Technol. 92, 1939-1945. doi: 10.1016/j.fuproc.2011.05.013

Fontoura, C. F., Brandão, L. E., and Gomes, L. L. (2015). Elephant grass biorefineries: towards a cleaner Brazilian energy matrix? J. Clean. Prod. 96, 85-93. doi: 10.1016/j.jclepro.2014.02.062

Frederix, M., Mingardon, F., Hu, M., Sun, N., Pray, T., Singh, S., et al. (2016). Development of an: E. coli strain for one-pot biofuel production from ionic liquid pretreated cellulose and switchgrass. Green Chem. 18, 4189-4197. doi: 10.1039/C6GC00642F

Ganguly, I., Pierobon, F., Bowers, T., C., Huisenga, M., Johnston, G., Eastin, I. L. (2018). 'Woods-to-Wake' life cycle assessment of residual woody biomass based jet-fuel using mild bisulfite pretreatment. Biomass Bioenergy 108, 207-216. doi: 10.1016/j.biombioe.2017.10.041

Gegg, P., Budd, L., and Ison, S. (2014). The market development of aviation biofuel: drivers and constraints. J. Air
Transport Manage. 39, 34-40. doi: 10.1016/j.jairtraman.2014 03.003

Geleynse, S., Brandt, K., Garcia-Perez, M., Wolcott, M., and Zhang, X. (2018). the alcohol-to-jet conversion pathway for drop-in biofuels: technoeconomic evaluation. ChemSusChem 11, 3728-3741. doi: 10.1002/cssc.2018 01690

Giudicianni, P., Pindozzi, S., Grottola, C. M., Stanzione, F., Faugno, S., Fagnano, M., et al. (2017). Pyrolysis for exploitation of biomasses selected for soil phytoremediation: characterization of gaseous and solid products. Waste Manage. 61, 288-299. doi: 10.1016/j.wasman.2017.01.031

Gold, S., and Seuring, S. (2011). Supply chain and logistics issues of bio-energy production. J. Clean. Prod. 19, 32-42. doi: 10.1016/j.jclepro.2010.08.009

Gonzales, D., Searcy, E. M., and Ekşioglu, S. D. (2013). Cost analysis for highvolume and long-haul transportation of densified biomass feedstock. Transport. Res. Part A Policy Pract. 49, 48-61. doi: 10.1016/j.tra.2013.01.005

Gonzalez, R., Phillips, R., Saloni, D., Jameel, H., Abt, R., Pirraglia, A., et al. (2011a). Biomass to energy in the Southern United States: supply chain and delivered cost. Bioresources 6, 2954-2976. Available online at: https://ojs.cnr.ncsu. edu/index.php/BioRes/article/view/BioRes_06_3_2954_Gonzalez_PJAPSW_ Biomass_Energy_South_US_Supply_Chain/1056 (accessed August 6, 2019).

Gonzalez, R., Treasure, T., Phillips, R., Jameel, H., Saloni, D., Abt, R.,et al. (2011b). Converting Eucalyptus biomass into ethanol: financial and sensitivity analysis in a co-current dilute acid process. Part II. Biomass Bioenergy 35, 767-772. doi: 10.1016/j.biombioe.2010.10.025

Gonzalez, R., Treasure, T., Wright, J., Saloni, D., Phillips, R., Abt, R., and Jameel, H. (2011c). Exploring the potential of Eucalyptus for energy production in the Southern United States: Financial analysis of delivered biomass. Part, I. Biomass Bioenergy 35, 755-766. doi: 10.1016/j.biombioe.2010.10.011

Gray, D., White, C., and Tomlinson, G. (2007). Increasing Security and Reducing Carbon Emissions of the US Transportation Sector: A Transformational Role for Coal With Biomass. Albany, OR: National Energy Technology Laboratory; U.S. Department of Energy, 1-69. Available online at http://www. canadiancleanpowercoalition.com/pdf/CLS1\%20-\%20NETL-AF\%2520CBTL \%2520Study\%2520Final\%25202007\%2520Aug\%252024.pdf (accessed April 2, 2019).

Green Car Congress (2016). ASTM Ballot Greenlights Approval of ATJ-SPK Biojet from Alcohol; Gevo 1st Commercial Test Flight with Alaska Airlines. Available online at: https://www.greencarcongress.com/2016/03/20160329-atjspk.html (accessed July 20, 2019).

Güell, B. M., Bugge, M., Kempegowda, R. S., George, A., and Paap, S. (2012). Benchmark of Conversion and Production Technologies for Synthetic Biofuels for Aviation. SINTEF Energy Research, 1-93. Available online at http://www. flygreenfund.se/wp-content/uploads/2015/05/Benchmark-of-conversionand-production-technologies-for-synthetic-biofuels-for-aviation-Sintef2013.pdf (accessed August 31, 2018).

Gutiérrez-Antonio, C., Gómez-Castro, F. I., de Lira-Flores J. A., and Hernández, S. (2017). A review on the production processes of renewable jet fuel. Renew. Sustain. Energy Rev. 79, 709-729. doi: 10.1016/j.rser.2017.05.108

Gutiérrez-Antonio, C., Israel Gómez-Castro, F., Segovia-Hernández, J. G., and Briones-Ramírez, A. (2013). "Simulation and optimization of a biojet fuel production process," in Computer Aided Chemical Engineering, eds A. Kraslawski and I. Turunen (Amsterdam: Elsevier B.V), 13-18. doi: 10.1016/B978-0-444-63234-0.50003-8

Han, S. H., Cho, D. H., Kim, Y. H., and Shin, S. J. (2013). Biobutanol production from 2-year-old willow biomass by acid hydrolysis and acetonebutanol-ethanol fermentation. Energy 61, 13-17. doi: 10.1016/j.energy.2013. 04.069

Harahap, F., Leduc, S., Mesfun, S., Khatiwada, D., Kraxner, F., and Silveira, S. (2019). Opportunities to optimize the palm oil supply chain in Sumatra, Indonesia. Energies 12:420. doi: 10.3390/en12030420

Harsono, S. S., Grundmann, P., and Soebronto, S. (2014). Anaerobic treatment of palm oil mill effluents: potential contribution to net energy yield and reduction of greenhouse gas emissions from biodiesel production. J. Clean. Prod. 64, 619-627. doi: 10.1016/j.jclepro.2013.07.056

He, C. R., Kuo, Y. Y., and Li, S. Y. (2017). Lignocellulosic butanol production from Napier grass using semi-simultaneous saccharification fermentation. Bioresour. Technol. 231, 101-108. doi: 10.1016/j.biortech.2017. 01.039 
Heinrich, G. (2018). “Jatropha curcas L. - An Alternative Oil Crop," in Biokerosene: Status and Prospects, eds M. Kaltschmitt and U. Neuling (Berlin; Heidelberg: Springer), 237-257. doi: 10.1007/978-3-662-53065-8_11

Hemighaus, G., Boval, T., Bacha, J., Barnes, F., Franklin, M., Gibbs, L., et al. (2006). Aviation Fuels Technical Review, 1-89. Available online at https://www. cgabusinessdesk.com/document/aviation_tech_review.pdf (accessed March 3, 2019)

Hendricks, R. C., Bushnell, D. M., and Shouse, D., T. (2011). Aviation fueling: a cleaner, greener approach. Int. J. Rotat. Mach. 2011:782969. doi: $10.1155 / 2011 / 782969$

Herr, A., O'Connell, D., Farine, D., Dunlop, M., Crimp, S., and Poole, M. (2012). Watching grass grow in Australia: is there sufficient production potential for a biofuel industry? Biofuels Bioprod. Bioref. 6, 257-268. doi: 10.1002/bbb.1321

Hickman, G. C., Vanloocke, A., Dohleman, F. G., and Bernacchi, C. J. (2010). A comparison of canopy evapotranspiration for maize and two perennial grasses identified as potential bioenergy crops. GCB Bioenergy 2, 157-168. doi: $10.1111 / j .1757-1707.2010 .01050 . x$

Howe, D., Westover, T., Carpenter, D., Santosa, D., Emerson, R., Deutch, S., et al. (2015). Field-to-fuel performance testing of lignocellulosic feedstocks: an integrated study of the fast pyrolysis-hydrotreating pathway. Energy Fuels 29, 3188-3197. doi: 10.1021/acs.energyfuels.5b0 0304

Huber, G. W., O'Connor, P., and Corma, A. (2007). Processing biomass in conventional oil refineries: production of high quality diesel by hydrotreating vegetable oils in heavy vacuum oil mixtures. Appl. Catal. A Gen. 329, 120-129. doi: $10.1016 /$ j.apcata.2007.07.002

Huzir, N. M., Aziz, M. M. A., Ismail, S. B., Abdullah, B., Nik Mahmood, N. A. B., Umor, N. A. M., et al. (2018). Agro-industrial waste to biobutanol production: eco-friendly biofuels for next generation. Renew. Sustain. Energy Rev. 94, 476-485. doi: 10.1016/j.rser.2018.06.036

Iakovou, E., Karagiannidis, A., Vlachos, D., Toka, A., and Malamakis, A. (2010). Waste biomass-to-energy supply chain management: a critical synthesis. Waste Manage. 30, 1860-1870. doi: 10.1016/j.wasman.2010.02.030

IATA (2009). World Business Summit on Climate Change. Copenhagen. Available online at: https://www.iata.org/pressroom/speeches/Pages/2009-05-24-01.aspx (accessed July 24, 2019).

ICAO (2009). US Fuel Trends Analysis and Comparison to GIACC/4IP/1. Montreal, QC: International Civil Aviation Organization (ICAO), 1-10. Available online at http://web.mit.edu/aeroastro/partner/reports/proj28/ fueltrend-analy.pdf (accessed July 31, 2019).

Jacobson, M. (2013a). NEWBio Energy Crop Profile: Giant Miscanthus. Available online at: https://extension.psu.edu/newbio-energy-crop-profile- giantmiscanthus (accessed July 19, 2019).

Jacobson, M. (2013b). NEWBio Energy Crop Profile: Switchgrass. Available online at: https://extension.psu.edu/newbio-energy-crop-profile-switchgrass (accessed July 19, 2019).

Jacobson, R., Keefe, R., F., Smith, A. M. S., Metlen, S., Saul, D., Newman, S. N., et al. (2016). Multi-spatial analysis of forest residue utilization for bioenergy. Biofuels Bioprod. Bioref. 10, 560-575. doi: 10.1002/bbb.1659

Jayaraman, K., and Gökalp, I. (2015). Pyrolysis, combustion and gasification characteristics of miscanthus and sewage sludge. Energy Convers. Manage. 89, 83-91. doi: 10.1016/j.enconman.2014.09.058

Jiang, W., Jacobson, M., G., and Langholtz, M., H. (2019). A sustainability framework for assessing studies about marginal lands for planting perennial energy crops. Biofuels Bioprod. Bioref. 13, 228-240. doi: 10.1002/bbb.1948

Jiménez-Díaz, L., Caballero, A., Pérez-Hernández, N., and Segura, A. (2017). Microbial alkane production for jet fuel industry: motivation, state of the art and perspectives. Microb. Biotechnol. 10, 103-124. doi: 10.1111/1751-7915.12423

Kaewmai, R. H., Kittikun, A., and Musikavong, C. (2012). Greenhouse gas emissions of palm oil mills in Thailand. Int. J. Greenhouse Gas Control 11, 141-151. doi: 10.1016/j.ijggc.2012.08.006

Kainer, D., and Kulheim, C. (2016). Renewable Jet Fuel Could be Growing on Australia's Iconic Gum Trees. Available online at: https://theconversation.com/ renewable-jet-fuel-could-be-growing-on-australias-iconic-gum- trees-59377 (accessed July 23, 2019).

Kalnes, T. M. T., Shonnard, D. R., and Koers, K. P. (2011). Green diesel production by hydrorefining renewable feedstocks. Biofuels Technol. 4, 7-11.Available online at: https://www.honeywell-uop.cn/wp-content/uploads/2011/01/UOPHydrorefining-Green-Diesel-Tech-Paper.pdf (accessed July 30, 2019).

Kandaramath Hari, T., Yaakob, Z., and Binitha, N. N. (2015). Aviation biofuel from renewable resources: routes, opportunities and challenges. Renew. Sustain. Energy Rev. 42, 1234-1244. doi: 10.1016/j.rser.2014.10.095

Karlen, D. L., Schmer, M. R., Kaffka, S., Clay, D. E., Wang, M. Q., Horwoth, W. R., et al. (2019). Unraveling crop residue harvest effects on soil organic carbon. Agron. J. 111, 93-98. doi: 10.2134/agronj2018.03.0207

Karmee, S. K. (2017). Fuel not food-towards sustainable utilization of gutter oil. Biofuels 8, 339-346. doi: 10.1080/17597269.2016.1231952

Keefe, Z. (2013). Industrial Hygiene - What Is Soot and Why Is It Dangerous? Available online at: http://blog.cashins.com/blog-0/bid/191511/IndustrialHygiene-What-is-Soot-and-Why-is-it-Dangerous (accessed April 4, 2019).

Keles, D., Choumert-Nkolo, J., Combes Motel, P., and Nazindigouba Kéré, E. (2018). Does the expansion of biofuels encroach on the forest? J. For. Econ. 33, 75-82. doi: 10.1016/j.jfe.2018.11.001

Khatun, R., Reza, M. I. H., Moniruzzaman, M., and Yaakob, Z. (2017). Sustainable oil palm industry: the possibilities. Renew. Sustain. Energy Rev. 76, 608-619. doi: 10.1016/j.rser.2017.03.077

Khezri, R., Ghani, W. A. A. K., Biak, D. R. A., Yunus, R., and Silas, K. (2019). Experimental evaluation of napier grass gasification in an autothermal bubbling fluidized bed reactor. Energies 12:1517. doi: 10.3390/en12081517

Klein, B. C., Chagas, M. F., Junqueira, T. L., Rezende, M. C. A., de Fatima Cardoso, T., Cavalett, O., et al. (2018). Techno-economic and environmental assessment of renewable jet fuel production in integrated Brazilian sugarcane biorefineries. Appl. Energy 209, 290-305. doi: 10.1016/j.apenergy.2017.10.079

Klinghoffer, N. (2013). Utilization of char from biomass gasification in catalytic applications (Ph.D. thesis). Columbia University, New York, NY, United States, 127. Available online at http://www.seas.columbia.edu/earth/wtert/newwtert/ Research/sofos/Klinghoffer_PhD__an.pdf (accessed July 30, 2019).

Ko, S., Lautala, P., and Handler, R. M. (2018). Securing the feedstock procurement for bioenergy products: a literature review on the biomass transportation and logistics. J. Clean. Prod. 200: 205-218. doi: 10.1016/j.jclepro.2018.07.241

Koh, L. P., and Wilcove, D. S. (2008). Is oil palm agriculture really destroying tropical biodiversity? Conserv. Lett. 1, 60-64. doi: 10.1111/j.1755-263X.2008.00011.x

Kolodziej, R., and Scheib, J. (2012). Bio-isobutanol: The Next-Generation Biofuel. 79-85. Available online at https://www.hydrocarbonprocessing.com/magazine/ 2012/september-2012/special-report-refining-developments/bio-isobutanolthe-next-generation-biofuel

KPMG International (2013). The Agricultural and Food Value Chain: Entering a New Era of Cooperation, 1-39. Available online at https://assets.kpmg/content/ dam/kpmg/pdf/2013/06/agricultural-and-food-value-chain-v2.pdf (accessed July 25, 2019)

Lamb, M. C., Anderson, W. F., Strickland, T. C., Coffin, A., Sorenson, R. B., Knoll, J. E., et al. (2018). Economic competitiveness of napier grass in irrigated and nonirrigated georgia coastal plain cropping systems. Bioenergy Res. 11, 574-582. doi: 10.1007/s12155-018-9916-1

LanzaTech (2018). UK Government Grant to Develop World First Waste Carbon to Jet Fuel Project. LanzaTech. Available online at: http://www.lanzatech.com/ lanzatech-virgin-atlantic-secure-uk-government-grant-develop-world-firstwaste-carbon-jet-fuel-project-uk/ (accessed April 6, 2019)

Lask, J., Wagner, M., Trindade, L. M., and Lewandowski, I. (2019). Life cycle assessment of ethanol production from miscanthus: a comparison of production pathways at two European sites. GCB Bioenergy 11, 269-288. doi: $10.1111 /$ gcbb.12551

Lee, R. A., and Lavoi, J. M. (2013). From first- to third-generation biofuels: challenges of producing a commodity from a biomass of increasing complexity. Anim. Front. 3, 6-11. doi: 10.2527/af.2013-0010

Lee, W. C., and Kuan, W. C. (2015). Miscanthus as cellulosic biomass for bioethanol production. Biotechnol. J. 10, 840-854. doi: 10.1002/biot.201400704

Lemus, R. (2009). Hay Storage: Dry Matter Losses and Quality Changes. Mississippi State University, $1-8$. Available online at Hay_Storage_DM_Losses_MissSt.pdf (accessed August 12, 2019).

Lewis, K. C., Newes, E. K., Peterson, S. O., Pearlson, M. N., Lawless, E. A., Camenzind, D., et al. (2019). US alternative jet fuel deployment scenario analyses identifying key drivers and geospatial patterns for the first billion gallons. Biofuels Bioprod. Bioref. 13, 471-485. doi: 10.1002/bbb.1951 
Liati, A., Schreiber, D., Alpert, P. A., Liao, Y., Brem, B., Arrayo, P. C., et al. (2019). Aircraft soot from conventional fuels and biofuels during ground idle and climb-out conditions: electron microscopy and X-ray micro-spectroscopy. Environ. Pollut. 247, 658-667. doi: 10.1016/j.envpol.2019.01.078

Liu, G., Yan, B., and Chen, G. (2013). Technical review on jet fuel production. Renew. Sustain. Energy Rev. 25, 59-70. doi: 10.1016/j.rser.2013. 03.025

Liu, W., Wu, J., Fan, H., Duan, H., Li, Q., Yuan, Y., et al. (2017). Estimations of evapotranspiration in an age sequence of Eucalyptus plantations in subtropical China. PLoS ONE 12:e0174208. doi: 10.1371/journal.pone.0174208

Liu, X., Zhang, S., and Bae, J. (2017). The nexus of renewable energyagriculture-environment in BRICS. Appl. Energy 204, 489-496. doi: 10.1016/j.apenergy.2017.07.077

Lobo, P., Hagen, D. E., and Whitefield, P. D. (2011). Comparison of PM emissions from a commercial jet engine burning conventional, biomass, and fischertropsch fuels. Environ. Sci. Technol. 45, 10744-10749. doi: 10.1021/es201902e

Madaki, Y. S., and Seng, L. (2013). Palm oil mill effluent (POME) from Malaysia palm oil mills: waste or resource. Int. J. Sci. Environ. Technol. 2, 1138-1155.

Mandolesi de Araújo, C. D., de Andrade, C. C., de Souza e Silva, E., and Dupas, F. A. (2013). Biodiesel production from used cooking oil: a review Renew. Sustain. Energy Rev. 27, 445-452. doi: 10.1016/j.rser.2013.06.014

Martinkus, N., Latta, G., Brandt, K., and Wolcott, M. (2018). A multicriteria decision analysis approach to facility siting in a wood-based depot-and-biorefinery supply chain model. Front. Energy Res. 6:124. doi: 10.3389/fenrg.2018.00124

Masimalai, S., and Subramaniyan, A. (2017). An experimental assessment on the influence of high octane fuels on biofuel based dual fuel engine performance, emission, and combustion. Ther. Sci. 21, 523-534. doi: 10.2298/TSCI161110323M

Mathioudakis, V., Gerbens-Leenes, P. W., van der Meer T. H., and Hoekstra, A. Y. (2017). The water footprint of second-generation bioenergy: a comparison of biomass feedstocks and conversion techniques. J. Clean. Prod. 148, 571-582. doi: 10.1016/j.jclepro.2017.02.032

Mawhood, R., Gazis, E., de Jong, S., Hoefnagels, R., and Slade, R. (2016). Production pathways for renewable jet fuel: a review of commercialization status and future prospects. Biofuels Bioprod. Bioref. 10, 462-484. doi: $10.1002 /$ bbb. 1644

McIsaac, G. F. (2014). Biomass production and water: a brief review of recent research. Curr. Sustain. Renew. Energy Rep. 1, 157-161. doi: 10.1007/s40518-014-0016-3

Mesfun, S., Sanchez, D. L., Leduc, S., Wetterlund, E., Lundgren, J., Biberacher, M., et al. (2017). Power-to-gas and power-to-liquid for managing renewable electricity intermittency in the Alpine Region. Renew. Energy 107, 361-372. doi: 10.1016/j.renene.2017.02.020

Michailos, S. (2018). Process design, economic evaluation and life cycle assessment of jet fuel production from sugar cane residue. Environ. Prog. Sustain. Energy 37, 1227-1235. doi: 10.1002/ep.12840

Mielke, T. (2018). "World markets for vegetable oils and animal fats," in Biokerosene: Status and Prospects, eds M. Kaltschmitt and U Neuling (Berlin; Heidelberg: Springer), 147-188. doi: 10.1007/978-3-662-53065-8_8

Miettinen, I., Kuittinen, S., Paasikallio, V., Mäkinen, M., Pappinen, A., and Jänis, J. (2017). Characterization of fast pyrolysis oil from short-rotation willow by high-resolution Fourier transform ion cyclotron resonance mass spectrometry. Fuel 207, 189-197. doi: 10.1016/j.fuel.2017.06.053

Millinger, M., Ponitka, J., Arendt, O., and Thrän, D. (2017). Competitiveness of advanced and conventional biofuels: results from least-cost modelling of biofuel competition in Germany. Energy Policy 107, 394-402. doi: 10.1016/j.enpol.2017.05.013

Mohammed, I. Y., Abakr, Y. A., and Mokaya, R. (2019). Integrated biomass thermochemical conversion for clean energy production: process design and economic analysis. J. Environ. Chem. Eng. 7:103093. doi: 10.1016/j.jece.2019.103093

Mohseni, S., and Pishvaee, M. S. (2016). A robust programming approach towards design and optimization of microalgae-based biofuel supply chain. Comput. Ind. Eng. 100, 58-71. doi: 10.1016/j.cie.2016.08.003

Moioli, E., Salvati, F., Chiesa, M., Siecha, R. T., Manenti, F., Laio, F., et al. (2018). Analysis of the current world biofuel production under a water-food-energy nexus perspective. Adv. Water Resour. 121, 22-31. doi: 10.1016/j.advwatres.2018.07.007

Molefe, M., Nkazi, D., and Mukaya, H. E. (2019). Method selection for biojet and biogasoline fuel production from castor oil: a review. Energy Fuels 33, 5918-5932. doi: 10.1021/acs.energyfuels.9b00384

MPOB (2010). Recommended Practices for Storage and Transport of Edible Oils and Fats. Washington, DC: Malaysian Palm Oil Board (MPOB), 1-13. Available online at http://www.palmoilworld.org/PDFs/Storage.pdf (accessed Septemeber 12, 2019).

Murdiyarso, D. K., Hergoualc', H. L., and Verchot, V. (2010). Opportunities for reducing greenhouse gas emissions in tropical peatlands. Proc. Natl. Acad. Sci. U.S.A. 107, 19655-19660. doi: 10.1073/pnas.091196 6107

Murphy, H. T., O’Connell, D. A., Raison, R. J., Warden, A., Booth, T. H., Her, A., et al. (2015). Biomass production for sustainable aviation fuels: a regional case study in Queensland. Renew. Sustain. Energy Rev. 44, 738-750. doi: 10.1016/j.rser.2015.01.012

Neslen, A. (2016). BA Blames UK Government for Scrapping of £340m Green Fuels Project. Available online at: https://www.theguardian.com/environment/ 2016/jan/06/ba-blames-uk-government-for-scrapping-of-340m-green-fuelsproject (accessed April 4, 2019).

Neuling, U., and Kaltschmitt, M. (2018). "Biokerosene from vegetable oils - technologies and processes," in Biokerosene: Status and Prospects, eds M. Kaltschmitt and U. Neuling (Berlin; Heidelberg: Springer), 475-496. doi: 10.1007/978-3-662-53065-8_19

Newes, E. K., Bush, B. W., Peck, C. T., and Peterson, S. (2015). Potential leverage points for development of the cellulosic ethanol industry supply chain. Biofuels 6, 21-29. doi: 10.1080/17597269.2015.1039452

Nguyen, D. D., Dharmaraja, J., Shobana, S., Sundaram, A., Chang, S. W., Kumar, G., et al. (2019). Transesterification and fuel characterization of rice bran oil: a biorefinery path. Fuel 253, 975-987. doi: 10.1016/j.fuel.2019.05.063

Nicodème, T., Berchem, T., Jacquet, N., and Richel, A. (2018). Thermochemical conversion of sugar industry by-products to biofuels. Renew. Sustain. Energy Rev. 88, 151-159. doi: 10.1016/j.rser.2018.02.037

O'Connell, A., Kousoulidou, M., Lonza, L., and Weindorf, W. (2019). Considerations on GHG emissions and energy balances of promising aviation biofuel pathways. Renew. Sustain. Energy Rev. 101, 504-515. doi: 10.1016/j.rser.2018.11.033

Oladosu, G., and Msangi, S. (2013). Biofuel-food market interactions: a review of modeling approaches and findings. Agriculture 3, 53-71. doi: 10.3390/agriculture3010053

Ondrey, G. (2012). Chementator: demo plant for high-yield biomass-togasoline process under construction. Chem. Eng. 119:9. Available online at: http://libproxy.bath.ac.uk/login?url=https://search.proquest.com/docview/ 917785288? accountid=17230 (accessed July 19, 2019).

Page, S. E., Morrison, R., Malins, C., Hooijer, A., and Rieley, J. O. (2011). Review of Peat Surface GHG Emissions From Oil Palm Plantations in Southeast Asia. Washington, DC: International Council on Clean Transportation, 1-77. Available online at https://theicct.org/sites/default/files/publications/ICCT_ Peat-Emissions_Sept2011.pdf (accessed July 13, 2019).

Pandey, V. C., Bajpai, O., and Singh, N. (2016). Energy crops in sustainable phytoremediation. Renew. Sustain. Energy Rev. 54, 58-73. doi: 10.1016/j.rser.2015.09.078

Pandiyan, K., Singh, A., Singh, S., Saxena, A., K., and Nain, L. (2019). Technological interventions for utilization of crop residues and weedy biomass for second generation bio-ethanol production. Renew. Energy 132, 723-741. doi: 10.1016/j.renene.2018.08.049

Pedroli, B., Elbersen, B., Frederiksen, P., Grandin, U., Heikkilä, R., Krogh, P., et al. (2013). Is energy cropping in Europe compatible with biodiversity? - Opportunities and threats to biodiversity from land-based production of biomass for bioenergy purposes. Biomass Bioenergy 55, 73-86. doi: 10.1016/j.biombioe.2012.09.054

Perkis, D. F., and Tyner, W. E., (2018). Developing a cellulosic aviation biofuel industry in Indiana: a market and logistics analysis. Energy 142, 793-802. doi: 10.1016/j.energy.2017.10.022

Pham, V., Holtzapple, M., and El-Halwagi, M. (2010). Techno-economic analysis of biomass to fuel conversion via the MixAlco process. J. Ind. Microbiol. Biotechnol. 37, 1157-1168. doi: 10.1007/s10295-010-0763-0 
Pimentel, D. (2009). Energy inputs in food crop production in developing and developed nations. Energies 2:1. doi: 10.3390/en2010 0001

Pirker, J., Mosnier, A., Kraxner, F., Havlík, P., and Obersteiner, M. (2016). What are the limits to oil palm expansion? Glob. Environ. Change 40, 73-81. doi: 10.1016/j.gloenvcha.2016.06.007

Popov, S., and Kumar, S. (2013). Renewable fuels via catalytic hydrodeoxygenation of lipid-based feedstocks. Biofuels 4, 219-239. doi: 10.4155/bfs.12.89

Popp, J., Lakner, Z., Harangi-Rákos, M., and Fári, M. (2014). The effect of bioenergy expansion: Food, energy, and environment. Renew. Sustain. Energy Rev. 32, 559-578. doi: 10.1016/j.rser.2014.01.056

Quarton, C. J., and Samsatli, S. (2018). Power-to-gas for injection into the gas grid: what can we learn from real-life projects, economic assessments and systems modelling? Renew.Sustain. Energy Rev. 98, 302-316. doi: 10.1016/j.rser.2018.09.007

Radich, T. (2015). The Flight Paths for Biofuel. Washington, DC: U.S. Energy Information Administration, 1-17.

Raje, A. P., and Davis, B. H. (1997). Fischer-Tropsch synthesis over iron-based catalysts in a slurry reactor. reaction rates, selectivities and implications for improving hydrocarbon productivity. Catal. Today 36, 335-345. doi: 10.1016/S0920-5861(96)00245-3

Rathmann, R., Szklo, A., and Schaeffer, R. (2010). Land use competition for production of food and liquid biofuels: an analysis of the arguments in the current debate. Renew. Energy 35, 14-22. doi: 10.1016/j.renene.2009.02.02

Ravi, V., Gao, A., H., Martinkus, N., B., Wolcott, M., and Lamb, B. K. (2018). Air quality and health impacts of an aviation biofuel supply chain using forest residue in the Northwestern United States. Environ. Sci. Tech. 52, 4154-4162. doi: 10.1021/acs.est.7b04860

Reimer, J. J., and Zheng, X. (2017). Economic analysis of an aviation bioenergy supply chain. Renew. Sustain. Energy Rev. 77, 945-954. doi: 10.1016/j.rser.2016.12.036

Rentizelas, A. A., Tolis, A. J., and Tatsiopoulos, I. P. (2009). Logistics issues of biomass: the storage problem and the multi-biomass supply chain. Renew. Sustain. Energ. Rev. 13, 887-894. doi: 10.1016/j.rser.2008.01.003

Richter, S., Braun-Unkhoff, M., Naumann, C., and Riedel, U. (2018). Paths to alternative fuels for aviation. CEAS Aeronaut. J. 9, 389-403. doi: 10.1007/s13272-018-0296-1

Rocca, S., Agostini, A., Giuntoli, J., and Marelli, L. (2015). Biofuels From Algae: Technology Options, Energy Balance and GHG Emissions: Insights From a Literature Review. Brussels: European Union, 83.

Roda, J.-M., Goralski, M., Benoist, A., Baptiste, A., Boudjema, V., Galanos, T., et al. (2015). Sustainability of Bio-jetfuel in Malaysia. Paris: Centre of International Cooperation in Agronomy Research for Development (CIRAD). Available online at https://agritrop.cirad.fr/577269/7/577269.pdf

Rödl, A. (2018). "Lignocellulosic Biomass," in Biokerosene: Status and Prospects, eds M. Kaltschmitt and U. Neuling (Berlin; Heidelberg: Springer), 189-220.

Roth, A., Riegel, F., and Batteiger, V. (2018). "Potentials of biomass and renewable energy: the question of sustainable availability," in Biokerosene: Status and Prospects, eds M. Kaltschmitt and U. Neuling (Berlin; Heidelberg: Springer), 95-122.

Ruttens, A., Boulet, J., Weyens, N., Smeets, K., Adriaensen, K., Meers, E., et al. (2011). Short rotation coppice culture of willows and poplars as energy crops on metal contaminated agricultural soils. Int. J. Phytoremed. 13(Suppl. 1), 194-207. doi: $10.1080 / 15226514.2011 .568543$

Rye, L., Blakey, S., and Wilson, C., W. (2010). Sustainability of supply or the planet: A review of potential drop-in alternative aviation fuels. Energy Environ. Sci. 3, 17-27. doi: 10.1039/B918197K

Samsatli, S., and Samsatli, N. J. (2018a). A general mixed integer linear programming model for the design and operation of integrated urban energy systems. J. Clean. Prod. 191, 458-479. doi: 10.1016/j.jclepro.2018.04.198

Samsatli, S., and Samsatli, N. J. (2018b). A multi-objective MILP model for the design and operation of future integrated multi-vector energy networks capturing detailed spatio-temporal dependencies. Appl. Energy 220, 893-920. doi: 10.1016/j.apenergy.2017.09.055

Samsatli, S., and Samsatli, N. J. (2019). The role of renewable hydrogen and inter-seasonal storage in decarbonising heat - Comprehensive optimisation of future renewable energy value chains. Appl. Energy 233-234, 854-893. doi: 10.1016/j.apenergy.2018.09.159
Samsatli, S., Samsatli, N. J., and Shah, N. (2015). BVCM: a comprehensive and flexible toolkit for whole system biomass value chain analysis and optimisation - Mathematical formulation. Appl. Energy 147, 131-160. doi: 10.1016/j.apenergy.2015.01.078

Samsatli, S., Staffell I., and Samsatli, N. J. (2016). Optimal design and operation of integrated wind-hydrogen-electricity networks for decarbonising the domestic transport sector in Great Britain. Int. J. Hydrogen Energy 41, 447-475. doi: 10.1016/j.ijhydene.2015.10.032

Sannan, S., Jordal, K., Roussanaly, S., Giraldi, C., and Clapis, A. (2017). Understanding the Cost of Retrofitting $\mathrm{CO} 2$ Capture in an Integrated Oil Refinery, Reference Base Case Plants: Economic Evaluation. Trondheim: SINTEF Energy Research, 1-16. Available online at https://www.sintef. no/globalassets/project/recap/deliverable-d3_reference-plants-economicevaluation_final_code.pdf (accessed March 17, 2020).

Sassner, P., Galbe, M., and Zacchi, G. (2006). Bioethanol production based on simultaneous saccharification and fermentation of steam-pretreated Salix at high dry-matter content. Enzyme Microb. Technol. 39, 756-762. doi: 10.1016/j.enzmictec.2005.12.010

Scagline-Mellor, S., Griggs, T., Skousen, J., Wolfrum, E., and Holásková, I. (2018). Switchgrass and giant miscanthus biomass and theoretical ethanol production from reclaimed mine lands. Bioenergy Res. 11, 562-573. doi: 10.1007/s12155-018-9915-2

Schmidt, P., Batteiger, V., Roth, A., Weindorf, W., and Raksha, T. (2018). Powerto-liquids as renewable fuel option for aviation: a review. Chem. Ing. Tech. 90, 127-140. doi: 10.1002/cite.201700129

Schmitt, N., Apfelbacher, A., Jäger, N., Daschner, R., Stenzel, F., and Hornung, A. (2019). Thermo-chemical conversion of biomass and upgrading to biofuel: the thermo-catalytic reforming process - a review. Biofuel Bioprod. Biorg. 13, 822-837. doi: 10.1002/bbb.1980

Schoneveld, G. C. (2010). "Potential land use competition from first-generation biofuel expansion in developing countries," in CIFOR Occasional Paper (Bogor: Center for International Forestry Research (CIFOR)), 1-21. Available online at https://www.cifor.org/publications/pdf_files/OccPapers/OP-58.pdf (accessed May 15, 2019).

Searle, S. Y., and Malins, C. J. (2014). |Will energy crop yields meet expectations? Biomass Bioenerg. 65, 3-12. doi: 10.1016/j.biombioe.2014.01.001

Seber, G., Malina, R., Pearlson, M. N., Olcay, H., Hileman, J., and Barrett, S. R. H. (2014). Environmental and economic assessment of producing hydroprocessed jet and diesel fuel from waste oils and tallow. Biomass Bioenerg. 67, 108-118. doi: 10.1016/j.biombioe.2014.04.024

Shah, Z., Veses, R. C., Vaghetti, J. C. P., Amorim, V., and da Silva, R. (2019). Preparation of jet engine range fuel from biomass pyrolysis oil through hydrogenation and its comparison with aviation kerosene. Int. J. Green Energ. 16, 350-360. doi: 10.1080/15435075.2019.1566730

Shahare, V. V., Kumar, B., and Singh, P. (2017). "Biofuels for sustainable development: a global perspective," in Green Technologies and Environmental Sustainability, eds M. R. Riazi and D. Chiaramonti (Springer International Publishing), 67-89. doi: 10.1007/978-3-319-50654-8_3

Sharif, M. K., Butt, M., S., Anjum, F., M., Khan, S. (2014). Rice bran: a novel functional ingredient. Crit. Rev. Food Sci. Nutr. 54, 807-816. doi: $10.1080 / 10408398.2011 .608586$

Shastri, Y., and Ting, K., C. (2014). "Biomass feedstock production and provision: overview, current status, and challenges," in Engineering and Science of Biomass Feedstock Production and Provision, eds Y.Shastri, A. Hansen, L. Rodríguez, and K. C. Ting (New York, NY: Springer), 1-15.

Silva Braz, D., and Pinto Mariano, A. (2018). Jet fuel production in eucalyptus pulp mills: economics and carbon footprint of ethanol vs. butanol pathway. Bioresour. Technol. 268, 9-19. doi: 10.1016/j.biortech.2018. 07.102

Sims, J. T., and Maguire, R., O. (2005). "Manure management," in Encyclopedia of Soils in the Environment, ed D. Hillel (Oxford: Elsevier), 402-410.

Sims, R., Flammini, A., Puri, S., and Bracco, S. (2015). Opportunities for AgriFood Chains to Become Energy-Smart. Washington, DC: Food and Agriculture Organization \& United States Agency for International Development, 1-198. Available online at http://www.fao.org/3/a-i5125e.pdf (accessed July 23, 2018).

Sinha, M., Sørensen, A., Ahamed, A., and Ahring, B. K. (2015). Production of hydrocarbons by Aspergillus carbonarius ITEM 5010. Fungal Biol. 119, 274-282. doi: 10.1016/j.funbio.2015.01.001 
Staples, M. D., Malina, R., Suresh, P., Hileman, J. I., and Barrett, S. (2018). Aviation $\mathrm{CO}_{2}$ emissions reductions from the use of alternative jet fuels. Energy Policy 114, 342-354. doi: 10.1016/j.enpol.2017.12.007

Stratton, R. W., Wong, H., M., and Hileman, J., I. (2010). "Life cycle greenhouse gas emissions from alternative jet fuels," in Partnership for Air Transportation Noise and Emissions Reduction Project 28. Cambrige, MA: Massachusetts Institute of Technology, 1-133. Available online at http://web.mit.edu/aeroastro/ partner/reports/proj28/partner-proj28-2010-001.pdf (accessed July 12, 2019).

Su, Y., Song, K., Zhang, P., Su, Y., Cheng, J., and Chen, X. (2017). Progress of microalgae biofuel's commercialization. Renew. Sustain. Energy Rev. 74, 402-411. doi: 10.1016/j.rser.2016.12.078

Su, Y., Zhang, P., and Su, Y. (2015). An overview of biofuels policies and industrialization in the major biofuel producing countries. Renew. Sustain. Energy Rev. 50, 991-1003. doi: 10.1016/j.rser.2015.04.032

Sun, A., Davis, R., Starbuck, M., Ben-Amotz, A., Pate, R., Pienkos, P., et al. (2011). "Comparative cost analysis of algal oil production for biofuels. Energy 36, 5169-5179. doi: 10.1016/j.energy.2011.06.020

Suntivarakorn, R., Treedet, W., Singbua, P., and Teeramaetawat, N. (2018). Fast pyrolysis from napier grass for pyrolysis oil production by using circulating fluidized bed reactor: improvement of pyrolysis system and production cost. Energ. Rep. 4, 565-575. doi: 10.1016/j.egyr.2018.08.004

Suresh, P., Malina, R., Staples, M. D., Lizin, S., Olcay, H., Blazy, D., et al. (2018). Life cycle greenhouse gas emissions and costs of production of diesel and jet fuel from municipal solid waste. Environ. Sci. Technol. 52, 12055-12065. doi: 10.1021/acs.est.7b04277

Surgenor, C. (2018). ASTM Approval of Ethanol-Based Renewable Jet Fuels a Green Light for LanzaTech and Byogy. Avaliable online at: https://www.greenaironline. com/news.php?viewStory=2469 (accessed June 04, 2019).

Surian Ganba, O., Tonello, K. C., García-Leite, H., Burguet, M., Taguas, E., and Teixeria Dias, H. C. (2016). Hydrological balance in a eucalyptus plantation watershed in minas gerais (Brazil). Soil Sci. 181, 347-357. doi: $10.1097 /$ SS.0000000000000163

Susila, W. R. (2004). Contribution of oil palm industry to economic growth and poverty alleviation in Indonesia. J. Penelit. Tanam. Ind. 23, 107-113.

Tao, L., Milbrandt, A., Zhang, Y., and Wang, W. C. (2017). Techno-economic and resource analysis of hydroprocessed renewable jet fuel. Biotechnol. Biofuels 10, 1-16. doi: 10.1186/s13068-017-0945-3

Tao, L., Tan, E. C. D., McCormick, R., Zhang, M., Aden, A., He, X., et al. (2014). Techno-economic analysis and life-cycle assessment of cellulosic isobutanol and comparison with cellulosic ethanol and n-butanol. Biofuel Bioprod. Biorg. 8, 30-48. doi: 10.1002/bbb.1431

Tapia, J. F. D., and Samsatli, S. (2020). Integrating fuzzy analytic hierarchy process into a multi-objective optimisation model for planning sustainable oil palm value chains. Food Bioprod. Process.119, 48-74. doi: 10.1016/j.fbp.2019. 10.002

Tapia, J. F. D., Samsatli, S., Doliente, S., S., Martinez-Hernandez, E., Ghani, W. A., et al. (2019). Design of biomass value chains that are synergistic with the foodenergy-water nexus: strategies and opportunities. Food Bioprod. Process. 116, 170-185. doi: 10.1016/j.fbp.2019.05.006

Taylor, J. D., Jenni, M. M., and Peters, M. W. (2010). Dehydration of fermented isobutanol for the production of renewable chemicals and fuels. Topics Catal. 53, 1224-1230. doi: 10.1007/s11244-010-9567-8

The Engineering ToolBox (2003). US. Standard Atmosphere. Available online at https://www.engineeringtoolbox.com/standard-atmosphere-d_604.html (accessed March 31, 2019).

Trivedi, P., Malina, R., and Barrett, S. R. H. (2015). Environmental and economic tradeoffs of using corn stover for liquid fuels and power production. Energy Environ. Sci. 8, 1428-1437. doi: 10.1039/C5EE00153F

U.S. Energy Information Administration (2018). Biofuels: Ethanol and Biodiesel Explained. Available online at https://www.eia.gov/energyexplained/index. php?page=biofuel_home (accessed April 10, 2019).

Ubando, A. T., Cuello, J. L., El-Halwagi, M. M., Culaba, A., and Tan, R. (2014). "Multi-regional multi-objective optimization of an algal biofuel polygeneration supply chain with fuzzy mathematical programming," in ASME 2014 8th International Conference on Energy Sustainability [Boston, MA; New York, NY: The American Society of Mechanical Engineers (ASME)].
United States Department of Agriculture - Research, Education and Economics (2012). Napiergrass: A Potential Biofuel Crop for the Sunny Southeast. Available online at: https://www.sciencedaily.com/releases/2012/09/120927142524.htm (accessed July 23, 2019).

US EIA (2020). U.S. Gulf Coast Kerosene-Type Jet Fuel Spot Price FOB (Dollars per Gallon). Washington, DC: U.S. Energy Information Administration (US EIA). Available online at https://www.eia.gov/dnav/pet/hist/LeafHandler.ashx? $\mathrm{n}=$ PET\&s=EER_EPJK_PF4_RGC_DPG\&f=M (accessed March 16, 2020).

Vásquez, M. C., Silva, E. E., and Castillo, E. F. (2017). Hydrotreatment of vegetable oils: a review of the technologies and its developments for jet biofuel production. Biomass Bioenergy 105, 197-206. doi: 10.1016/j.biombioe.2017.07.008

Velazquez Abad, A., Cherrett, T., and Holdsworth, P. (2015). Waste-to-fuel opportunities for British quick service restaurants: a case study. Resour. Conserv. Recycl. 104, 239-253. doi: 10.1016/j.resconrec.2015.08.004

Vijay, V., Pimm, S. L., Jenkins, C. N., and Smith, S. (2016). The impacts of oil palm on recent deforestation and biodiversity loss. PLoS ONE 11:e0159668. doi: 10.1371/journal.pone.0159668

von Maltitz, G., Gasparatos, A., and Fabricius, C. (2014). The rise, fall and potential resilience benefits of Jatropha in Southern Africa. Sustainability 6, 3615-3643. doi: $10.3390 /$ su6063615

Wang, M., Han, J., Dunn, J. B., Cai, H., and Elgowainy, A. (2012). Wellto-wheels energy use and greenhouse gas emissions of ethanol from corn, sugarcane and cellulosic biomass for US use. Environ. Res. Lett. 7:045905 doi: $10.1088 / 1748-9326 / 7 / 4 / 045905$

Wang, W.-C., and Tao, L. (2016). Bio-jet fuel conversion technologies. Renew. Sustain. Energy Rev. 53, 801-822. doi: 10.1016/j.rser.2015.09.016

Wang, W. C., and Lee, A. C. (2019). The study of producing "drop-in" fuels from agricultural waste through fast pyrolysis and catalytic hydro-processing. Renew. Energy 133, 1-10. doi: 10.1016/j.renene.2018.10.022

Wani, S. P., Garg, K. K., and Chander, G. (2016). Water needs and productivity of Jatropha curcas in India: myths and facts. Biofuels Bioprod. Bioref. 10, 240-254. doi: 10.1002/bbb.1630

Warshay, B., Pan, J., and Sgouridis, S. (2011). Aviation industry's quest for a sustainable fuel: Considerations of scale and modal opportunity carbon benefit. Biofuels 2, 33-58. doi: 10.4155/bfs. 10.70

Wei, H., Liu, W., Chen, X., Yang, Q., Li, J., and Chen, H. (2019). Renewable bio-jet fuel production for aviation: a review. Fuel 254:115599. doi: 10.1016/j.fuel.2019.06.007

Weissermel, K., and Arpe, H.-J. (2008). Industrial Organic Chemistry. New York, NY: John Wiley \& Sons.

Wenger, J., and Stern, T. (2019). Reflection on the research on and implementation of biorefinery systems - a systematic literature review with a focus on feedstock. Biofuels Bioprod. Bioref. 3, 1347-1364. doi: 10.1002/bbb.2021

Wilbrand, K. (2018). "Potential of fossil kerosene," in Biokerosene: Status and Prospects, eds M. Kaltschmitt and U. Neuling (Berlin; Heidelberg: Springer), 43-57. doi: 10.1007/978-3-662-53065-8_4

Wong, H. M. (2008). Life-Cycle Assessment of Greenhouse Gas Emissions From Alternative Jet Fuels. Master of Science in Technology and Policy Massachusetts Institute of Technology. 147. Available online at http://citeseerx.ist.psu.edu/ viewdoc/download?doi=10.1.1.717.8365\&rep=rep1\&type=pdf (accessed July 7, 2019)

Woytiuk, K., Campbell, W., Gerspacher, R., Evitts, R. W., and Phoenix, A. (2017). The effect of torrefaction on syngas quality metrics from fluidized bed gasification of SRC willow. Renew. Energy 101, 409-416. doi: 10.1016/j.renene.2016.08.071

Wright, M. E., Harvey, B. G., and Quintana, R. L. (2008). Highly efficient zirconium-catalyzed batch conversion on 1-butene: a new route to jet fuels. Energy Fuels 22, 3299-3302. doi: 10.1021/ef800380b

Wu, T. Y., Mohammad, A. W., Jahim, J. M., and Anuar, N. (2009). A holistic approach to managing palm oil mill effluent (POME): biotechnological advances in the sustainable reuse of POME. Biotechnol. Adv. 27, 40-52. doi: 10.1016/j.biotechadv.2008.08.005

Xue, C., Liu, M., Guo, X., Hudson, E. P., Chen, L., Bai, F., et al. (2017). Bridging chemical- and bio-catalysis: high-value liquid transportation fuel production from renewable agricultural residues. Green Chem. 19, 660-669. doi: $10.1039 / \mathrm{C} 6 \mathrm{GC} 02546 \mathrm{C}$ 
Yan, X., Jiang, D., Fu, J., and Hao, M. (2018). Assessment of sweet sorghum-based ethanol potential in China within the water-energy-food nexus framework. Sustainability 10:10041046. doi: 10.3390/su10041046

Yang, J., Xin, Z., He, Q. S., Corscadden, K., and Niu, H. (2019). An overview on performance characteristics of bio-jet fuels. Fuel 237, 916-936. doi: 10.1016/j.fuel.2018.10.079

Yao, G., Staples, M. D., Malina, R., and Tyner, W. E. (2017). Stochastic technoeconomic analysis of alcohol-to-jet fuel production. Biotechnol. Biofuels 10:18. doi: 10.1186/s13068-017-0702-7

Zafar, S. (2018). How Is Biomass Transported? Available online at: https://www. bioenergyconsult.com/biomass-transportation/ (accessed April 6, 2019).

Zaher, F. A., Hussein, A. E. S., Hassan, B. H., and Hamed, F. S. (2015). Potential of castor oil as a feedstock for the production of bio-fuel via catalytic hydrocracking. Curr. Sci. Int. 4, 443-449.Available online at: http://www.curresweb. com/csi/csi/2015/443-449.pdf (accessed July 29, 2019).

Zalesny, R. S. Jr., Berndes, G., Dimitriou, I., Fritsche, U., and Miller, C. (2019). "Positive water linkages of producing short rotation poplars and willows for bioenergy and phytotechnologies," in Wiley Interdisciplinary Reviews: Energy and Environment, eds P. Lund and J. Byrne (John Wiley and Sons Ltd.), 1-20. doi: 10.1002/wene.345

Zhang, B., Wu, J., Yang, C., Qiu, Q., Yan, Q., Li, R., et al. (2018). Recent developments in commercial processes for refining bio-feedstocks to renewable diesel. Bioenergy Res. 11, 689-702. doi: 10.1007/s12155-018-9927-y

Zhang, X., Lei, H., Zhu, L., Qian, M., Chan, J. C., Zhu, X., et al. (2016). Development of a catalytically green route from diverse lignocellulosic biomasses to high-density cycloalkanes for jet fuels. Catal. Sci. Technol. 6, 4210-4220. doi: 10.1039/C5CY01623A

Zhang, Z., Wang, Q., Chen, H., and Zhang, X. (2018). Hydroconversion of waste cooking oil into bio-jet fuel over a hierarchical NiMo/USY@AlSBA-15 Zeolite. Chem. Eng. Technol. 41, 590-597. doi: 10.1002/ceat.20160 0601

Zhu, Z., Chu, F., Dolgui, A., Chu, C., Zhou, W., and Piramuthu, S. (2018). Recent advances and opportunities in sustainable food supply chain: a modeloriented review. Int. J. Prod. Res. 56, 5700-5722. doi: 10.1080/00207543.2018.14 25014

Conflict of Interest: NS was employed by Process Systems Enterprise Ltd. and is co-founder of Samsatli Solutions.

The remaining authors declare that the research was conducted in the absence of any commercial or financial relationships that could be construed as a potential conflict of interest.

Copyright (c) 2020 Doliente, Narayan, Tapia, Samsatli, Zhao and Samsatli. This is an open-access article distributed under the terms of the Creative Commons Attribution License (CC BY). The use, distribution or reproduction in other forums is permitted, provided the original author(s) and the copyright owner(s) are credited and that the original publication in this journal is cited, in accordance with accepted academic practice. No use, distribution or reproduction is permitted which does not comply with these terms. 


\section{NOMENCLATURE}

\begin{tabular}{ll}
\hline 1-G & First-generation \\
2-G & Second-generation \\
3-G & Third-generation \\
4-G & Fourth-generation \\
AJF & Alternative jet fuel \\
ASTM & American Standard Testing Method \\
ATJ & Alcohol-to-jet production pathway \\
ATAG & Air Transport Action Group \\
BAF & Bio-aviation fuel \\
CAPEX & Capital expenditures \\
CTL & Coal-to-Liquid process \\
CJF & Conventional jet fuel \\
DSCH & Direct sugar-to-hydrocarbon jet fuel synthesis \\
DML & Dry matter losses \\
FAME & Fatty acid methyl ester \\
FT & Fischer-Tropsch production pathway \\
FRL & Fuel readiness level \\
GHG & Greenhouse gases \\
GIS & Geographic Information System \\
HVO & Hydrotreated vegetable oils \\
HEFA & Hydroprocessed esters and fatty acids production pathway \\
IATA & International Air Transport Association \\
ICAO & International Civil Aviation Organisation \\
LUC & Land-use change \\
LCA & Life cycle assessment \\
MJSP & Minimum jet fuel selling price \\
MSW & Municipal solid waste \\
MILP & Mixed-integer linear programming \\
OPEX & Operating \& maintenance expenditures \\
POME & Palm oil mill effluent \\
PM & Particulate matter \\
PtG & Power-to-Gas \\
PtL & Power-to-Liquid \\
SPK & Synthetic paraffinic kerosene \\
TTW & Tank-to-wake \\
UCO & Used cooking oil \\
USD & United States Dollar \\
WTT & Well-to-tank \\
WTW & Well-to-wake \\
&
\end{tabular}

